INSTITUTO DE PESQUISAS ENERGÉTICAS E NUCLEARES

Autarquia Associada à Universidade de São Paulo

\title{
ELETRÓLITOS SÓLIDOS CERÂMICOS À BASE DE ÓXIDO DE ZIRCÔNIO PARA A DETECÇÃO DE OXIGÊNIO
}

\author{
Érica Caproni
}

Tese apresentada como parte dos requisitos para a obtenção do Grau de Doutor em Ciências na Área de Tecnologia Nuclear - Materiais.

Orientador:

Dr. Reginaldo Muccillo

São Paulo

2007 
É na experiência da vida que o Homem evolui. (Harvey Spencer Lewis) 
Aos meus pais, Wagner e Margarida. 


\section{AGRADECIMENTOS}

Gostaria de agradecer primeiramente ao Dr. Reginaldo Muccillo, pelos ensinamentos, apoio e orientação de mais um trabalho.

À Dr. Eliana N. S. Muccillo, pelas discussões e sugestões.

À FAPESP pela concessão da bolsa de Doutorado (03/07331-0).

Ao IPEN pela oportunidade de realizar o projeto.

Ao Dr. Kleber Franke Portella e ao Orlando Baron do Instituto de Tecnologia para o Desenvolvimento, LACTEC, de Curitiba-PR, pela permissão para o uso do dilatômetro.

Ao Celso V. Moraes do Instituto de Pesquisas Energéticas e Nucleares-IPEN, pelas imagens de microscopia eletrônica de varredura.

Ao Dr. Flavio Machado de Sousa Carvalho do Instituto de Geociências da USP, pela ajuda no refinamento de estruturas cristalinas pelo método de Rietveld.

Aos colegas do Centro de Ciência e Tecnologia de Materiais, CCTM.

Não poderia deixar de agradecer em especial aos meus pais, Wagner e Margarida, e aos meus irmãos, Anderson e Priscila, que sempre estiveram ao meu lado, pela paciência e apoio durante toda a execução deste trabalho.

E a todos que direta ou indiretamente contribuíram para realização deste trabalho. 


\section{Eletrólitos sólidos cerâmicos à base de óxido de zircônio para a detecção de oxigênio}

\section{RESUMO}

Tendo como vantagem a elevada resistência ao choque térmico da zircônia:magnésia e a alta condutividade iônica da zircônia:ítria, compósitos dessas cerâmicas foram preparados por meio da mistura, em diferentes concentrações, de eletrólitos sólidos de $\mathrm{ZrO}_{2}:$ 8,6 mol\% $\mathrm{MgO}$ e de $\mathrm{ZrO}_{2}: 3 \mathrm{~mol} \% \mathrm{Y}_{2} \mathrm{O}_{3}$, compactação e sinterização. A caracterização microestrutural foi feita por meio de difração de raios X e microscopia eletrônica de varredura. A análise do comportamento térmico foi feita por dilatometria. As propriedades elétricas foram estudadas por meio de espectroscopia de impedância. Foi feita uma montagem experimental para monitorar a resposta elétrica gerada em função do teor de oxigênio a altas temperaturas. Os principais resultados mostram que os compósitos cerâmicos são parcialmente estabilizados nas fases monoclínica, cúbica e tetragonal, e apresentam comportamento térmico similar ao apresentado por eletrólitos sólidos de zircônia:magnésia de dispositivos sensores de oxigênio. Além disso, os resultados de análise de espectroscopia de impedância mostram que a adição da zircônia:ítria melhora o comportamento elétrico da zircônia:magnésia, e que resposta elétrica gerada é dependente do teor de oxigênio a $1000{ }^{\circ} \mathrm{C}$, mostrando ser possível construir sensores de oxigênio utilizando compósitos cerâmicos. 


\title{
Zirconium oxide based ceramic solid electrolytes for oxygen detection
}

\begin{abstract}
Taking advantage of the high thermal shock resistance of zirconia-magnesia ceramics and the high oxide ion conductivity of zirconia-yttria ceramics, composites of these ceramics were prepared by mixing, pressing and sintering different relative concentrations of $\mathrm{ZrO}_{2}: 8.6 \mathrm{~mol} \%$ $\mathrm{MgO}$ and $\mathrm{ZrO}_{2}: 3 \mathrm{~mol} \% \mathrm{Y}_{2} \mathrm{O}_{3}$ solid electrolytes. Microstructural analysis of the composites was carried out by X-ray diffraction and scanning electron microscopy analyses. The thermal behavior was studied by dilatometric analysis. The electrical behavior was evaluated by the impedance spectroscopy technique. An experimental setup was designed for measurement the electrical signal generated as a function of the amount of oxygen at high temperatures. The main results show that these composites are partially stabilized (monoclinic, cubic and tetragonal) and the thermal behavior is similar to that of $\mathrm{ZrO}_{2}: 8.6 \mathrm{~mol} \% \mathrm{MgO}$ materials used in disposable high temperature oxygen sensors. Moreover, the results of analysis of impedance spectroscopy show that the electrical conductivity of zirconia:magnesia is improved with zirconia-yttria addition and that the electrical signal depends on the amount of oxygen at $1000{ }^{\circ} \mathrm{C}$, showing that the ceramic composites can be used in oxygen sensors.
\end{abstract}




\section{ÍNDICE}

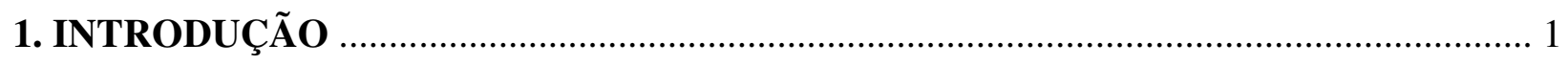

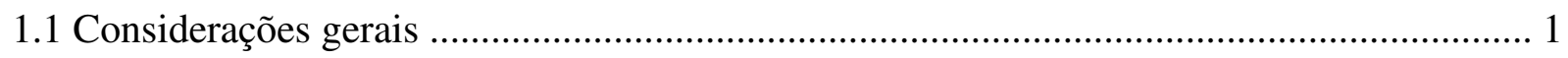

1.2. Eletrólitos sólidos à base de óxido de zircônio ................................................................... 1

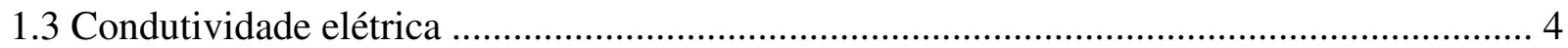

1.4 Aplicações de eletrólitos sólidos à base de óxido de zircônio ............................................. 8

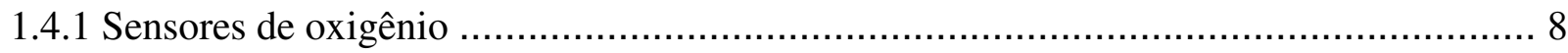

1.4.2 Sensores de oxigênio na industria siderúrgica .................................................... 13

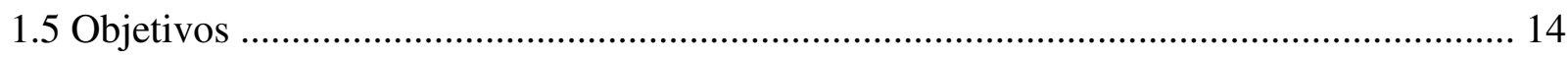

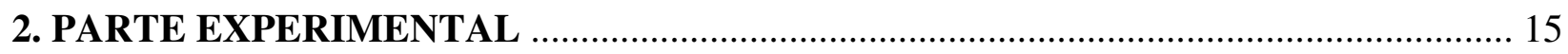

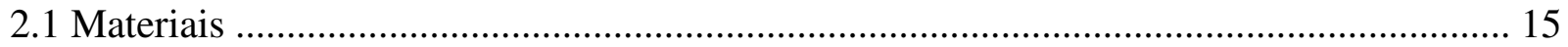

2.2 Preparação e caracterização dos compósitos cerâmicos …………………………………... 15

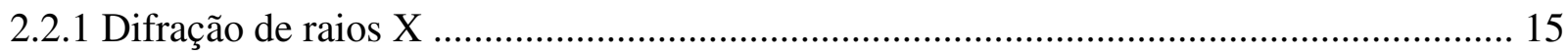

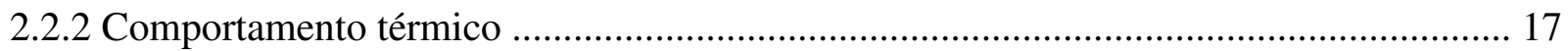

2.2.3 Densidade aparente …………………………..................................................... 17

2.2.4 Microscopia eletrônica de varredura ……………………………………………….... 17

2.2.5 Comportamento elétrico ………………………….............................................. 17

2.3 Preparação e testes dos compósitos cerâmicos na forma de tubo ...........................................17

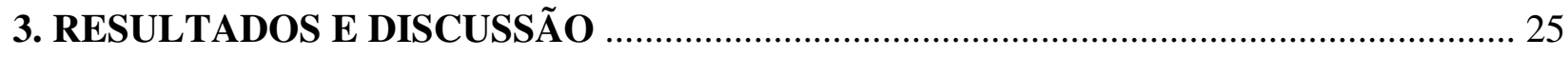

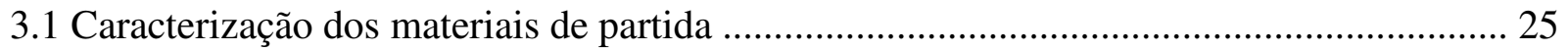

3.2 Caracterização dos compósitos cerâmicos ……………………………………………...... 26

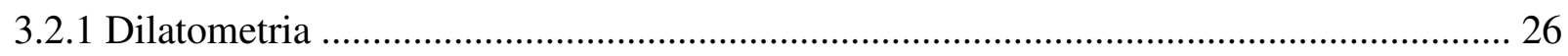

3.2.2 Difração de raios $X$ e refinamento da estrutura cristalina

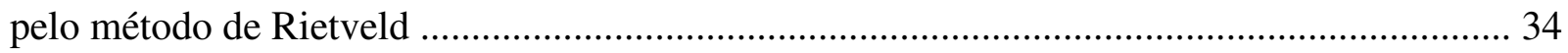

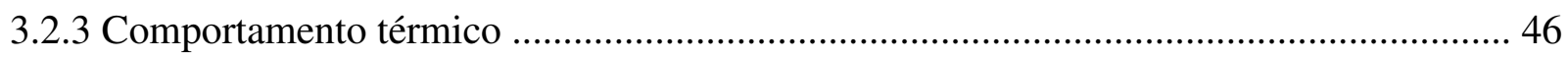

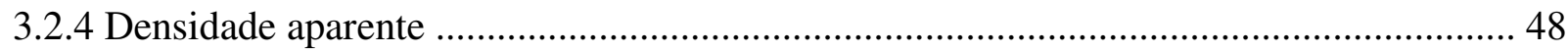

3.2.5 Microscopia eletrônica de varredura ……………………………………………........ 49

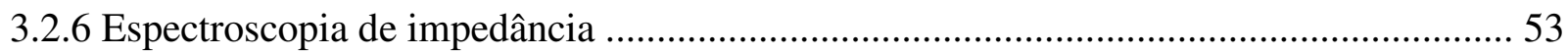

3.3 Testes nos compósitos cerâmicos na forma de tubo …………………………………...... 58 
4. CONCLUSÕES .

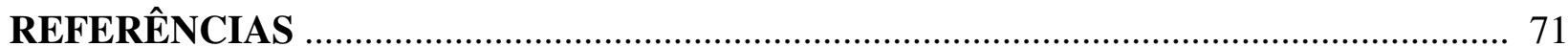




\section{Lista de Figuras}

Figura 1: Diagrama de fases de $\mathrm{ZrO}_{2}: \mathrm{MgO}$................................................................. 3

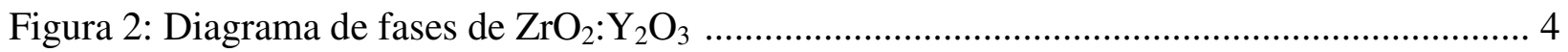

Figura 3: Representação de um circuito elétrico RC em paralelo ............................................ 5

Figura 4: Esquema de um diagrama de impedância de uma cerâmica policristalina .................... 6

Figura 5: Comparação entre diagramas de impedância obtidos para zircônia:ítria

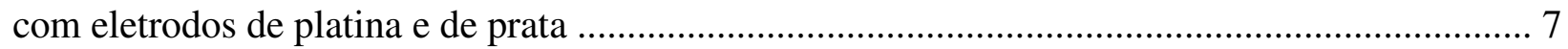

Figura 6: Esquema de uma célula eletroquímica amperométrica ........................................ 11

Figura 7: Esquema de uma célula eletroquímica potenciométrica ......................................... 12

Figura 8: Compósito cerâmico na forma de tubo para teste do sensor .................................... 18

Figura 9: Esquema do arranjo experimental para medidas elétricas ..................................... 18

Figura 10: Esquema e foto da montagem experimental para medidas da

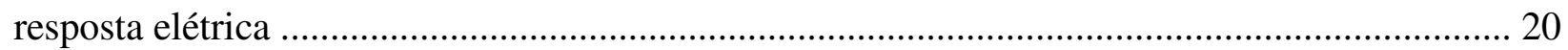

Figura 11: Esquema do sistema de medidas elétricas em função da pressão parcial

de oxigênio

Figura 12: Compósito cerâmico para as medidas da resistividade elétrica em função da pressão parcial de oxigênio

Figura 13: Esquema e foto da câmara porta-amostra para medidas de espectroscopia

de impedância sob diferentes teores de oxigênio para avaliação do sensor

Figura 14: Esquema do sistema de medidas de espectroscopia de impedância

em função da pressão parcial de oxigênio

Figura 15: Difratogramas de raios $\mathrm{X}$ dos pós de zircônia:ítria e zircônia:magnésia 26

Figura 16: Análise de dilatometria dos compactos cerâmicos a verde

$\left(\mathrm{ZrO}_{2}: 8,6 \mathrm{~mol} \% \mathrm{MgO}\right)_{\mathrm{x}}\left(\mathrm{ZrO}_{2}: 3 \mathrm{~mol} \% \mathrm{Y}_{2} \mathrm{O}_{3}\right)_{1-\mathrm{x}}, \mathrm{x}=0,2,0,5$ e 0,8

Figura 17: Difratogramas de raios $\mathrm{X}$ a altas temperaturas $\left(27^{\circ} \mathrm{C}-1300^{\circ} \mathrm{C}\right)$

do pó cerâmico de zircônia:ítria $\left(\mathrm{ZrO}_{2}: 3 \mathrm{~mol} \% \mathrm{Y}_{2} \mathrm{O}_{3}\right)$

Figura 18: Difratogramas de raios $\mathrm{X}$ a altas temperaturas $\left(27^{\circ} \mathrm{C}-1300^{\circ} \mathrm{C}\right)$

do pó cerâmico de $\left(\mathrm{ZrO}_{2}: 8,6 \mathrm{~mol} \% \mathrm{MgO}\right)_{0,2}\left(\mathrm{ZrO}_{2}: 3 \mathrm{~mol} \% \mathrm{Y}_{2} \mathrm{O}_{3}\right)_{0,8} \ldots$ 29 
Figura 19: Difratogramas de raios $\mathrm{X}$ a altas temperaturas $\left(27^{\circ} \mathrm{C}-1300^{\circ} \mathrm{C}\right)$

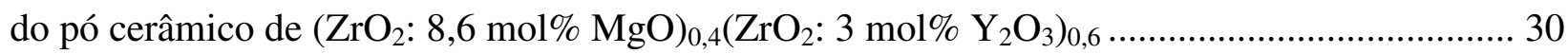

Figura 20: Difratogramas de raios $\mathrm{X}$ a altas temperaturas $\left(27^{\circ} \mathrm{C}-1300^{\circ} \mathrm{C}\right)$

do pó cerâmico de $\left(\mathrm{ZrO}_{2}: 8,6 \mathrm{~mol} \% \mathrm{MgO}\right)_{0,5}\left(\mathrm{ZrO}_{2}: 3 \mathrm{~mol} \% \mathrm{Y}_{2} \mathrm{O}_{3}\right)_{0,5}$

Figura 21: Difratogramas de raios $\mathrm{X}$ a altas temperaturas $\left(27^{\circ} \mathrm{C}-1300^{\circ} \mathrm{C}\right)$

do pó cerâmico de $\left(\mathrm{ZrO}_{2}: 8,6 \mathrm{~mol} \% \mathrm{MgO}\right)_{0,6}\left(\mathrm{ZrO}_{2}: 3 \mathrm{~mol} \% \mathrm{Y}_{2} \mathrm{O}_{3}\right)_{0,4}$

Figura 22: Difratogramas de raios $\mathrm{X}$ a altas temperaturas $\left(27^{\circ} \mathrm{C}-1300^{\circ} \mathrm{C}\right)$

do pó cerâmico de $\left(\mathrm{ZrO}_{2}: 8,6 \mathrm{~mol} \% \mathrm{MgO}\right)_{0,8}\left(\mathrm{ZrO}_{2}: 3 \mathrm{~mol} \% \mathrm{Y}_{2} \mathrm{O}_{3}\right)_{0,2}$

Figura 23: Difratogramas de raios $\mathrm{X}$ a altas temperaturas $\left(27^{\circ} \mathrm{C}-1300^{\circ} \mathrm{C}\right)$

do pó cerâmico de zircônia:magnésia $\left(\mathrm{ZrO}_{2}: 8,6 \mathrm{~mol} \% \mathrm{MgO}\right)$

Figura 24: Valores do teor da fase monoclínica dos compósitos cerâmicos

$\left(\mathrm{ZrO}_{2}: 8,6 \mathrm{~mol} \% \mathrm{MgO}\right)_{\mathrm{x}}\left(\mathrm{ZrO}_{2}: 3 \mathrm{~mol} \% \mathrm{Y}_{2} \mathrm{O}_{3}\right)_{1-\mathrm{x}}$

Figura 25: Padrões de difração calculado e observado para $\mathrm{ZrO}_{2}: 3 \mathrm{~mol} \% \mathrm{Y}_{2} \mathrm{O}_{3}$

Figura 26: Padrões de difração calculado e observado para

$\left(\mathrm{ZrO}_{2}: 8,6 \mathrm{~mol} \% \mathrm{MgO}\right)_{0,2}\left(\mathrm{ZrO}_{2}: 3 \mathrm{~mol} \% \mathrm{Y}_{2} \mathrm{O}_{3}\right)_{0,8}$

Figura 27: Padrões de difração calculado e observado para

$\left(\mathrm{ZrO}_{2}: 8,6 \mathrm{~mol} \% \mathrm{MgO}\right)_{0,4}\left(\mathrm{ZrO}_{2}: 3 \mathrm{~mol} \% \mathrm{Y}_{2} \mathrm{O}_{3}\right)_{0,6}$

Figura 28: Padrões de difração calculado e observado para

$\left(\mathrm{ZrO}_{2}: 8,6 \mathrm{~mol} \% \mathrm{MgO}\right)_{0,5}\left(\mathrm{ZrO}_{2}: 3 \mathrm{~mol} \% \mathrm{Y}_{2} \mathrm{O}_{3}\right)_{0,5}$

Figura 29: Padrões de difração calculado e observado para

$\left(\mathrm{ZrO}_{2}: 8,6 \mathrm{~mol} \% \mathrm{MgO}\right)_{0,6}\left(\mathrm{ZrO}_{2}: 3 \mathrm{~mol} \% \mathrm{Y}_{2} \mathrm{O}_{3}\right)_{0,4}$

Figura 30: Padrões de difração calculado e observado para

$\left(\mathrm{ZrO}_{2}: 8,6 \mathrm{~mol} \% \mathrm{MgO}\right)_{0,8}\left(\mathrm{ZrO}_{2}: 3 \mathrm{~mol} \% \mathrm{Y}_{2} \mathrm{O}_{3}\right)_{0,2}$

Figura 31: Padrões de difração calculado e observado para $\left(\mathrm{ZrO}_{2}: 8,6 \mathrm{~mol} \% \mathrm{MgO}\right)$

Figura 32: Porcentagem das fases tetragonal, cúbica e monoclínica nos

compósitos cerâmicos $\left(\mathrm{ZrO}_{2}: 8,6 \mathrm{~mol} \% \mathrm{MgO}\right)_{\mathrm{x}}\left(\mathrm{ZrO}_{2}: 3 \mathrm{~mol} \% \mathrm{Y}_{2} \mathrm{O}_{3}\right)_{1-\mathrm{x}}, 0 \leq \mathrm{x} \leq 1$

Figura 33: Ciclos de aquecimento e resfriamento durante o processo

de sinterização e comportamento ao choque térmico

46 
Figura 34: Análise de dilatometria dos compactos cerâmicos sinterizados

$\left(\mathrm{ZrO}_{2}: 8,6 \mathrm{~mol} \% \mathrm{MgO}\right)_{\mathrm{x}}\left(\mathrm{ZrO}_{2}: 3 \mathrm{~mol} \% \mathrm{Y}_{2} \mathrm{O}_{3}\right)_{1-\mathrm{x}}, \mathrm{x}=0,2,0,5$ e 0,8

Figura 35: Micrografias obtidas por microscopia eletrônica de varredura das superfícies

de fratura dos compósitos cerâmicos $\left(\mathrm{ZrO}_{2}: 8,6 \mathrm{~mol} \% \mathrm{MgO}\right)_{\mathrm{x}}\left(\mathrm{ZrO}_{2}: 3 \mathrm{~mol} \% \mathrm{Y}_{2} \mathrm{O}_{3}\right)_{1-\mathrm{x}} \ldots \ldots \ldots \ldots . . . .50$

Figura 36: Diagramas de impedância de $\left(\mathrm{ZrO}_{2}: 8,6 \mathrm{~mol} \% \mathrm{MgO}\right)_{\mathrm{x}}$

$\left(\mathrm{ZrO}_{2}: 3 \mathrm{~mol} \% \mathrm{Y}_{2} \mathrm{O}_{3}\right)_{1-\mathrm{x}}$, medidos a aproximadamente $430{ }^{\circ} \mathrm{C}$

Figura 37: Diagramas de impedância de $\left(\mathrm{ZrO}_{2}: 8,6 \mathrm{~mol} \% \mathrm{MgO}\right)_{\mathrm{x}}$

$\left(\mathrm{ZrO}_{2}: 3 \mathrm{~mol} \% \mathrm{Y}_{2} \mathrm{O}_{3}\right)_{1-\mathrm{x}}, \mathrm{x}=0,2,0,5,0,8 \mathrm{e} 1$, medidos a aproximadamente $430{ }^{\circ} \mathrm{C}$

Figura 38: Resistividade elétrica intragranular (AF), intergranular (BF)

e total de $\left(\mathrm{ZrO}_{2}: 8,6 \mathrm{~mol} \% \mathrm{MgO}\right)_{\mathrm{x}}\left(\mathrm{ZrO}_{2}: 3 \mathrm{~mol} \% \mathrm{Y}_{2} \mathrm{O}_{3}\right)_{1-\mathrm{x}}$ 58

Figura 39: Dependência da fem com a temperatura do compósito cerâmico

$\left(\mathrm{ZrO}_{2}: 8,6 \mathrm{~mol} \% \mathrm{MgO}\right)_{0,5}\left(\mathrm{ZrO}_{2}: 3 \mathrm{~mol} \% \mathrm{Y}_{2} \mathrm{O}_{3}\right)_{0,5}$; eletrodo de referência: ar

Figura 40: Dependência da fem com o tempo de resposta para o compósito cerâmico

$\left(\mathrm{ZrO}_{2}: 8,6 \mathrm{~mol} \% \mathrm{MgO}\right)_{0,2}\left(\mathrm{ZrO}_{2}: 3 \mathrm{~mol} \% \mathrm{Y}_{2} \mathrm{O}_{3}\right)_{0,8}$ sob pulsos de argônio a $1000{ }^{\circ} \mathrm{C}$

Figura 41: Dependência da fem com o tempo de resposta para o compósito cerâmico

$\left(\mathrm{ZrO}_{2}: 8,6 \mathrm{~mol} \% \mathrm{MgO}\right)_{0,5}\left(\mathrm{ZrO}_{2}: 3 \mathrm{~mol} \% \mathrm{Y}_{2} \mathrm{O}_{3}\right)_{0,5}$ sob pulsos de argônio a $1000{ }^{\circ} \mathrm{C}$

Figura 42: Comportamento da fem de $\left(\mathrm{ZrO}_{2}: 8,6 \mathrm{~mol} \% \mathrm{MgO}\right)_{\mathrm{x}}\left(\mathrm{ZrO}_{2}: 3 \mathrm{~mol} \% \mathrm{Y}_{2} \mathrm{O}_{3}\right)_{1-\mathrm{x}}$, $\mathrm{x}=0,5$ e 1 em função da $\mathrm{pO}_{2}$

Figura 43: Dependência da fem com a $\mathrm{pO}_{2}$ de $\left(\mathrm{ZrO}_{2}: 8,6 \mathrm{~mol} \% \mathrm{MgO}\right)_{\mathrm{x}}$

$\left(\mathrm{ZrO}_{2}: 3 \mathrm{~mol} \% \mathrm{Y}_{2} \mathrm{O}_{3}\right)_{1-\mathrm{x}}, \mathrm{x}=0,5$ e 1 . Figura inserida: lei de de Nernst

Figura 44: Dependência da fem medida com o calculado em sensores

construídos com compósito cerâmico $\left(\mathrm{ZrO}_{2}: 8,6 \mathrm{~mol} \% \mathrm{MgO}\right)_{0,5}\left(\mathrm{ZrO}_{2}: 3 \mathrm{~mol} \% \mathrm{Y}_{2} \mathrm{O}_{3}\right)_{0,5}$

Figura 45: Diagramas de impedância dos compactos cerâmicos sinterizados, na forma

de tubo, $\left(\mathrm{ZrO}_{2}: 8,6 \mathrm{~mol} \% \mathrm{MgO}\right)_{\mathrm{x}}\left(\mathrm{ZrO}_{2}: 3 \mathrm{~mol} \% \mathrm{Y}_{2} \mathrm{O}_{3}\right)_{1-\mathrm{x}}$, medidos a $620^{\circ} \mathrm{C}$

sob diferentes teores de oxigênio ( 1 a $860 \mathrm{ppm}$ ).

Figura 46: Valores da resistividade dos compósitos $\left(\mathrm{ZrO}_{2}: 8,6 \mathrm{~mol} \% \mathrm{MgO}\right)_{\mathrm{x}}$

$\left(\mathrm{ZrO}_{2}: 3 \mathrm{~mol} \% \mathrm{Y}_{2} \mathrm{O}_{3}\right)_{1-\mathrm{x}}, \mathrm{x}=0,0,2,0,5,0,8 \mathrm{e} \mathrm{1}$, em função da pressão parcial de oxigênio 67 
Figura 47: Diagramas de impedância dos compactos cerâmicos sinterizados, na forma de tubo, $\left(\mathrm{ZrO}_{2}: 8,6 \mathrm{~mol} \% \mathrm{MgO}\right)_{0,2}\left(\mathrm{ZrO}_{2}: 3 \mathrm{~mol} \% \mathrm{Y}_{2} \mathrm{O}_{3}\right)_{0,8}$, medidos a aproximadamentes $640{ }^{\circ} \mathrm{C}$ sob diferentes teores de oxigênio (3 a 59 ppm); eletrodo de referência $\mathrm{Cr}-\mathrm{Cr}_{2} \mathrm{O}_{3}$ 68 Figura 48: Diagramas de impedância dos compactos cerâmicos sinterizados, na forma de tubo, $\left(\mathrm{ZrO}_{2}: 8,6 \mathrm{~mol} \% \mathrm{MgO}\right)_{0,2}\left(\mathrm{ZrO}_{2}: 3 \mathrm{~mol} \% \mathrm{Y}_{2} \mathrm{O}_{3}\right)_{0,8}$, , medidos a aproximadamente $640{ }^{\circ} \mathrm{C}$ sob diferentes teores de oxigênio (3 a 59 ppm); eletrodo de referência $\mathrm{Ni}-\mathrm{NiO}$

Figura 49: Comparação entre diagramas de impedância obtidos para

$\left(\mathrm{ZrO}_{2}: 8,6 \mathrm{~mol} \% \mathrm{MgO}\right)_{0,2}\left(\mathrm{ZrO}_{2}: 3 \mathrm{~mol} \% \mathrm{Y}_{2} \mathrm{O}_{3}\right)_{0,8}$

eletrodos de referência $\mathrm{Cr}-\mathrm{Cr}_{2} \mathrm{O}_{3}$ e Ni-NiO 69 


\section{Lista de Tabelas}

Tabela 1: Valores de área de superfície específica

Tabela 2: Valores estruturais teóricos e experimentais da fase tetragonal

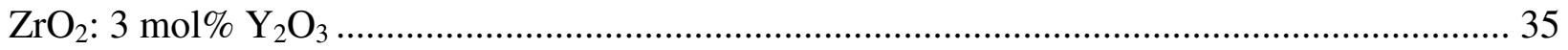

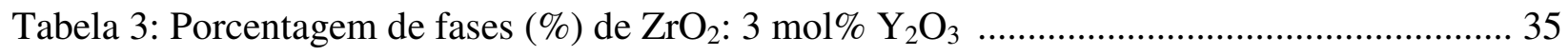

Tabela 4: Valores estruturais teóricos e experimentais da fase tetragonal

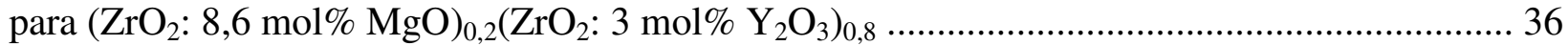

Tabela 5: Valores estruturais teóricos e experimentais da fase cúbica

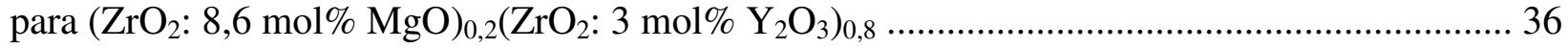

Tabela 6: Valores estruturais teóricos e experimentais da fase monoclínica

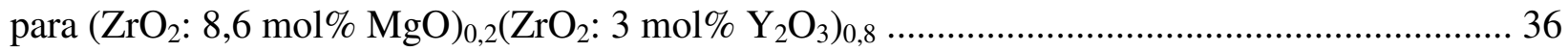

Tabela 7: Porcentagem de fases $(\%)$ de $\left(\mathrm{ZrO}_{2}: 8,6 \mathrm{~mol} \% \mathrm{MgO}\right)_{0,2}\left(\mathrm{ZrO}_{2}: 3 \mathrm{~mol} \% \mathrm{Y}_{2} \mathrm{O}_{3}\right)_{0,8} \ldots \ldots . .36$

Tabela 8: Valores estruturais teóricos e experimentais da fase tetragonal

para $\left(\mathrm{ZrO}_{2}: 8,6 \mathrm{~mol} \% \mathrm{MgO}\right)_{0,4}\left(\mathrm{ZrO}_{2}: 3 \mathrm{~mol} \% \mathrm{Y}_{2} \mathrm{O}_{3}\right)_{0,6}$

Tabela 9: Valores estruturais teóricos e experimentais da fase cúbica

para $\left(\mathrm{ZrO}_{2}: 8,6 \mathrm{~mol} \% \mathrm{MgO}\right)_{0,4}\left(\mathrm{ZrO}_{2}: 3 \mathrm{~mol} \% \mathrm{Y}_{2} \mathrm{O}_{3}\right)_{0,6}$

Tabela 10: Valores estruturais teóricos e experimentais da fase monoclínica

para $\left(\mathrm{ZrO}_{2}: 8,6 \mathrm{~mol} \% \mathrm{MgO}\right)_{0,4}\left(\mathrm{ZrO}_{2}: 3 \mathrm{~mol} \% \mathrm{Y}_{2} \mathrm{O}_{3}\right)_{0,6}$

Tabela 11: Porcentagem de fases $(\%)$ de $\left(\mathrm{ZrO}_{2}: 8,6 \mathrm{~mol} \% \mathrm{MgO}\right)_{0,4}\left(\mathrm{ZrO}_{2}: 3 \mathrm{~mol} \% \mathrm{Y}_{2} \mathrm{O}_{3}\right)_{0,6} \ldots . . .38$

Tabela 12: Valores estruturais teóricos e experimentais da fase tetragonal

para $\left(\mathrm{ZrO}_{2}: 8,6 \mathrm{~mol} \% \mathrm{MgO}\right)_{0,5}\left(\mathrm{ZrO}_{2}: 3 \mathrm{~mol} \% \mathrm{Y}_{2} \mathrm{O}_{3}\right)_{0,5}$

Tabela 13: Valores estruturais teóricos e experimentais da fase cúbica

para $\left(\mathrm{ZrO}_{2}: 8,6 \mathrm{~mol} \% \mathrm{MgO}\right)_{0,5}\left(\mathrm{ZrO}_{2}: 3 \mathrm{~mol} \% \mathrm{Y}_{2} \mathrm{O}_{3}\right)_{0,5}$

Tabela 14: Valores estruturais teóricos e experimentais da fase monoclínica

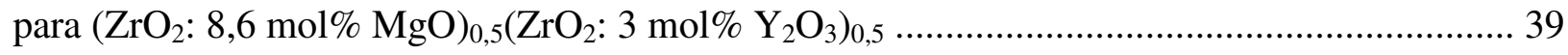

Tabela 15: Porcentagem de fases (\%) de $\left(\mathrm{ZrO}_{2}: 8,6 \mathrm{~mol} \% \mathrm{MgO}\right)_{0,5}\left(\mathrm{ZrO}_{2}: 3 \mathrm{~mol} \% \mathrm{Y}_{2} \mathrm{O}_{3}\right)_{0,5} \ldots . .39$

Tabela 16: Valores estruturais teóricos e experimentais da fase tetragonal

para $\left(\mathrm{ZrO}_{2}: 8,6 \mathrm{~mol} \% \mathrm{MgO}\right)_{0,6}\left(\mathrm{ZrO}_{2}: 3 \mathrm{~mol} \% \mathrm{Y}_{2} \mathrm{O}_{3}\right)_{0,4}$ 
Tabela 17: Valores estruturais teóricos e experimentais da fase cúbica

para $\left(\mathrm{ZrO}_{2}: 8,6 \mathrm{~mol} \% \mathrm{MgO}\right)_{0,6}\left(\mathrm{ZrO}_{2}: 3 \mathrm{~mol} \% \mathrm{Y}_{2} \mathrm{O}_{3}\right)_{0,4}$

Tabela 18: Valores estruturais teóricos e experimentais da fase monoclínica

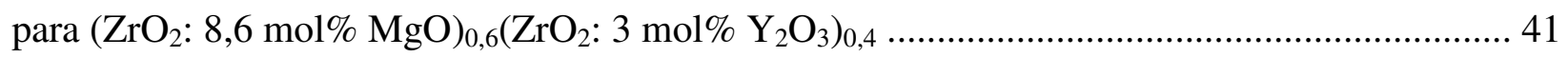

Tabela 19: Porcentagem de fases $(\%)$ de $\left(\mathrm{ZrO}_{2}: 8,6 \mathrm{~mol} \% \mathrm{MgO}\right)_{0,6}\left(\mathrm{ZrO}_{2}: 3 \mathrm{~mol} \% \mathrm{Y}_{2} \mathrm{O}_{3}\right)_{0,4} \ldots . .41$

Tabela 20: Valores estruturais teóricos e experimentais da fase tetragonal

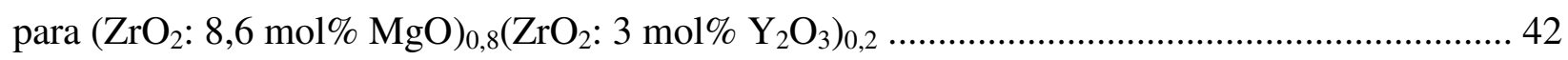

Tabela 21: Valores estruturais teóricos e experimentais da fase cúbica

para $\left(\mathrm{ZrO}_{2}: 8,6 \mathrm{~mol} \% \mathrm{MgO}\right)_{0,8}\left(\mathrm{ZrO}_{2}: 3 \mathrm{~mol} \% \mathrm{Y}_{2} \mathrm{O}_{3}\right)_{0,2}$

Tabela 22: Valores estruturais teóricos e experimentais da fase monoclínica

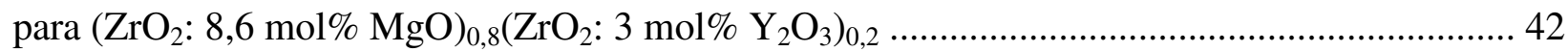

Tabela 23: Porcentagem de fases $(\%)$ de $\left(\mathrm{ZrO}_{2}: 8,6 \mathrm{~mol} \% \mathrm{MgO}\right)_{0,5}\left(\mathrm{ZrO}_{2}: 3 \mathrm{~mol} \% \mathrm{Y}_{2} \mathrm{O}_{3}\right)_{0,5} \ldots . .42$

Tabela 24: Valores estruturais teóricos e experimentais da fase tetragonal

para $\mathrm{ZrO}_{2}: 8,6 \mathrm{~mol} \% \mathrm{MgO}$

Tabela 25: Valores estruturais teóricos e experimentais da fase cúbica para

$\mathrm{ZrO}_{2}: 8,6 \mathrm{~mol} \% \mathrm{MgO}$

Tabela 26: Valores estruturais teóricos e experimentais da fase monoclínica

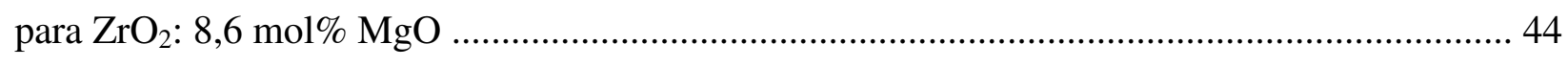

Tabela 27: Porcentagem de fases $(\%)$ de $\mathrm{ZrO}_{2}: 8,6 \mathrm{~mol} \% \mathrm{MgO}$............................................ 44

Tabela 28: Resíduos obtidos no refinamento de

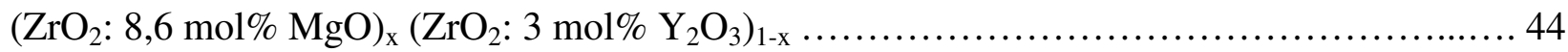

Tabela 29: Valores da densidade teórica e de densidade aparente dos compósitos

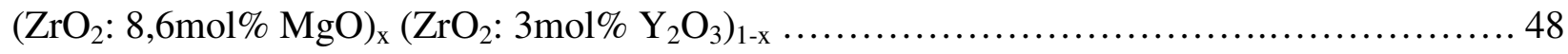




\section{INTRODUÇÃO}

Neste capítulo são introduzidas algumas considerações gerais sobre a motivação para o desenvolvimento deste trabalho, alguns conceitos sobre eletrólitos sólidos à base de zircônia e suas aplicações, e sobre a técnica de espectroscopia de impedância.

\subsection{Considerações gerais}

Nas ultimas décadas o interesse em desenvolvimento de eletrólitos sólidos à base de zircônia ${ }^{[1-3]}$ vem sendo crescente, pois estes materiais constituem um importante subgrupo dos materiais condutores iônicos em uma ampla faixa de temperatura e pressão parcial de oxigênio, determinando o seu uso em várias aplicações eletroquímicas de alta temperatura ${ }^{[4]}$, como por exemplo, em sensores de oxigênio.

As indústrias siderúrgicas estão voltadas para o uso dos sensores de oxigênio, objetivando rapidez, precisão e reprodutividade no processo. Para conseguir um desempenho adequado do sensor de oxigênio nas condições severas em que é submetido (temperatura do aço líquido na faixa entre $1500^{\circ} \mathrm{C}$ e $1700^{\circ} \mathrm{C}$ ), alguns desafios técnicos devem ser superados, como:

$\checkmark \quad$ o desenvolvimento de materiais estáveis, com características adequadas, tais como: condutividade puramente iônica quando submetidos a meios que envolvam baixos teores de oxigênio e resistência ao choque térmico na temperatura de operação.

$\checkmark \quad$ a confiabilidade de desempenho em um curto tempo (aferição em questão de segundos).

Neste contexto, o presente trabalho teve como motivação principal desenvolver um novo material com propriedades elétricas e mecânicas necessárias para o desempenho exigido em sensores de oxigênio para detecção de baixos teores de oxigênio a altas temperaturas.

\subsection{Eletrólitos sólidos à base de óxido de zircônio}

$\mathrm{O}$ óxido de zircônio $\left(\mathrm{ZrO}_{2}\right)$ é conhecido pelo seu polimorfismo, isto é, apresenta três formas estruturais principais: cúbica de face centrada (estrutura fluorita) desde seu ponto de fusão de $2680{ }^{\circ} \mathrm{C}$ a $2370{ }^{\circ} \mathrm{C}$, tetragonal (estrutura fluorita distorcida) de $2370{ }^{\circ} \mathrm{C}$ a $1150{ }^{\circ} \mathrm{C}$ e monoclínica para temperaturas inferiores a $1150{ }^{\circ} \mathrm{C}^{[5]}$.

A transformação de fase reversível tetragonal-monoclínica é a mais estudada, pois é acompanhada de uma expansão volumétrica de até cerca de 5\% durante o resfriamento, 
provocando trincas em toda extensão do material, e consequentemente prejudicando as propriedades mecânicas de peças fabricadas com zircônia pura em altas temperaturas. $\mathrm{Na}$ zircônia, essa transformação caracteriza-se por um movimento ordenado de átomos através do mecanismo de cisalhamento e dilatação da estrutura original, sem que ocorra a difusão, conhecido como transformação martensítica ${ }^{[1,5-7]}$.

Através da adição de certos óxidos, tais como $\mathrm{CaO}, \mathrm{MgO}, \mathrm{Y}_{2} \mathrm{O}_{3}$ e óxidos de terras raras, na zircônia, o íon $\mathrm{Zr}^{4+}$ é parcialmente substituído por cátions divalentes ou trivalentes $\left(\mathrm{Ca}^{2+}\right.$, $\mathrm{Mg}^{2+}, \mathrm{Y}^{3+}, \mathrm{TR}^{3+}$ : terras raras), nas posições normais da sub-rede catiônica, para formar uma solução sólida substitucional, nas quais as fases cúbicas e/ou tetragonal são retidas à temperatura ambiente; esse processo é mais conhecido como a estabilização da zircônia, podendo ser total (fase cúbica) ou parcial (mistura das fases cúbica e/ou tetragonal e monoclínica) dependendo da quantidade adicionada de estabilizante ${ }^{[1,5,8]}$.

A estabilização da zircônia é acompanhada pela formação de defeitos, isto é, ocorre à formação de vacâncias aniônicas para manter a neutralidade elétrica, sendo as vacâncias as responsáveis pelo aumento da mobilidade dos íons oxigênio, e consequentemente, o aumento da condutividade iônica em relação ao $\mathrm{ZrO}_{2}$ puro.

Entre os óxidos estabilizantes mais utilizados podem ser citados $\mathrm{MgO}$ e $\mathrm{Y}_{2} \mathrm{O}_{3}$.

Dentre os eletrólitos sólidos de zircônia:magnésia, o que mais se destaca é o $\mathrm{ZrO}_{2}$ : 8,6 mol\% MgO, devido à elevada resistência ao choque térmico em condições severas de temperaturas, e o maior valor de condutividade elétrica.

A Figura 1 mostra um diagrama de fases para a zircônia:magnésia. Para a concentração de 8,6 mol\% a fase $\mathrm{MgO}$ coexiste com a zircônia monoclínica até a temperatura de transformação de fase tetragonal $\left(\sim 900{ }^{\circ} \mathrm{C}\right)$. A solubilidade do $\mathrm{MgO}$ na zircônia tetragonal aumenta com o aumento da temperatura. Uma solução sólida contendo a fase cúbica é observada para temperaturas acima de $1500{ }^{\circ} \mathrm{C}$ na composição eutética de $27 \mathrm{~mol} \% \mathrm{MgO}$. 


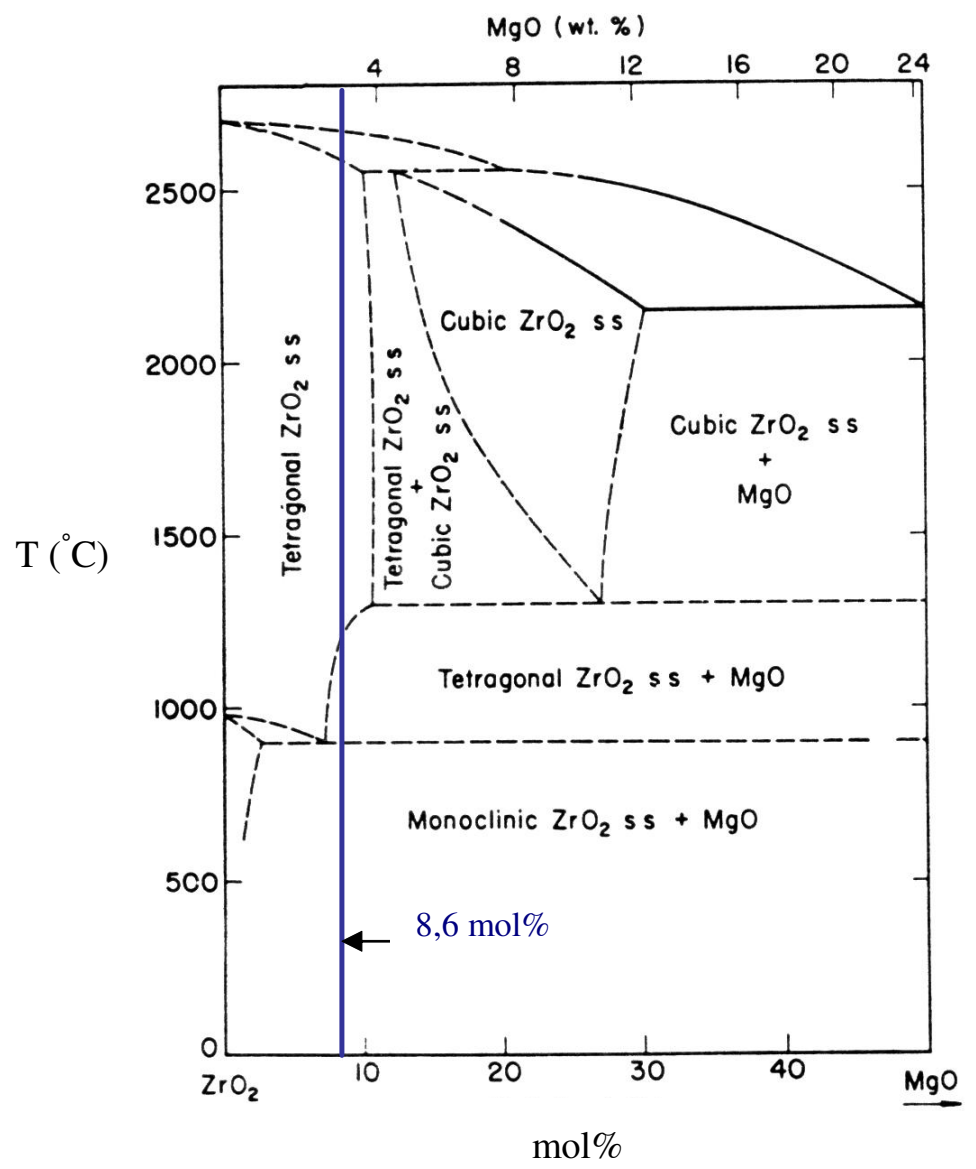

Figura 1: Diagrama de fases de $\mathrm{ZrO}_{2}: \mathrm{MgO}^{[9]}$.

Já os eletrólitos sólidos de zircônia:ítria são amplamente estudados devido às boas propriedades mecânicas e elétricas, podendo ser citados os eletrólitos de $\mathrm{ZrO}_{2}: 8 \mathrm{~mol} \% \quad \mathrm{Y}_{2} \mathrm{O}_{3}$ (maior valor de condutividade elétrica) e de $\mathrm{ZrO}_{2}: 3 \mathrm{~mol} \% \mathrm{Y}_{2} \mathrm{O}_{3}$ (além de ser um eletrólito sólido com alta condutividade elétrica, apresenta alta tenacidade).

O diagrama de fases para a zircônia:ítria pode ser visto na Figura 2. Para concentrações de $3 \mathrm{~mol} \% \mathrm{Y}_{2} \mathrm{O}_{3}$, a fase cúbica está em equilíbrio com a fase monoclínica até aproximadamente $400{ }^{\circ} \mathrm{C}$, e acima desta temperatura a fase tetragonal é formada. A solução sólida contendo a fase cúbica é conseguida para mais altas concentrações de $\mathrm{Y}_{2} \mathrm{O}_{3}$. 


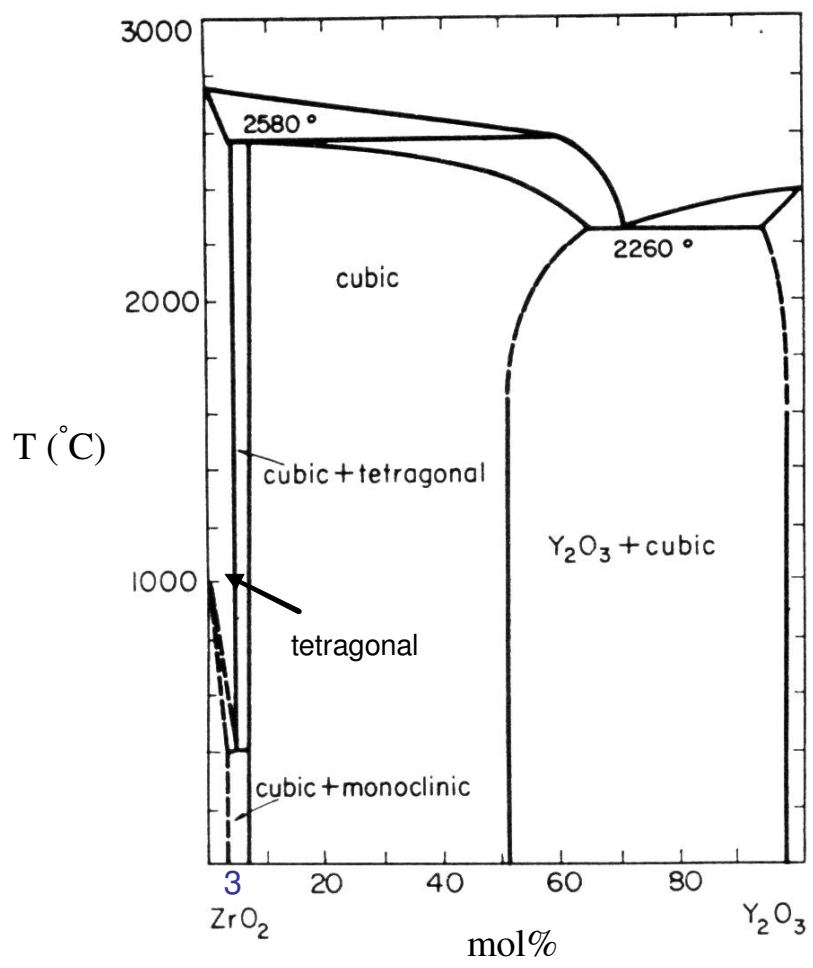

Figura 2: Diagrama de fases de $\mathrm{ZrO}_{2}: \mathrm{Y}_{2} \mathrm{O}_{3}{ }^{[9]}$.

\subsection{Condutividade elétrica}

Eletrólitos sólidos apresentam defeitos puntiformes (vacâncias), que são os principais responsáveis pela condutividade elétrica $(\sigma)^{[6]}$ :

$$
\sigma=\sum_{i} \eta_{i} z_{i} q \mu_{i}
$$

$\eta$ : densidade do portador de carga

z: número de cargas eletrônicas

q: carga do portador

$\mu$ : mobilidade do portador de carga.

A condutividade elétrica total $\left(\sigma_{\mathrm{t}}\right)$ de um sólido é dada pela soma das contribuições das condutividades dos portadores de carga: iônicos (i) e eletrônicos (e), segundo a equação 2.

$$
\sigma_{\mathrm{t}}=\sigma_{\mathrm{i}}+\sigma_{\mathrm{e}}
$$


Uma das técnicas utilizadas para o estudo do comportamento elétrico é a espectroscopia de impedância ${ }^{[10,11]}$, pois possibilita a separação das diferentes contribuições individuais da condutividade elétrica dos constituintes microestruturais do material (grão, contornos de grão, segundas fases, poros) ${ }^{[12]}$.

A técnica de espectroscopia de impedância consiste em aplicar numa célula (eletrodo/material/eletrodo) uma tensão $V(\omega)=V_{0} \cdot \exp (j \cdot \omega \cdot t), j=\sqrt{-1}, \omega$ é a freqüuência angular e $\mathrm{V}_{\mathrm{O}}$ é amplitude, e analisar a relação entre tensão $\mathrm{V}(\omega)$ e corrente $\mathrm{I}(\omega)=\mathrm{I}_{\mathrm{O}} \cdot \exp [\mathrm{j} \cdot(\omega \cdot \mathrm{t}+\phi)]$, na qual $\mathrm{I}_{\mathrm{O}}$ é a amplitude da corrente e $\phi$ o ângulo de fase, sendo estes dois valores relacionados pela lei de $\mathrm{Ohm}{ }^{[6,13,14]}$ :

$$
\mathrm{V}=\mathrm{Z} \cdot \mathrm{I}
$$

$\mathrm{Z}$ representa a impedância.

A impedância de um circuito é $Z(\omega)=V / I=Z_{0} \exp (-j \phi)=Z(\omega)+Z^{\prime}(\omega)$, na qual $Z^{\prime}$ e $\mathrm{Z}^{\prime \prime}$ são as partes real e imaginária da impedância e $\mathrm{Z}_{\mathrm{o}}=\mathrm{V}_{\mathrm{o}} / \mathrm{I}_{\mathrm{o}}$.

Os materiais cerâmicos podem ser tratados, com relação às suas propriedades elétricas, como associações em série de circuitos R//C (resistor em paralelo com capacitor). A resistência representa o grau de impedimento da migração de portadores de carga (para cerâmicas à base de zircônia é o íon oxigênio $\mathrm{O}^{2-}$ ) pelos grãos e interfaces (contorno de grão), e a capacitância representa a capacidade de armazenamento de energia originária da aplicação do campo elétrico. A Figura 3 representa o esquema elétrico equivalente deste sistema.

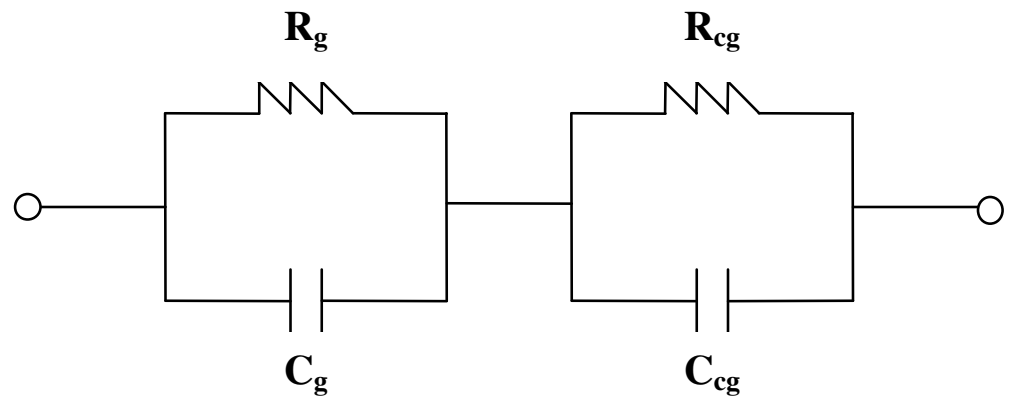

Figura 3: Representação de um circuito elétrico RC em paralelo.

A impedância deste dielétrico é: 


$$
\begin{aligned}
& Z^{\prime}=R / 2=R /\left(1+\omega_{O}^{2} \cdot R^{2} \cdot C^{2}\right) \\
& Z^{\prime \prime}=R / 2=\omega_{O} \cdot R^{2} \cdot C /\left(1+\omega_{O}^{2} \cdot R^{2} \cdot C^{2}\right)
\end{aligned}
$$

$\mathrm{R} / 2$ é o raio de um círculo, e rearranjando as equações (4) temos:

$$
\omega_{\mathrm{O}} \mathrm{RC}=1
$$

Assim, o diagrama de impedância de um resistor em paralelo com um capacitor é um semicírculo interceptando o eixo dos reais em $\mathrm{R}$ e 0 e a constante de tempo desse circuito $(\tau=R \cdot C)$ é o inverso da frequiência no apex desse semicírculo. Esta frequiência $\omega_{0}$ é a freqüência de máximo, isto é, frequiência característica ou de relaxação de um determinado mecanismo. A partir da equação (5) pode-se deduzir a constante dielétrica específica $\varepsilon$ do material:

$$
\varepsilon=\mathrm{C} \cdot \mathrm{K} / \varepsilon_{\mathrm{O}}
$$

$\varepsilon_{0}$ : permissividade do vácuo $\left(8,854 \times 10^{-12} \mathrm{~F} / \mathrm{m}\right)$

K: constante geométrica dada pela relação espessura/área da amostra perpendicular ao campo elétrico.

Portanto, um diagrama de impedância consiste na representação da parte imaginária $Z^{\prime \prime}$ em função da parte real $Z^{\prime}$, tendo como parâmetro a frequiência, chamado também de diagrama de Nyquist. O diagrama de impedância para o eletrólito sólido de zircônia ítria estudado por Bauerle ${ }^{[11]}$, mostra três semicírculos, como pode ser visto na Figura 4.

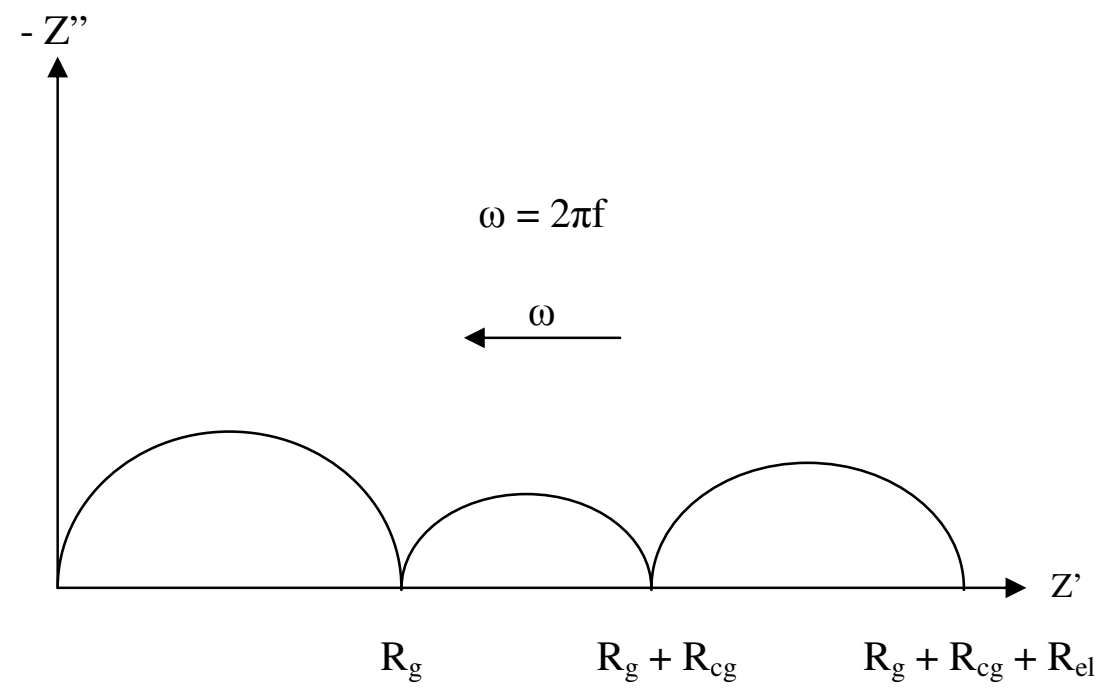

Figura 4: Esquema de um diagrama de impedância de uma cerâmica policristalina. 
O intercepto do semicírculo de frequiência mais elevada com o eixo real fornece a resistência intragranular (grão) $\mathrm{R}_{\mathrm{g}}$, o de frequiências intermediárias a resistência intergranular (contornos de grão) $\mathrm{R}_{\mathrm{cg}}$, e o de baixas freqüências a resistência de polarização do eletrodo $\mathrm{R}_{\text {ele }}$.

A Figura 5 mostra os diagramas de impedância de $\mathrm{ZrO}_{2}: 3$ mol\% $\mathrm{Y}_{2} \mathrm{O}_{3}$ com eletrodo de platina $(\mathrm{Pt})$ e de prata $(\mathrm{Ag})$. Os números que substituem os pontos em cada diagrama são o logaritmo decimal da freqüência em $\mathrm{Hz}$, e a letra $\omega$ e a seta representam a freqüência angular e o sentido do aumento da frequiência. $\mathrm{O}$ eletrodo de prata facilita a separação dos semicírculos relacionados a resistividades intragranular e intergranular, além de apresentar menor contribuição no diagrama de impedância. A diferença entre os valores de resistividade total é devido à diferença de temperatura de medida.

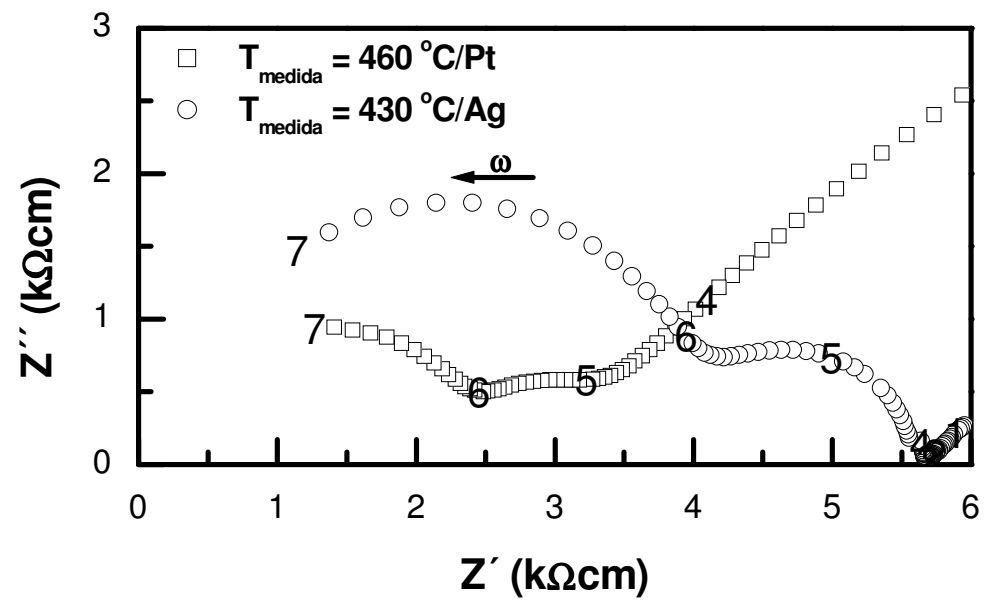

Figura 5: Comparação entre diagramas de impedância obtidos para zircônia:ítria com eletrodos de platina e de prata.

Neste trabalho foram usados eletrodos de Ag e de Pt, dependendo da faixa de temperatura de medida de interesse: eletrodo de Ag para temperaturas inferiores $500{ }^{\circ} \mathrm{C}$ e de $\mathrm{Pt}$ para temperaturas superiores. 


\subsection{Aplicações de eletrólitos sólidos à base de óxido de zircônio}

São várias as aplicações de eletrólitos sólidos à base de óxido de zircônio, dentre as principais podem ser citadas: em células a combustível ${ }^{[15,16]}$, em sensores de oxigênio ${ }^{[16,17]}$ e em bombas eletroquímicas ${ }^{[16]}$.

Neste trabalho será dada ênfase na aplicação de eletrólitos sólidos à base de zircônia em sensores de oxigênio.

\subsubsection{Sensores de oxigênio}

Sensores eletroquímicos são células galvânicas, com eletrólitos sólidos, que podem ser usados para medidas rápidas e diretas de teores de gases e de concentrações ou atividades em líquidos ou fundidos ${ }^{[18]}$. Apresentam grande vantagem por serem altamente compactos e robustos ${ }^{[19]}$. Estas são as principais razões para a pesquisa e investimento nesta área.

Entre os vários sensores eletroquímicos de gases, baseados em materiais condutores iônicos, os sensores de oxigênio têm um lugar de destaque, devido à sua ampla aplicação, quer seja no monitoramento de oxigênio em gases de exaustão em automóveis para controlar a razão ar/combustível minimizando a emissão de poluentes ${ }^{[20,21]}$, ou mesmo no monitoramento de oxigênio durante processos metalúrgicos permitindo um melhor controle da qualidade de produtos $^{[22-27]}$.

De uma maneira geral, os sensores de oxigênio têm vários componentes; porém, dentre os componentes principais podem ser citados dois eletrodos separados por um eletrólito sólido. Para garantir o funcionamento de um sensor de oxigênio, algumas condições gerais devem ser satisfeitas:

$\checkmark \quad$ Eletrólito sólido ${ }^{[28,29]}$

- elevada densidade (maior que $92 \%$ da densidade teórica) para evitar a passagem de gases pelos poros ${ }^{[30]}$;

- alta condutividade iônica (número de transporte iônico $\mathrm{t}_{\mathrm{i}}$ próximo de 1 , segundo a equação 7), em ampla faixa de temperatura e pressão parcial de oxigênio, para evitar o transporte de elétrons através do eletrólito e causar problemas de polarização na interface eletrodo/eletrólito; 


$$
\mathrm{t}_{\mathrm{i}}=\frac{\sigma_{\mathrm{i}}}{\sigma_{\mathrm{t}}} \sim 1
$$

$\sigma_{\mathrm{i}}:$ condutividade iônica

$\sigma_{\mathrm{t}}$ : condutividade total (iônica e eletrônica).

- baixa resistência interfacial, para transferência de massa no interior e a partir do eletrólito;

- resistência ao choque térmico, a fim de não se formar trincas;

- $\quad$ ser inerte aos gases analisados e aos materiais de contato;

- coeficiente de expansão ou contração térmica compatível com os outros materiais envolvidos.

$\checkmark \quad$ Eletrodo de referência ${ }^{[19,28]}$

- podem ser usados, por exemplos, um gás puro ou diluído em outro gás inerte, uma mistura de gases ou de sólidos;

- $\quad$ ser independente do gás sob investigação;

- $\quad$ ser quimicamente estável;

- ter um potencial químico conhecido e fixo;

- deve estar selado na célula eletroquímica para evitar a exposição com o gás sob investigação, o que poderia influenciar a aferição; a selagem é um processo tecnológico complicado, devido à diferença do coeficiente de expansão térmica entre o selante, o eletrólito e o eletrodo de referência, e uma possível reatividade do eletrodo de referência.

$\checkmark \quad$ Eletrodo de medida ${ }^{[28]}$

- deve ser um condutor eletrônico inerte ao eletrólito sólido e ao gás sob investigação.

Os sensores podem ser caracterizados por três parâmetros durante o seu funcionamento $^{[31]}$ :

$\checkmark \quad$ Sensitividade: é a capacidade de quantificar a medida, sendo governada pelas propriedades físicas e químicas do material utilizado. É dada pela relação $\mathrm{RT} / \mathrm{zF}$, dependendo somente da temperatura.

$\mathrm{R}$ : constante dos gases $(8,31451 \mathrm{~J} / \mathrm{mol} . \mathrm{K})$

T: temperatura absoluta de operação 
Z: número de elétrons envolvidos na reação (para eletrólitos sólidos à base de zircônia $\mathrm{n}=4$ );

F: constante de Faraday (96484,6 C/mol).

$\checkmark \quad$ Seletividade: é a capacidade de diferenciar espécies químicas.

$\checkmark \quad$ Tempo de resposta: é a medida do tempo mínimo decorrido para a mudança do sinal antes e após exposição ao meio sob medida.

Dependendo do modo de operação, os sensores de oxigênio podem ser classificados em dois tipos, amperométricos e potenciométricos. Em ambos os casos o princípio de funcionamento é baseado na reação entre os defeitos no eletrólito sólido e o oxigênio no ambiente de medida. O defeito predominante é a vacância de oxigênio $\mathrm{V}_{\ddot{\mathrm{o}}}$, e seu equilíbrio pode ser descrito pela reação (8):

$$
\mathrm{O}_{2}+\mathrm{V}_{\ddot{\mathrm{O}}}+2 \mathrm{e}^{-} \leftrightarrow \mathrm{O}_{\mathrm{O}}^{\mathrm{X}}
$$

na qual íons e defeitos no eletrólito sólido são representados usando a notação de Kroger-Vink ${ }^{[26]}$.

\section{Sensores amperométricos ${ }^{[19,28,32]}$}

Os sensores amperométricos são caracterizados pela não utilização de um eletrodo de referência, facilitando assim a sua construção. Um desenho de um sensor de oxigênio operando no modo amperométrico pode ser visto na Figura 6.

O oxigênio é bombeado pelo canal de difusão através da aplicação de um potencial externo na célula eletroquímica, resultando em uma corrente iônica (I) que passa através do eletrólito sólido e transporta um fluxo de oxigênio (J), segundo a Lei de Faraday (equação 9).

$$
\mathrm{J}=\frac{\mathrm{I}}{\mathrm{zF}}
$$

Quando a taxa de oxigênio bombeada através do eletrólito sólido exceder a taxa de oxigênio difundido, uma corrente limite é alcançada.

A corrente limite $\left(\mathrm{I}_{\mathrm{lim}}\right)$ é relacionada aos parâmetros geométricos do canal de difusão e a concentração de oxigênio, podendo ser definida de acordo com a primeira lei de Fick para difusão e com a equação do gás ideal (10):

$$
\mathrm{I}_{\lim }=\frac{\mathrm{zFD}_{\mathrm{o}_{2}} \mathrm{AP}}{\mathrm{RTL}} \ln \left(1-\mathrm{x}_{\mathrm{O}_{2}}\right)
$$


$\mathrm{D}_{\mathrm{O}_{2}}$ : coeficiente de difusão do oxigênio;

A: área do canal de difusão;

P: pressão barométrica;

L: comprimento do canal de difusão;

$\mathrm{x}_{\mathrm{O}_{2}}$ : fração molar do oxigênio.

Neste tipo de sensor a intensidade de corrente iônica é proporcional à pressão parcial ou à concentração do gás, sendo dependente das condições de difusão do gás.

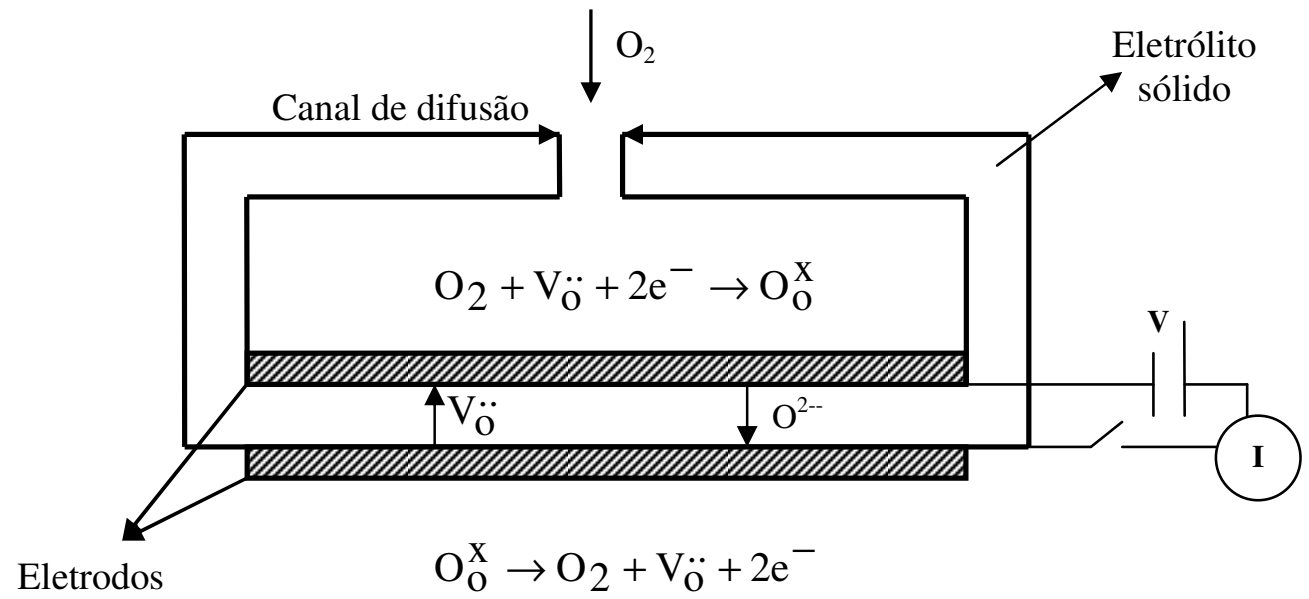

Figura 6: Esquema de uma célula eletroquímica amperométrica.

Sensores potenciométricos ${ }^{[19,28,31,32]}$

Os sensores potenciométricos são caracterizados pela utilização de dois eletrodos, o de trabalho e o de referência, sendo que este último deve ser selado, dificultando assim a construção da célula. O princípio de funcionamento é relativamente simples comparado com os sensores amperométricos; operam em condições de circuito aberto entre os dois eletrodos, onde não ocorre a passagem de uma corrente elétrica através do eletrólito sólido. Este tipo de sensor é o objeto de estudo neste trabalho.

Os sensores potenciométricos são constituídos por um eletrólito sólido na forma de tubo fechado em uma extremidade, onde interna e externamente são depositados eletrodos, promovendo uma superfície catalítica para a transformação de moléculas de oxigênio $\left(\mathrm{O}_{2}\right)$ em 
íons oxigênio $\left(\mathrm{O}^{2-}\right)$, os quais movem através do eletrólito sólido e se recombinam com o eletrodo de referência, como pode ser visto na Figura 7.

O movimento dos íons oxigênio produz uma força eletromotriz no circuito externo, que é função da diferença de pressão parcial de oxigênio entre a superfície externa (meio sob medida) e a superfície interna (eletrodo de referência com potencial de oxigênio conhecido). A força eletromotriz E é expressa pela equação de Nernst (11), sendo válida apenas para eletrólitos condutores puramente iônicos.

$$
\mathrm{E}=\left(\frac{\mathrm{RT}}{\mathrm{zF}}\right) \ln \left(\frac{\mathrm{pO}_{2}{ }^{(1)}}{\mathrm{pO}_{2}{ }^{(2)}}\right)
$$

$\mathrm{pO}_{2}$ : pressão parcial de oxigênio nos meios 1 (referência) e 2 (meio sob medida).

A pressão parcial de oxigênio da referência é calculada a partir da energia livre de formação do óxido de referência ( $\Delta \mathrm{G}^{\mathrm{O}}$ ), dada pela equação (12):

$$
\Delta \mathrm{G}^{\mathrm{o}}=-\mathrm{RT} \ln \mathrm{pO}_{2}{ }^{(1)}
$$

Neste tipo de sensor a E gerada é numericamente igual à diferença de potencial entre o eletrodo de referência e o eletrodo sob medida, ou seja, é uma medida direta da pressão parcial do gás.

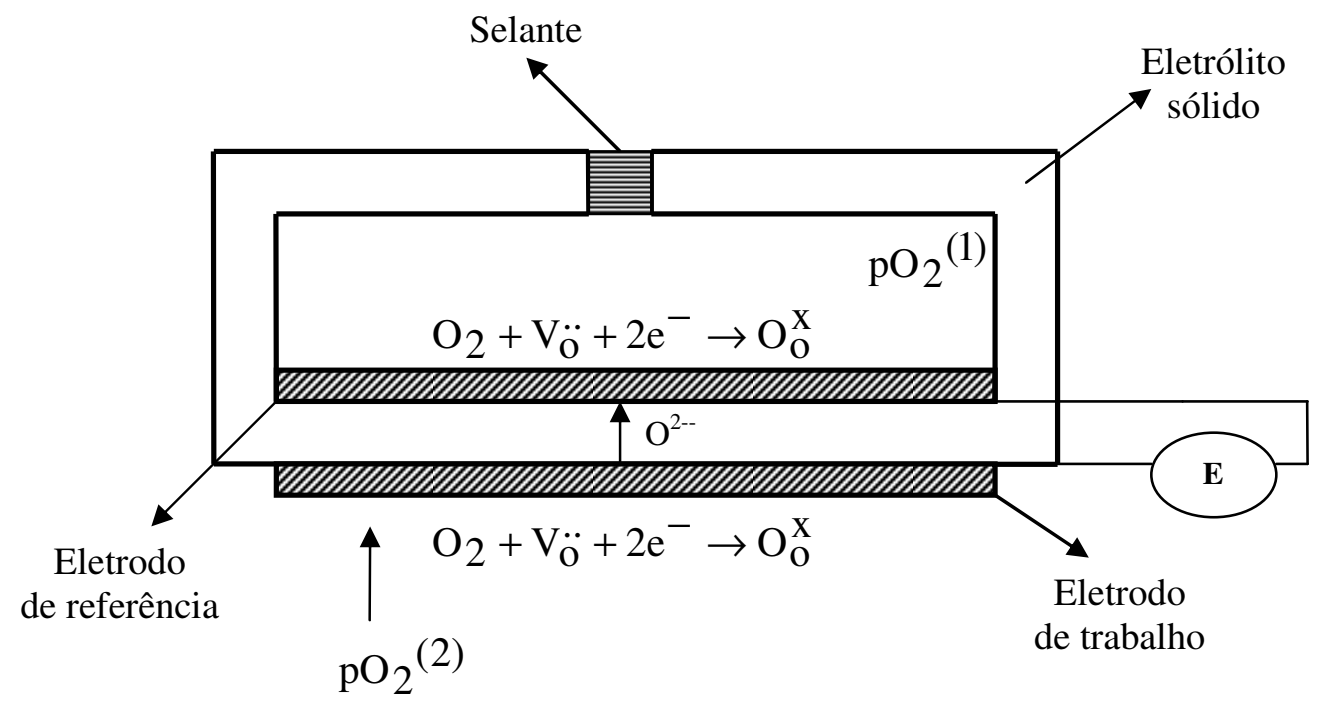

Figura 7: Esquema de uma célula eletroquímica potenciométrica. 


\subsubsection{Sensores de oxigênio na indústria siderúrgica}

Uma das mais importantes indústrias é a indústria do aço. Elementos como oxigênio e hidrogênio podem ser incorporados durante a fabricação do aço, resultando em mudanças indesejáveis na composição da liga ${ }^{[22,33]}$. O oxigênio é removido pela adição de alumínio ou de ligas de silício, que reagem para formar óxidos ${ }^{[22]}$. Para determinar a quantidade ótima necessária dessas ligas para que se forme o óxido, o teor de oxigênio dissolvido no aço é medido com um sensor de oxigênio ${ }^{[22,23-27,34-38]}$.

O eletrólito sólido mais utilizado atualmente no sensor de oxigênio na indústria siderúrgica é o $\mathrm{ZrO}_{2}: 8,6 \mathrm{~mol} \% \mathrm{MgO}$. O eletrólito sólido é o responsável pela geração de uma força eletromotriz a partir da diferença entre a pressão parcial de oxigênio dissolvido no banho metálico e a pressão parcial de oxigênio de um eletrodo de referência.

Apesar do uso desse eletrólito sólido, um inconveniente pode ser encontrado, como a presença da condutividade eletrônica quando submetido a meios que envolvam baixos teores de oxigênio ${ }^{[24]}$. Nesse caso ocorre a permeação química do oxigênio através do eletrólito sólido, causando problemas de polarização na interface eletrodo/eletrólito e, conseqüentemente, a queda no valor de E. A principal razão para o uso desse material em sensores de oxigênio é a alta resistência ao choque térmico ${ }^{[39,40]}$ que este material possui em condições severas, suportando um tempo suficiente para detectar um sinal elétrico $(\mathrm{E})$ antes de se romper.

Tendo em vista esse problema, já que em certos processos industriais se requer medidas que envolvam baixo teor de oxigênio $(<50 \mathrm{ppm})$, é essencial o desenvolvimento de novos materiais, buscando assim otimizar as propriedades para garantir um bom funcionamento do sensor de oxigênio.

Uma maneira de se conseguir materiais com propriedades específicas é a obtenção de materiais compósitos (neste trabalho usamos a seguinte definição de materiais compósitos: mistura homogênea de materiais com diferentes propriedades e/ou funções) com a finalidade de se otimizar as propriedades para um bom funcionamento de um dispositivo eletroquímico.

São encontrados estudos de sistemas ternários ${ }^{[41-44]}$ envolvendo a adição de dois óxidos estabilizantes $\left(\mathrm{Y}_{2} \mathrm{O}_{3}\right.$ e $\mathrm{MgO}, \mathrm{MgO}$ e $\mathrm{CaO}, \mathrm{Y}_{2} \mathrm{O}_{3}$ e $\left.\mathrm{TiO}_{2}\right)$ na zircônia, com o objetivo de se melhorar as propriedades da zircônia, para utilização em sensores de oxigênio; ou ainda estudo da adição de um filme espesso (1 $\sim \mu \mathrm{m}$ de espessura) de zircônia:ítria na matriz de 
zircônia:magnésia para diminuir a contribuição da condutividade eletrônica, quando exposta a meios com baixo teor de oxigênio ${ }^{[45]}$.

\subsection{Objetivos}

Os objetivos deste trabalho são:

1. A preparação e caracterização de compósitos de eletrólitos sólidos à base de zircônia para utilização em sensores para a detecção de baixos teores de oxigênio $(<50 \mathrm{ppm})$, tendo como matriz $\mathrm{ZrO}_{2}: 8,6 \mathrm{~mol} \% \mathrm{MgO}$, que apresenta boa resistência ao choque térmico e o maior valor de condutividade elétrica (maior resposta elétrica) entre as soluções de zircônia:magnésia, e $\mathrm{ZrO}_{2}: 3 \mathrm{~mol} \% \mathrm{Y}_{2} \mathrm{O}_{3}$, que além de ser uma cerâmica com alta tenacidade, apresenta excelente resposta elétrica relativamente ao eletrólito sólido $\mathrm{ZrO}_{2}: 8,6 \mathrm{~mol} \% \mathrm{MgO}$.

2. A montagem e testes de protótipos de sensores de oxigênio usando compósitos cerâmicos. 


\section{PARTE EXPERIMENTAL}

\subsection{Materiais}

Os materiais utilizados para a preparação dos compósitos cerâmicos de zircônia:magnésia e zircônia:ítria foram:

$\checkmark \quad \mathrm{ZrO}_{2}: 8,6 \mathrm{~mol} \% \mathrm{MgO}$, Zirconia Sales - EUA (\% em peso: $\mathrm{MgO}-2,65, \mathrm{Al}_{2} \mathrm{O}_{3}-0,30$, $\left.\mathrm{SiO}_{2}-0,20, \mathrm{Fe}_{2} \mathrm{O}_{3}-0,01, \mathrm{Na}_{2} \mathrm{O}-0,05, \mathrm{CaO}-0,20\right)$

$\checkmark \quad \mathrm{ZrO}_{2}: 3$ mol\% $\mathrm{Y}_{2} \mathrm{O}_{3}$, Tosoh - Japão (\% em peso: $\mathrm{Y}_{2} \mathrm{O}_{3}-5,17, \mathrm{Al}_{2} \mathrm{O}_{3}-0,005$, $\left.\mathrm{SiO}_{2}-0,005, \mathrm{Fe}_{2} \mathrm{O}_{3}-0,002, \mathrm{Na}_{2} \mathrm{O}-0,021\right)$.

Os pós cerâmicos foram caracterizados quanto ao teor de fases cristalinas por difração de raios $X$ na faixa de $2 \theta=20^{\circ}$ a $40^{\circ}$, com radiação $\mathrm{CuK} \alpha$, em um difratômetro Bruker-AXS D8 Advance. Para a indexação das fases cristalinas foram utilizados os arquivos ICDD.

\subsection{Preparação e caracterização dos compósitos cerâmicos}

Compósitos cerâmicos de $\left(\mathrm{ZrO}_{2}: 8,6 \mathrm{~mol} \% \mathrm{MgO}\right)_{\mathrm{x}}\left(\mathrm{ZrO}_{2}: 3 \mathrm{~mol} \% \mathrm{Y}_{2} \mathrm{O}_{3}\right)_{1-\mathrm{x}}, 0 \leq \mathrm{x} \leq 1$, foram preparados por meio de mistura de pós de $\mathrm{ZrO}_{2}: 8,6 \mathrm{~mol} \% \mathrm{MgO}$ e $\mathrm{ZrO}_{2}: 3 \mathrm{~mol} \% \mathrm{Y}_{2} \mathrm{O}_{3}$. A homogeneização das composições foi feita em almofariz de ágata por aproximadamente 15 min. As composições foram prensadas uniaxialmente a $50 \mathrm{MPa}$. Para a determinação da temperatura de sinterização dos compactos cerâmicos, foi feito um estudo da retração linear em função da temperatura em um dilatômetro Netzsch DIL 402 ES/3/E na faixa de temperaturas entre a ambiente e $1550{ }^{\circ} \mathrm{C}$ com razão de aquecimento $8{ }^{\circ} \mathrm{C} / \mathrm{min}$ e de resfriamento $10{ }^{\circ} \mathrm{C} / \mathrm{min}$. Os compactos cerâmicos foram sinterizados em forno resistivo tubular Lindberg a $1500{ }^{\circ} \mathrm{C} / 60 \mathrm{~min}$, com razão de aquecimento $8{ }^{\circ} \mathrm{C} / \mathrm{min}$ e de resfriamento $10{ }^{\circ} \mathrm{C} / \mathrm{min}$, para minimizar o choque térmico.

\subsubsection{Difração de raios $X$}

A identificação de fases cristalinas foi feita por difração de raios $\mathrm{X}$, e as fases foram quantificadas por meio de refinamento da estrutura cristalina pelo método de Rietveld.

O método de Rietveld é uma aplicação dos princípios básicos de física da difração e de parâmetros cristalográficos fundamentais, como parâmetros de rede e posições de ocupação na 
cela unitária, para o cálculo das intensidades do padrão de difração. É baseado na construção de um padrão de difração calculado, de acordo com o modelo estrutural. O padrão calculado é obtido pela introdução direta dos dados cristalográficos, tais como simetria do grupo espacial, posições atômicas, fatores de ocupação e parâmetros de rede. O padrão calculado ao se ajustar ao padrão observado fornece os parâmetros estruturais do material e parâmetros do perfil de $\operatorname{difração~}^{[46]}$.

O termo refinamento no método de Rietveld refere-se ao processo de ajuste do modelo de parâmetros utilizados no cálculo de um padrão de difração, que seja o mais próximo do observado. São obtidos os dados do padrão de difração calculado e observado, fornecidos os dados estruturais teóricos e experimentais para as fases tetragonal, cúbica e monoclínica, as porcentagens de cada fase presente, e os resíduos $\chi^{2}$ e $\mathrm{R}_{\mathrm{wp}}$ obtidos a partir da diferença das intensidades observadas e calculadas (parâmetros que avaliam o progresso de refinamento e a concordância entre o perfil observado e calculado). Para bons resultados $\chi \sim 1$ e $\mathrm{R}_{\mathrm{wp}} \sim 2-10 \%{ }^{[46]}$.

Para o refinamento, foram usados os resultados das análises de difração de raios $\mathrm{X}$ de compósitos cerâmicos na forma de pastilha sinterizada a $1500{ }^{\circ} \mathrm{C}$, obtidos nas seguintes condições:

a) Coleta de dados

Difratômetro Bruker-AXS modelo D8 Advance, condições de operação 40 kV-40 mA, radiação $\mathrm{CuK} \alpha$, faixa angular $(2 \theta)$ de $20^{\circ}$ a $80^{\circ}$, tamanho do passo $0,05^{\circ}$, tempo por passo $10 \mathrm{~s}$.

\section{b) Padrão instrumental}

Óxido de cério $\left(\mathrm{CeO}_{2}\right)$, preparado neste laboratório ${ }^{[47]}$

c) Programa utilizado para o refinamento

GSAS (General Structure Analysis System)*

A pesquisa de dados cristalográficos para a construção dos padrões de difração teóricos do óxido de zircônio $\left(\mathrm{ZrO}_{2}\right)$ foi feita no banco de dados ICSD (89426 para a fase monoclínica, 88022 para a fase tetragonal e 89429 para a fase cúbica) e arquivos ICDD.

* A. C. Larson, R. B. Von Dreele, General Structure Analysis System (GSAS), Los Alamos National Laboratory Report LAUR 86-748 (2004). 


\subsubsection{Comportamento térmico}

O estudo do comportamento térmico dos compósitos cerâmicos sinterizados, por dilatometria, foi realizado nas mesmas condições que o descrito para os compactos a verde.

\subsubsection{Densidade aparente}

Os compósitos cerâmicos foram caracterizados quanto à determinação da densidade aparente pelo método de Arquimedes.

\subsubsection{Microscopia eletrônica de varredura}

As superfícies de fratura dos compactos cerâmicos sinterizados foram observadas em microscópio eletrônico de varredura modelo LEO 440I da Oxford, com recobrimento de ouro.

\subsubsection{Comportamento elétrico}

Para as medidas elétricas dos compósitos cerâmicos, foram pintadas com prata coloidal as faces paralelas das amostras, sendo a cura da solução feita a $400{ }^{\circ} \mathrm{C} / 15 \mathrm{~min}$. As medidas foram feitas em câmara porta-amostra de inconel inserida em forno resistivo, em atmosfera ambiente. A temperatura foi monitorada com termopar tipo $\mathrm{K}$. O equipamento usado foi o analisador de impedância Hewlett Packard modelo 4192A, acoplado a um controlador HP modelo 362 e operado por meio de software desenvolvido no LIESG, Grenoble, França, sendo as medidas feitas na faixa de frequiências $5 \mathrm{~Hz}-13 \mathrm{MHz}$ a $\sim 430{ }^{\circ} \mathrm{C}$, com tensão de $100 \mathrm{mV}$.

\subsection{Preparação e testes dos compósitos cerâmicos na forma de tubo}

Para simular o funcionamento de um sensor de oxigênio, foram preparados compósitos cerâmicos na forma de tubo, por meio de mistura de pós com $\mathrm{ZrO}_{2}$ : 8,6 mol\% $\mathrm{MgO}$ e $\mathrm{ZrO}_{2}: 3 \mathrm{~mol} \% \mathrm{Y}_{2} \mathrm{O}_{3}$. A homogeneização das composições foi feita em almofariz de ágata por $15 \mathrm{~min}$. As composições obtidas foram compactadas uniaxialmente a $50 \mathrm{MPa}$ e tratadas termicamente ao ar a $800{ }^{\circ} \mathrm{C} / 60$ min para aumentar a resistência mecânica durante o processo de furação em torno mecânico. Após o processo de furação, os compactos cerâmicos, na forma de tubo fechado em uma extremidade, foram sinterizados a $1500{ }^{\circ} \mathrm{C} / 60 \mathrm{~min}$. 
Os tubos foram pintados interna e externamente com platina coloidal e na parte interna de cada tubo foi colocado o eletrodo de referência $\left(\mathrm{Cr}-\mathrm{Cr}_{2} \mathrm{O}_{3}\right.$ ou Ni-NiO). Em contato com o eletrodo de platina e com o eletrodo de referência foram colocados fios de liga $\mathrm{Ni}-\mathrm{Cr}$, como mostra a Figura 8. Cada compósito cerâmico foi colocado dentro de um tubo de quartzo e foi feita a selagem com cimento refratário, obtendo-se um arranjo experimental para medidas elétricas, como mostra a Figura 9.

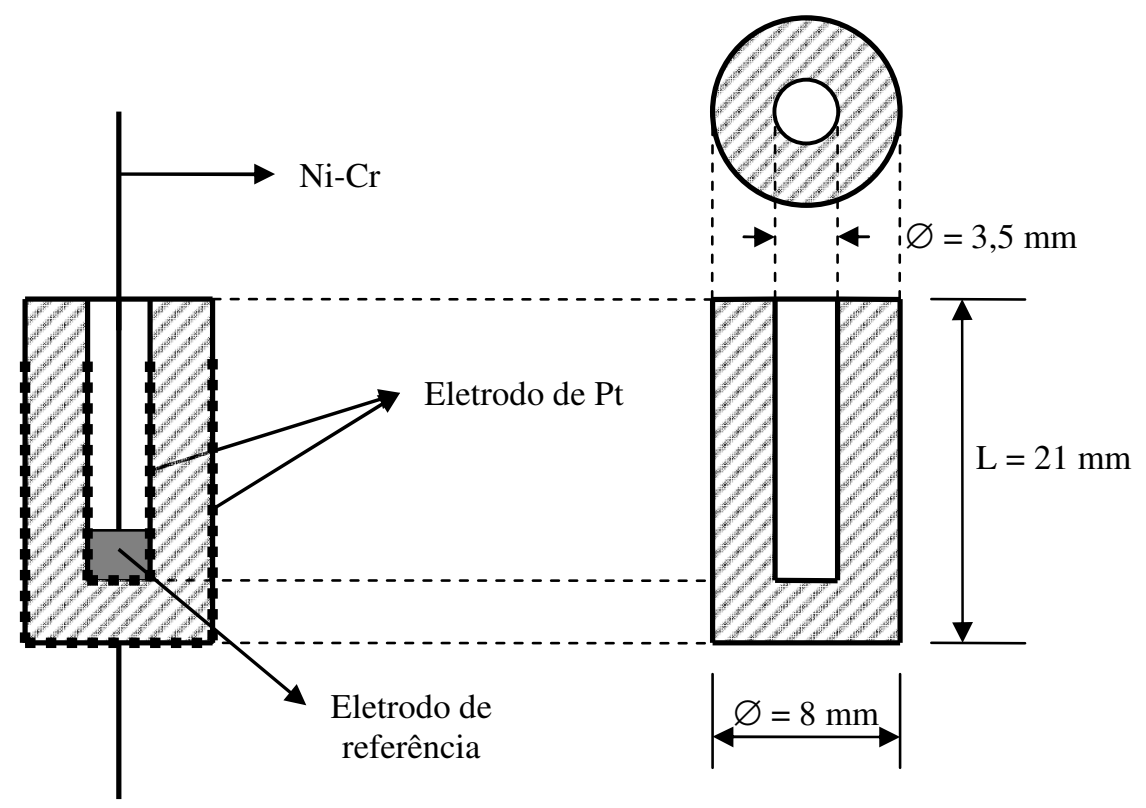

Figura 8: Compósito cerâmico na forma de tubo para teste do sensor.

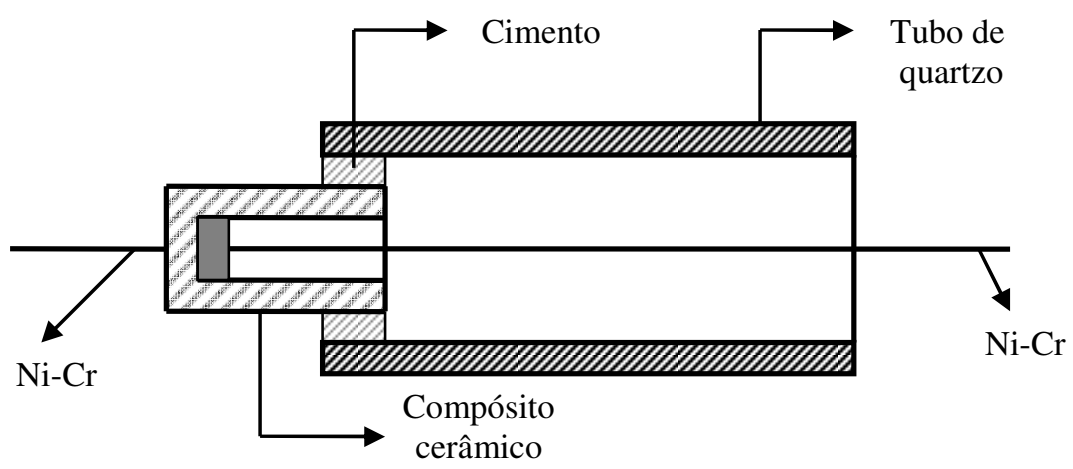

Figura 9: Esquema do arranjo experimental para medidas elétricas. 
Os testes para simular o funcionamento do sensor de oxigênio com o arranjo (compósito cerâmico, eletrodo de referência, fios de liga $\mathrm{Ni}-\mathrm{Cr}$, tubo de quartzo e cimento refratário) preparado neste trabalho, são descritos a seguir.

\section{Teste 1: Comportamento da força eletromotriz com a temperatura}

Inicialmente foi feito um estudo da estabilização da força eletromotriz com a temperatura, tendo ar como eletrodo de referência. A montagem foi colocada dentro de um forno tubular, programado na faixa de temperatura entre ambiente e $1000{ }^{\circ} \mathrm{C}$. A força eletromotriz E gerada através do eletrólito sólido, na faixa de $500{ }^{\circ} \mathrm{C}-1000{ }^{\circ} \mathrm{C}$ com um patamar de 30 min para cada temperatura, foi medida com um multímetro digital (Fluke 8050A) ligado a um computador através de uma interface de coleta de dados (Construmaq, São Carlos, SP). A montagem experimental pode ser vista na Figura 10.

\section{Teste 2: Tempo de resposta}

Para a medida do tempo de resposta foi utilizado como eletrodo de referência Ni-NiO. A medida do tempo de resposta a $1000{ }^{\circ} \mathrm{C}$ para cada compósito foi feita da seguinte maneira: pulsos de argônio são introduzidos em um dos lados do tubo (extremidade fechada), deixando um fluxo contínuo durante aproximadamente $3 \mathrm{~min}$; após esse tempo, o fluxo de gás é interrompido deixando a força eletromotriz voltar ao seu valor original. Esse procedimento foi repetido pelo menos 4 vezes para cada composição. 


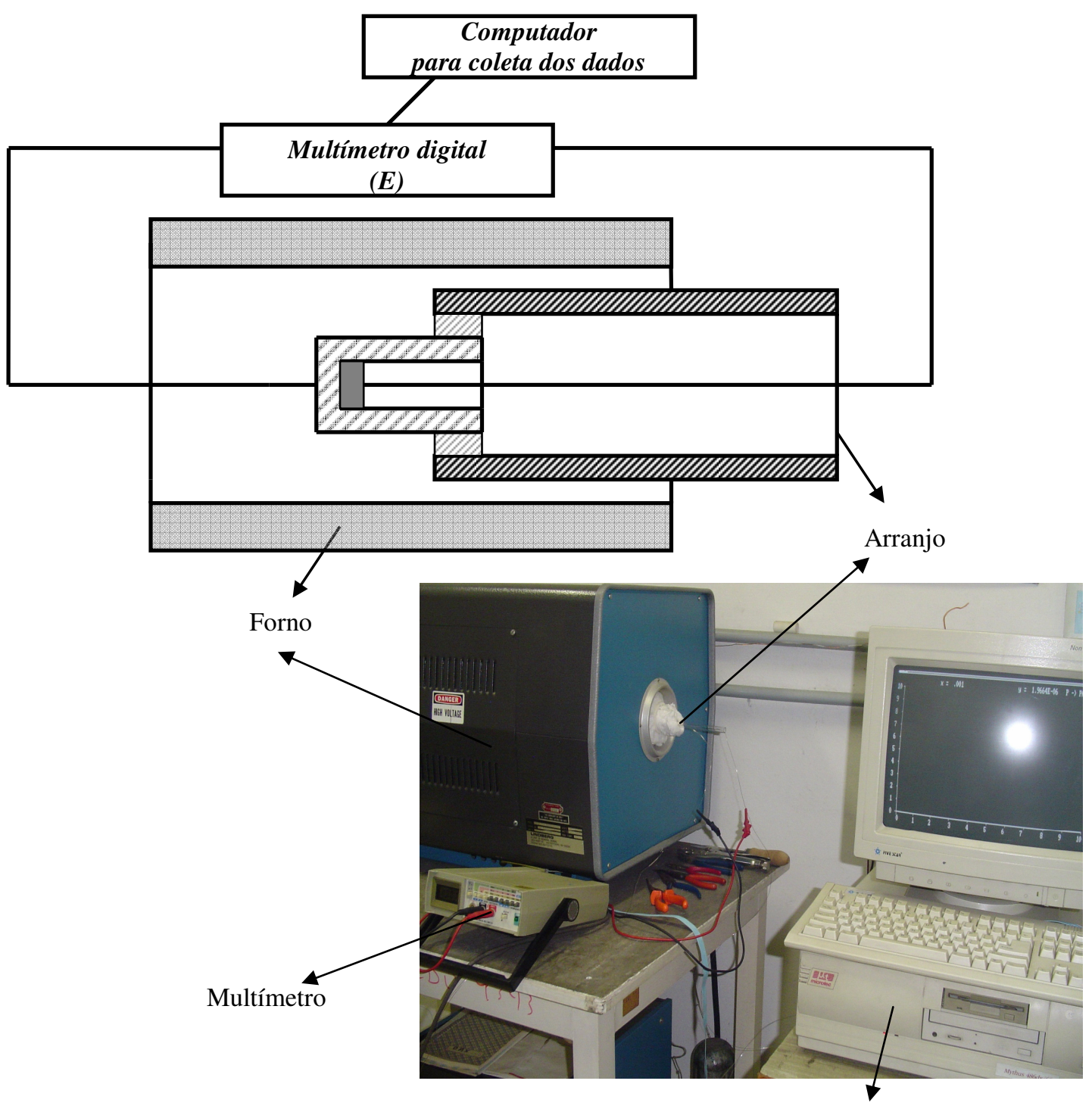

Computador/Interface

Figura 10: Esquema e foto da montagem experimental para medidas da resposta elétrica.

Teste 3: Comportamento da força eletromotriz e do tempo de resposta com a pressão parcial de oxigênio

Para as medidas da resposta elétrica em função da pressão parcial de oxigênio, o eletrodo de referência foi uma mistura de cromo metálico $\mathrm{Cr}$ e de seu óxido $\mathrm{Cr}_{2} \mathrm{O}_{3}$, na proporção em peso 90 do metal para 10 do óxido. Cada arranjo foi colocado dentro de um forno tubular acoplado a um sistema que permite controlar a $\mathrm{pO}_{2}$ na amostra. Esse sistema ${ }^{[48]}$ consiste basicamente de: 
- um cilindro de gás (neste trabalho foi usado o argônio 5.0 Analítico, White Martins, como gás vetor);

- uma bomba eletroquímica de oxigênio constituída por um eletrólito sólido de zircônia:ítria na forma de tubo, com platina depositada nas partes internas e externas, inserida em um forno que opera a $800{ }^{\circ} \mathrm{C}$. A bomba eletroquímica é responsável pelo enriquecimento em oxigênio do gás argônio. O funcionamento é baseado na lei de Faraday (equação 9). Neste trabalho foram aplicadas as correntes $\mathrm{I}=0$ a $50 \mathrm{~mA}$, permitindo controlar a atmosfera de $\mathrm{O}_{2}$ de 1 a $1000 \mathrm{ppm}$.

- um sensor de oxigênio composto por um eletrólito sólido de zircônia:ítria na forma de um tubo fechado em uma de suas extremidades, inserido em um forno tubular a $800{ }^{\circ} \mathrm{C}$. $\mathrm{O}$ sensor de oxigênio é responsável pela determinação da $\mathrm{pO}_{2}$ presente no gás vetor que passa pela amostra. A determinação da $\mathrm{pO}_{2}$ é baseada na lei de Nernst conforme equação (11), onde o eletrólito sólido é colocado entre duas atmosferas contendo diferentes teores de oxigênio, referência (ar) e o oxigênio a ser determinado no gás vetor que circula no interior do tubo de zircônia.

$\mathrm{O}$ esquema do sistema utilizado para as medidas da resposta elétrica em função da $\mathrm{pO}_{2}$ pode ser visto na Figura 11.

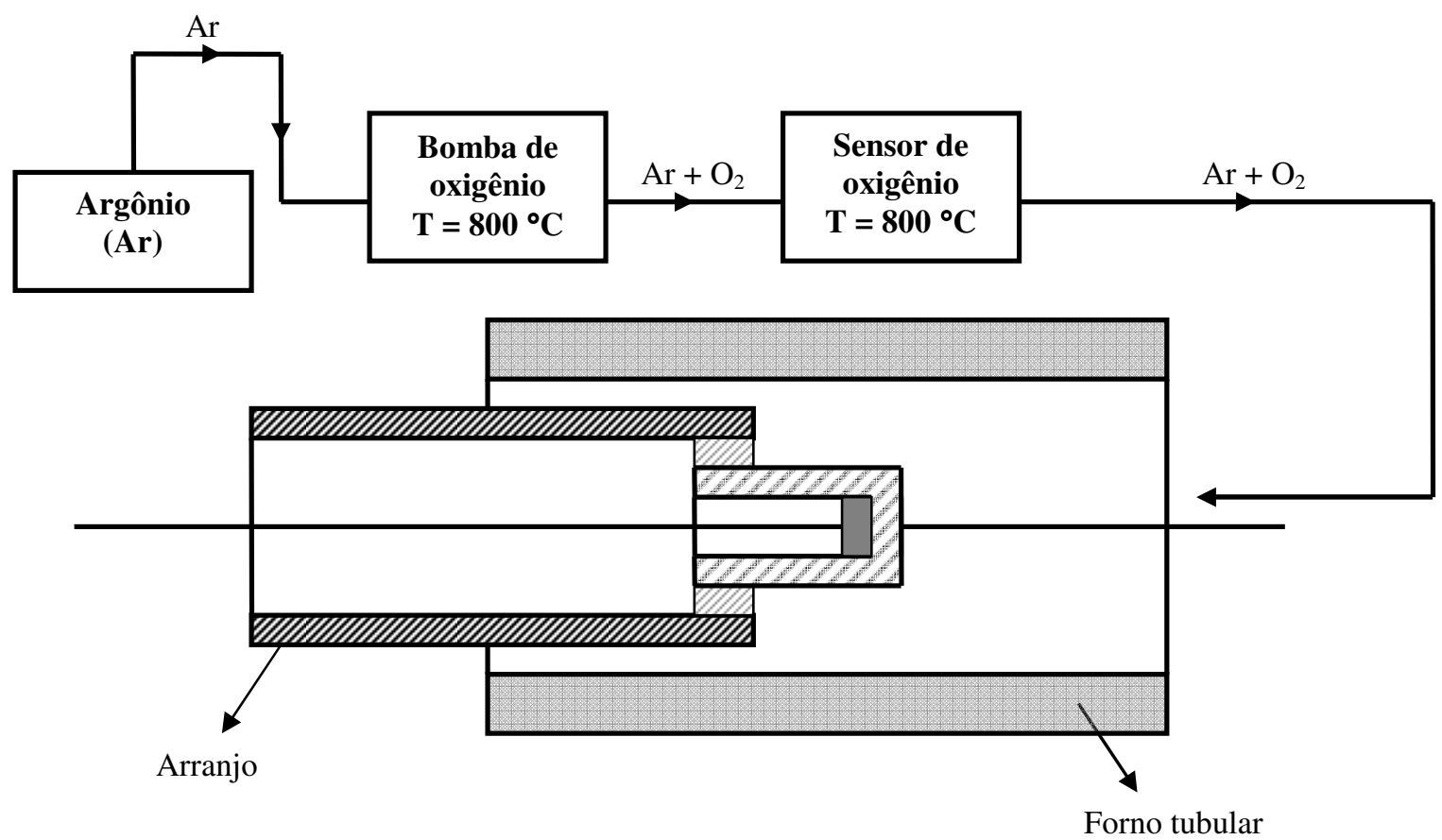

Figura 11: Esquema do sistema de medidas elétricas em função da pressão parcial de oxigênio. 
Para as medidas elétricas em função da $\mathrm{pO}_{2}$, o forno foi mantido a $1000{ }^{\circ} \mathrm{C}$, sob fluxo de argônio. Após a estabilização da força eletromotriz em atmosfera de argônio, foram introduzidas diferentes quantidades de oxigênio no gás vetor (argônio) durante 30 s. Após este tempo, o fluxo de oxigênio é interrompido deixando a fem voltar ao seu valor original.

\section{Teste 4: Comportamento da resistividade elétrica com a pressão parcial de oxigênio}

Para as medidas da resistividade elétrica em função da pressão parcial de oxigênio, os tubos cerâmicos foram preparados da mesma maneira que os descritos anteriormente, com eletrodo de referência $\mathrm{Cr}-\mathrm{Cr}_{2} \mathrm{O}_{3}$ ou Ni-NiO. A única diferença é que cada tubo foi selado diretamente com cimento refratário, como mostra a Figura 12, e não colocado dentro de um tubo de quartzo.

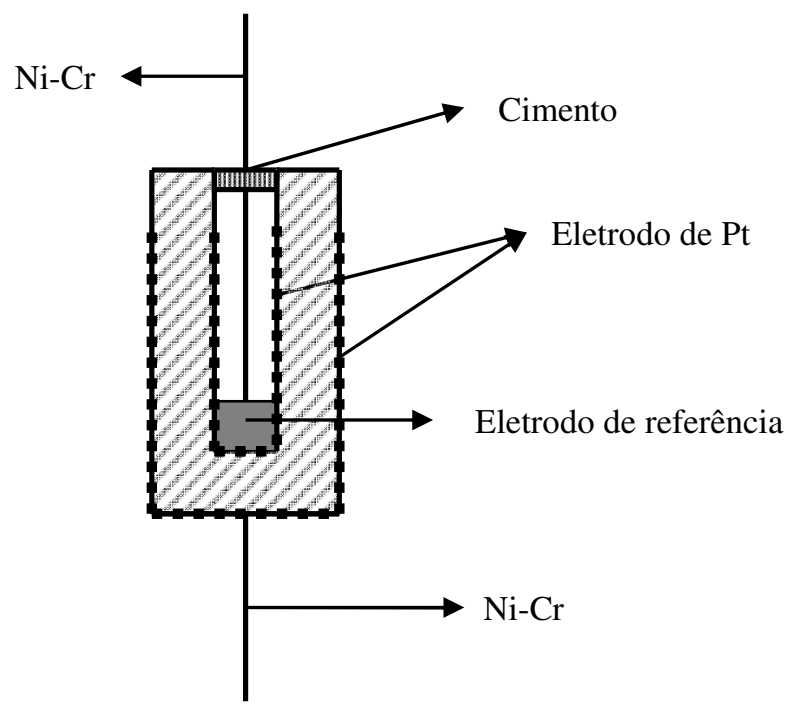

Figura 12: Compósito cerâmico para as medidas da resistividade elétrica em função da pressão parcial de oxigênio.

Cada tubo foi colocado dentro de uma câmara porta-amostra projetada para medidas seqüenciais de três amostras, Figura 13. A câmara consiste de uma estrutura metálica em inconel 600, terminais de fiação de platina, disco de platina, tubos de alumina e conectores do tipo bnc para conexão através de cabos coaxiais com o analisador de impedância. Através de um sistema de molas é possível aplicar uma pressão nas amostras garantindo o contato elétrico. 
A foto na Figura 13, mostra a montagem dos tubos na câmara. Os fios de Ni-Cr do tubo cerâmico foram colocados em contato com o disco de platina, e estes isolados por um disco de alumina.
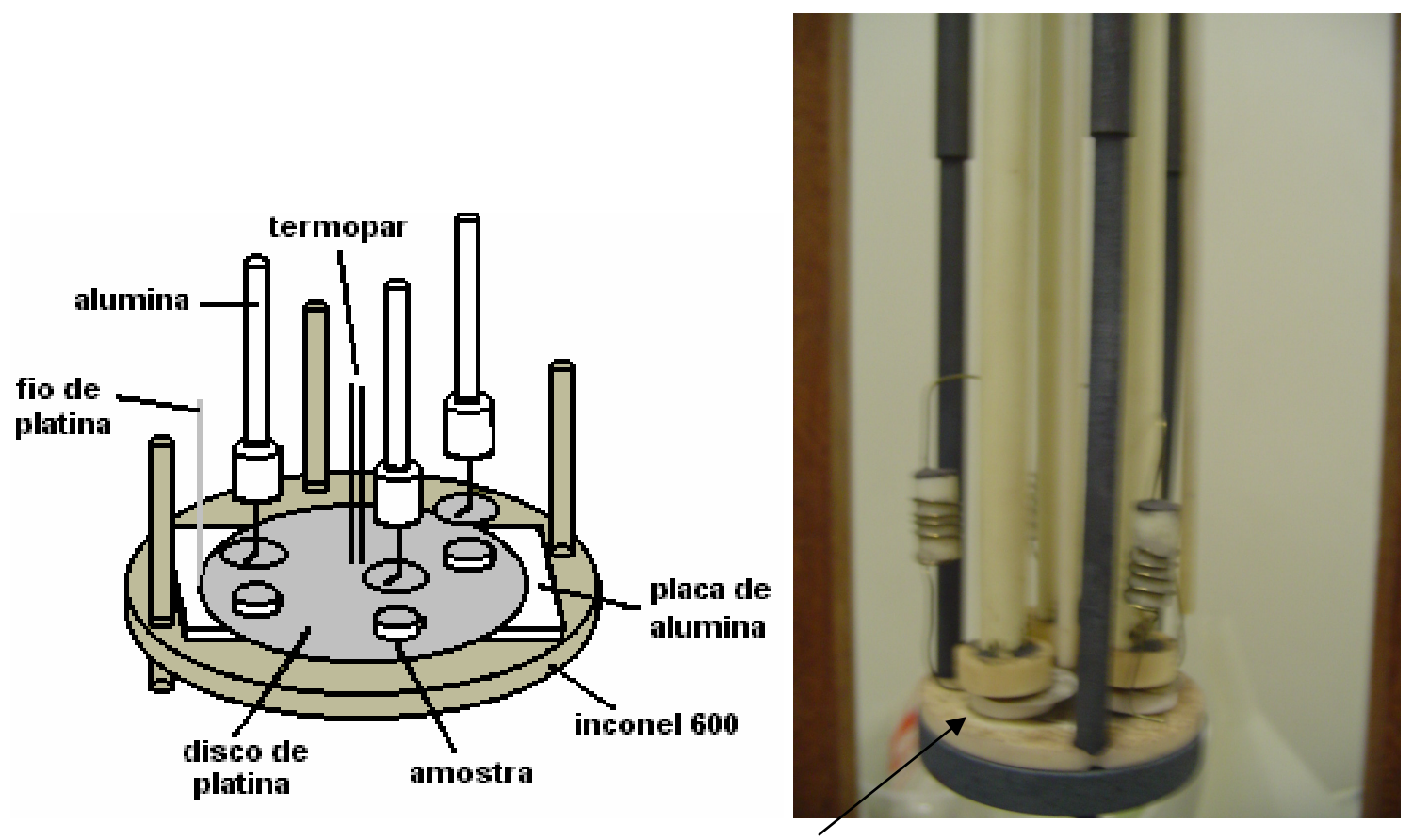

disco de alumina

Figura 13: Esquema e foto da câmara porta-amostra para medidas de espectroscopia de impedância sob diferentes teores de oxigênio para avaliação do sensor.

Os diagramas de impedância foram obtidos na faixa de freqüências $5 \mathrm{~Hz}-13 \mathrm{MHz}$ a $620^{\circ} \mathrm{C}$ e $640^{\circ} \mathrm{C}$ com um analisador de impedância acoplado a um sistema que permite controlar a $\mathrm{pO}_{2}$ na amostra. A Figura 14 apresenta um esquema da montagem experimental para análise de espectroscopia de impedância em função da pressão parcial de oxigênio. 


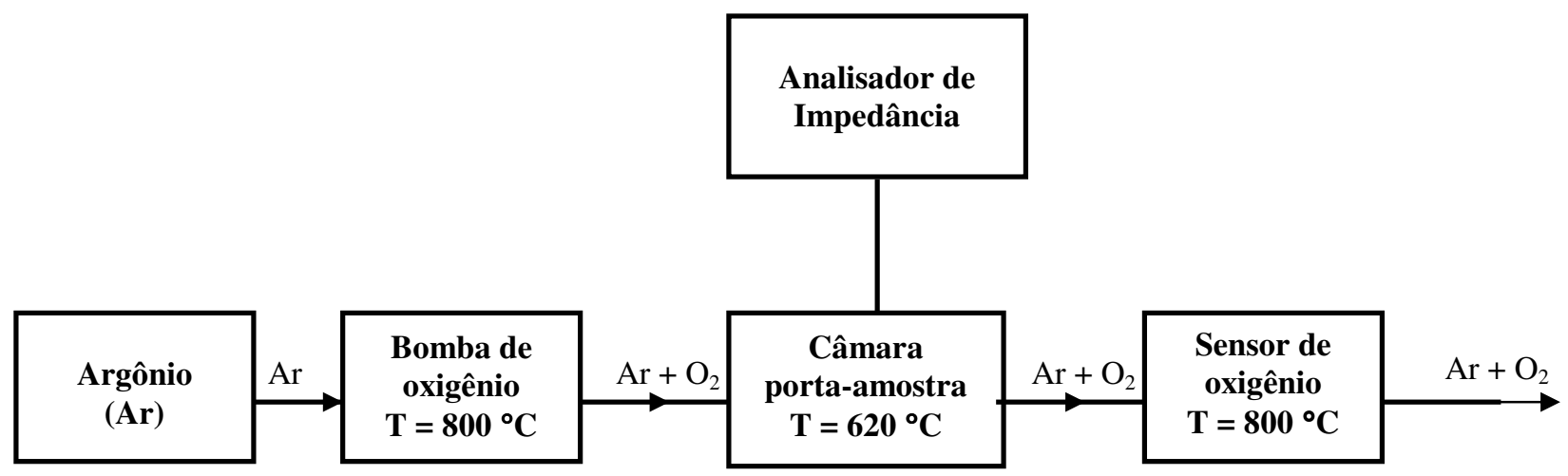

Figura 14: Esquema do sistema de análise de espectroscopia de impedância em função da pressão parcial de oxigênio. 


\section{RESULTADOS E DISCUSSÃO}

Este capítulo é dividido em três seções principais, nas quais são apresentados os resultados da caracterização dos materiais de partida e dos compósitos cerâmicos, e testes realizados nos compósitos cerâmicos na forma de tubo para simulação do seu uso em sensores de oxigênio a altas temperaturas.

\subsection{Caracterização dos materiais de partida}

A área de superfície específica, fornecida pelos fabricantes, pode ser vista na Tabela 1. As partículas de zircônia:ítria tem menor tamanho médio que as de zircônia magnésia, segundo a equação (13):

$$
\mathrm{Sd} \cong 6 / \rho
$$

$\mathrm{S}$ : área de superfície específica $\left(\mathrm{m}^{2} / \mathrm{g}\right)$

d: diâmetro médio de partículas (m)

$\rho:$ densidade $\left(\mathrm{g} / \mathrm{m}^{3}\right)$.

Tabela 1: Valores de área de superfície específica.

\begin{tabular}{ccc}
\hline Material & $\mathbf{S}\left(\mathbf{m}^{2} / \mathbf{g}\right)$ & $\mathbf{d}(\mu \mathbf{m})$ \\
\hline $\mathrm{ZrO}_{2}: 8,6 \mathrm{~mol} \% \mathrm{MgO}$ & 4 & 0,26 \\
$\mathrm{ZrO}_{2}: 3 \mathrm{~mol} \% \mathrm{Y}_{2} \mathrm{O}_{3}$ & 16 & 0,06 \\
\hline
\end{tabular}

A Figura 15 mostra os difratogramas de raios $\mathrm{X}$ dos pós $\mathrm{ZrO}_{2}: 8,6 \mathrm{~mol} \% \mathrm{MgO}$ e $\mathrm{ZrO}_{2}: 3 \mathrm{~mol} \% \mathrm{Y}_{2} \mathrm{O}_{3}$, onde $\mathrm{m}$ representa a fase monoclínica e $\mathrm{t}$ a fase tetragonal.

A zircônia:magnésia é monoclínica $\left(\mathrm{I}_{-111}, 100 \%, 2 \theta=28,2^{\circ}\right)$, enquanto que a zircônia:ítria tem as fases monoclínica e tetragonal $\left(\mathrm{I}_{111}, 100 \%, 2 \theta=30,2^{\circ}\right)$.

A condutividade iônica de eletrólitos sólidos à base de zircônia com fase cúbica ou tetragonal é muito maior que a dos com estrutura monoclínica ${ }^{[49]}$. De acordo com o diagrama de fases da zircônia:magnésia, durante a sinterização a fase monoclínica se transformará em fase tetragonal ${ }^{[9]}$. 


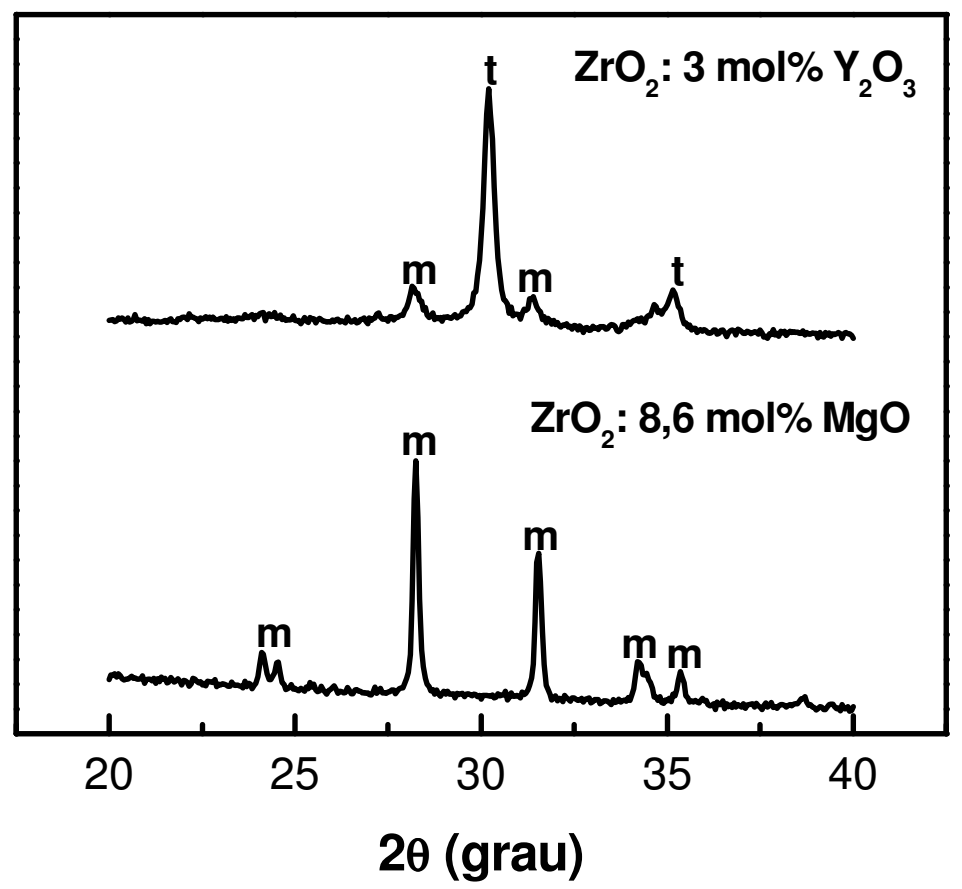

Figura 15: Difratogramas de raios X dos pós de zircônia:ítria e zircônia:magnésia.

\subsection{Caracterização dos compósitos cerâmicos}

\subsubsection{Dilatometria}

Inicialmente foi feita a análise de dilatometria para a determinação do perfil de sinterização dos compósitos cerâmicos.

Como são conhecidos os comportamentos térmicos por análises de dilatometria de zircônia:magnésia (curva de histerese relacionada com a transformação de fase tetragonal $\rightarrow$ monoclínica) ${ }^{[39,50]}$ e zircônia:ítria (alta densificação pode ser obtida para temperatura de sinterização relativamente baixa, próxima a $\left.1200{ }^{\circ} \mathrm{C}\right){ }^{[51]}$, neste trabalho foram escolhidos os compósitos cerâmicos com composições intermediárias de zircônia:magnésia e de zircônia:ítria para a análise de dilatometria.

A Figura 16 mostra a retração linear em função da temperatura dos compactos cerâmicos $\left(\mathrm{ZrO}_{2}: 8,6 \mathrm{~mol} \% \mathrm{MgO}\right)_{\mathrm{x}}\left(\mathrm{ZrO}_{2}: 3 \mathrm{~mol} \% \mathrm{Y}_{2} \mathrm{O}_{3}\right)_{1-\mathrm{x}}, \mathrm{x}=0,2,0,5$ e 0,8 .

A temperatura de início da densificação para todas amostras é aproximadamente $1000{ }^{\circ} \mathrm{C}$, não sendo completada a densificação até a temperatura de $1550{ }^{\circ} \mathrm{C}$. Os valores de 
retração máxima atingida das amostras $\mathrm{x}=0,2,0,5$ e 0,8 foram $20,7,18,8$ e 18,9\%, respectivamente.

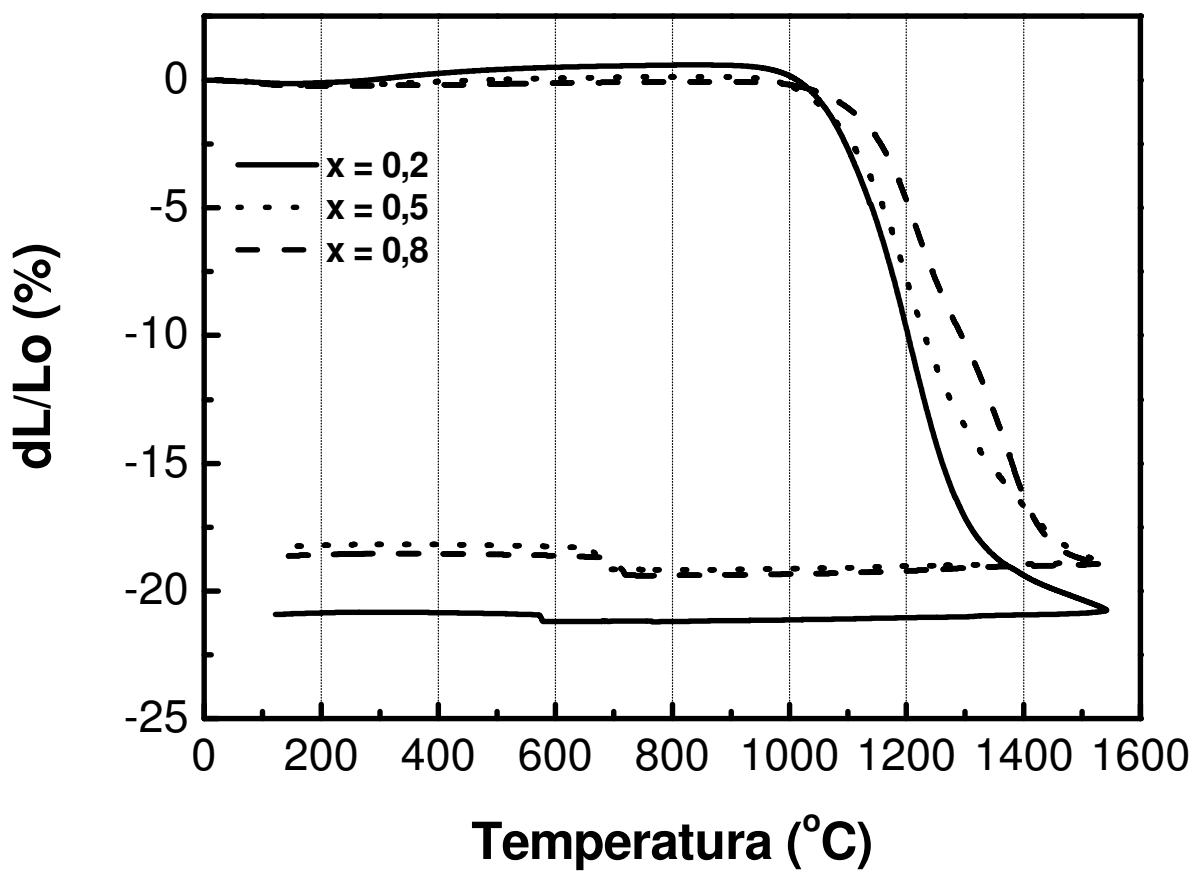

Figura 16: Análise de dilatometria dos compactos cerâmicos a verde $\left(\mathrm{ZrO}_{2}: 8,6 \mathrm{~mol} \% \mathrm{MgO}\right)_{\mathrm{x}}$ $\left(\mathrm{ZrO}_{2}: 3 \mathrm{~mol} \% \mathrm{Y}_{2} \mathrm{O}_{3}\right)_{1-\mathrm{x}}, \mathrm{x}=0,2,0,5$ e 0,8 .

Para entender os fenômenos que ocorrem durante a retração dos compósitos cerâmicos, foi feita a análise de difração de raios $\mathrm{X}$, a alta temperatura, dos pós $\left(\mathrm{ZrO}_{2}: 8,6 \mathrm{~mol} \% \mathrm{MgO}\right)_{\mathrm{x}}$ $\left(\mathrm{ZrO}_{2}: 3 \mathrm{~mol} \% \mathrm{Y}_{2} \mathrm{O}_{3}\right)_{1-\mathrm{x}}, 0 \leq \mathrm{x} \leq 1$, na faixa de $2 \theta=25^{\circ}$ a $35^{\circ}$, com radiação $\mathrm{CuK} \alpha$ em um difratômetro que opera na configuração $\theta-\theta$, com detector sensível à posição Braun. Para esta análise, o pó cerâmico é depositado em uma placa de platina de uma câmara Anton Paar HTK 1400, que é submetida a uma corrente elétrica para o aquecimento controlado da amostra, entre $27^{\circ} \mathrm{C}$ e $1300{ }^{\circ} \mathrm{C}$. Os resultados estão nos difratogramas de raios $\mathrm{X}$ nas Figuras 17 a 23, nas quais $\mathrm{m}$ representa a fase monoclínica e c,t as fases cúbica/tetragonal. O símbolo c,t foi utilizado porque as raias principais das fases cúbica e tetragonal nas cerâmicas à base de zircônia estão próximas nos difratogramas de raios $\mathrm{X}$. As amplitudes foram normalizadas para a intensidade da raia $100 \%$ das fases cúbica e/ou tetragonal. 
Os difratogramas de raios X obtidos para o pó de zircônia:ítria (Figura 17) estão de acordo com o diagrama de fases do sistema $\mathrm{ZrO}_{2}: 3 \mathrm{~mol} \% \mathrm{Y}_{2} \mathrm{O}_{3}$ (Figura 2), onde se observa que a fase cúbica está em equilíbrio com a fase monoclínica até aproximadamente $400{ }^{\circ} \mathrm{C}$; e uma solução sólida contendo a fase tetragonal torna-se estável acima de $1000{ }^{\circ} \mathrm{C}$.

De acordo com o diagrama de fases do sistema $\mathrm{ZrO}_{2}: 8,6 \mathrm{~mol} \% \mathrm{MgO}$ (Figura 1), pouca ou nenhuma solubilidade do $\mathrm{MgO}$ na fase monoclínica é observada até a temperatura de transformação para a fase tetragonal $\left(\sim 1170^{\circ} \mathrm{C}\right)$. A solubilidade do $\mathrm{MgO}$ na zircônia tetragonal aumenta pouco com o aumento da temperatura. Uma solução sólida contendo a fase tetragonal torna-se estável acima de $1250{ }^{\circ} \mathrm{C}$. A diferença encontrada entre os difratogramas de raios $\mathrm{X}$ do pó de zircônia:magnésia (Figura 23: acima de $1200{ }^{\circ} \mathrm{C}$ observam-se as raias de difração das fases cúbica/tetragonal e monoclínica) e o diagrama de fases pode estar relacionada ao método de preparação da zircônia:magnésia ou ao tamanho de partículas do pó (quanto menor o tamanho de partículas, a predominância é da fase cúbica/tetragonal relativamente à fase monoclínica) ${ }^{[52]}$.

Os difratogramas de raios $\mathrm{X}$ dos pós cerâmicos de composições $\left(\mathrm{ZrO}_{2}\right.$ : 8,6 mol\% $\mathrm{MgO})_{\mathrm{x}}\left(\mathrm{ZrO}_{2}: 3 \mathrm{~mol} \% \mathrm{Y}_{2} \mathrm{O}_{3}\right)_{1-\mathrm{x}}, \mathrm{x}=0,2,0,4$ e 0,5 (Figuras 18, 19 e 20, respectivamente) mostram que os pós tratados termicamente até $1200{ }^{\circ} \mathrm{C}$ são parcialmente estabilizados nas fases cúbica/tetragonal e monoclínica, e a partir desta temperatura ocorre a transformação da fase monoclínica em cúbica/tetragonal. Já as composições com x =0,6 e 0,8 (Figuras 21 e 22, respectivamente) são parcialmente estabilizadas nas fases cúbica/tetragonal e monoclínica em toda faixa de temperatura estudada. 


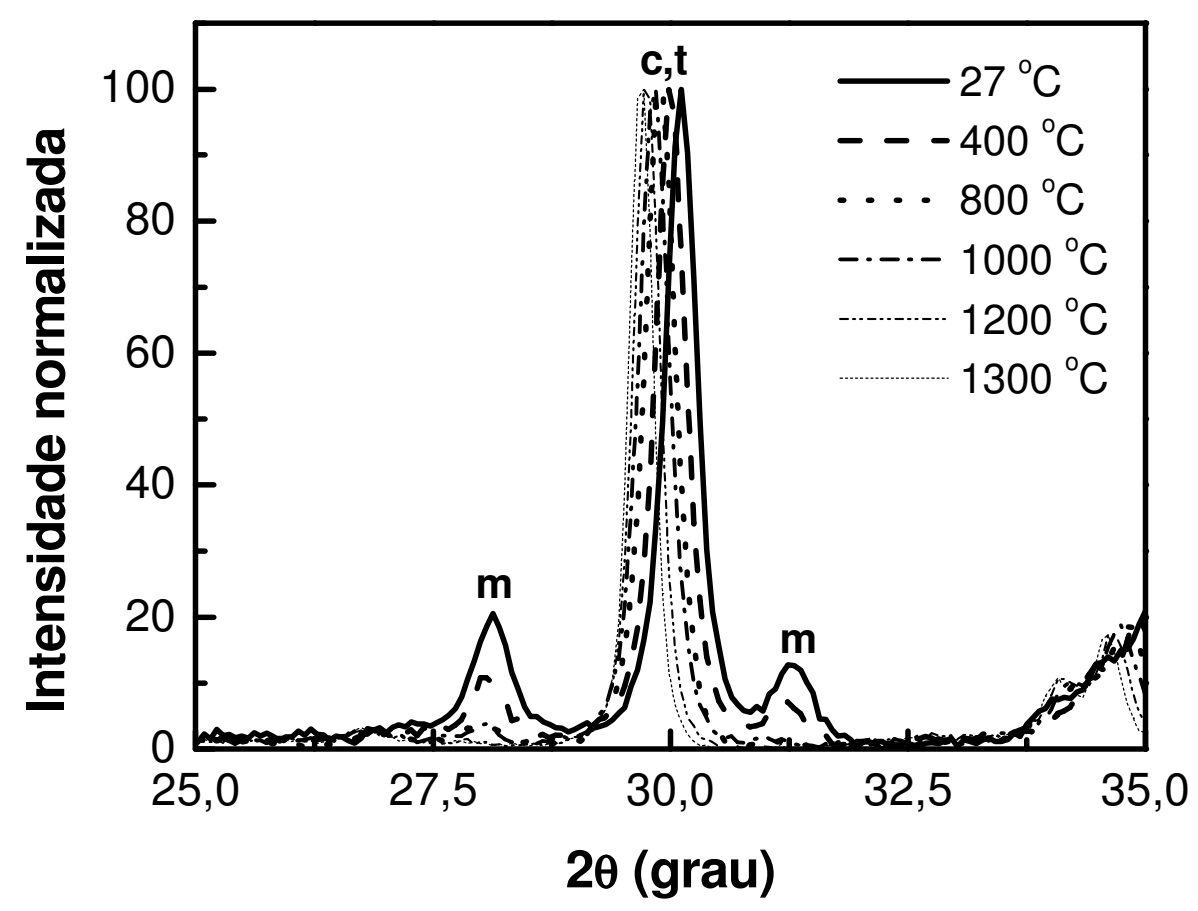

Figura 17: Difratogramas de raios $\mathrm{X}$ a altas temperaturas $\left(27^{\circ} \mathrm{C}-1300^{\circ} \mathrm{C}\right)$ do pó cerâmico de zircônia:ítria $\left(\mathrm{ZrO}_{2}: 3 \mathrm{~mol} \% \mathrm{Y}_{2} \mathrm{O}_{3}\right)$.

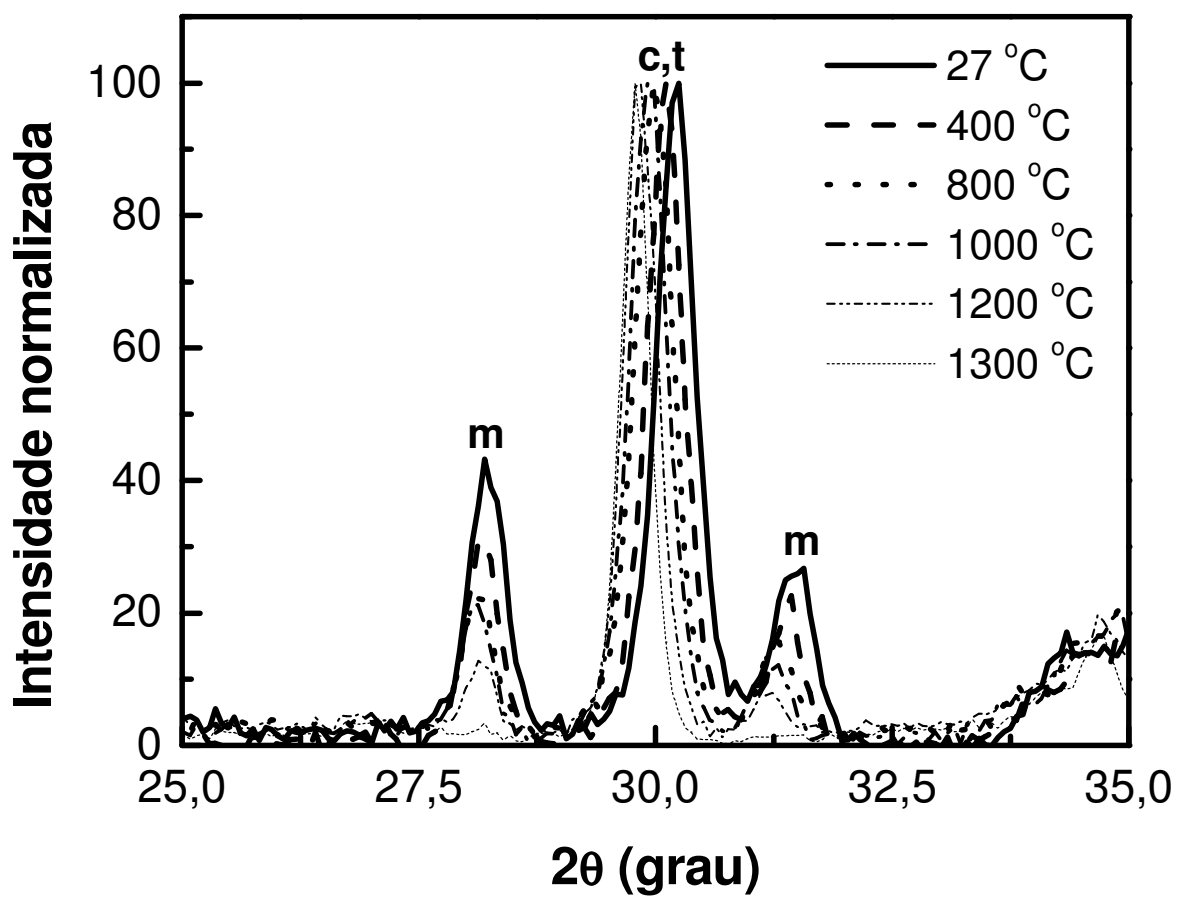

Figura 18: Difratogramas de raios $\mathrm{X}$ a altas temperaturas $\left(27^{\circ} \mathrm{C}-1300^{\circ} \mathrm{C}\right)$ do pó cerâmico de $\left(\mathrm{ZrO}_{2}: 8,6 \mathrm{~mol} \% \mathrm{MgO}\right)_{0,2}\left(\mathrm{ZrO}_{2}: 3 \mathrm{~mol} \% \mathrm{Y}_{2} \mathrm{O}_{3}\right)_{0,8}$. 


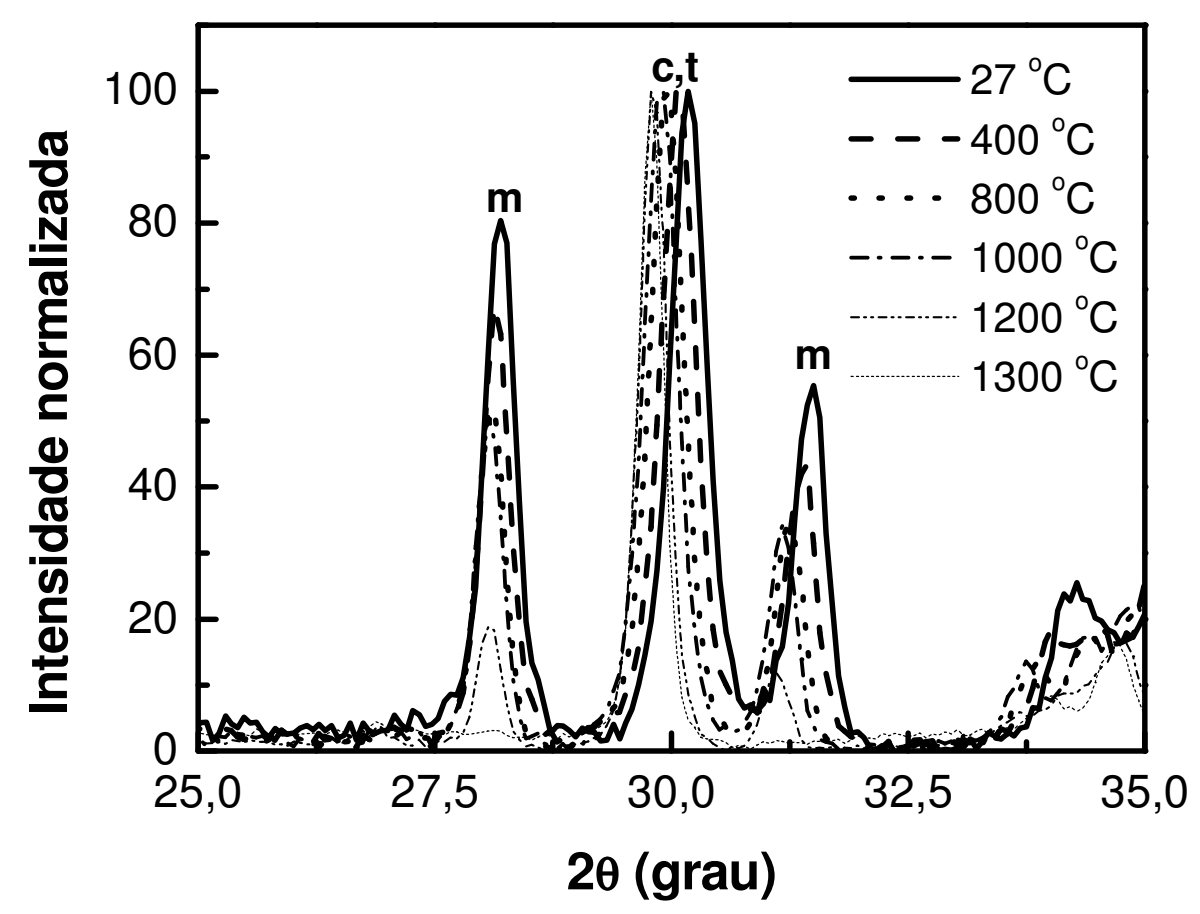

Figura 19: Difratogramas de raios $\mathrm{X}$ a altas temperaturas $\left(27^{\circ} \mathrm{C}-1300^{\circ} \mathrm{C}\right)$ do pó cerâmico de $\left(\mathrm{ZrO}_{2}: 8,6 \mathrm{~mol} \% \mathrm{MgO}\right)_{0,4}\left(\mathrm{ZrO}_{2}: 3 \mathrm{~mol} \% \mathrm{Y}_{2} \mathrm{O}_{3}\right)_{0,6}$.

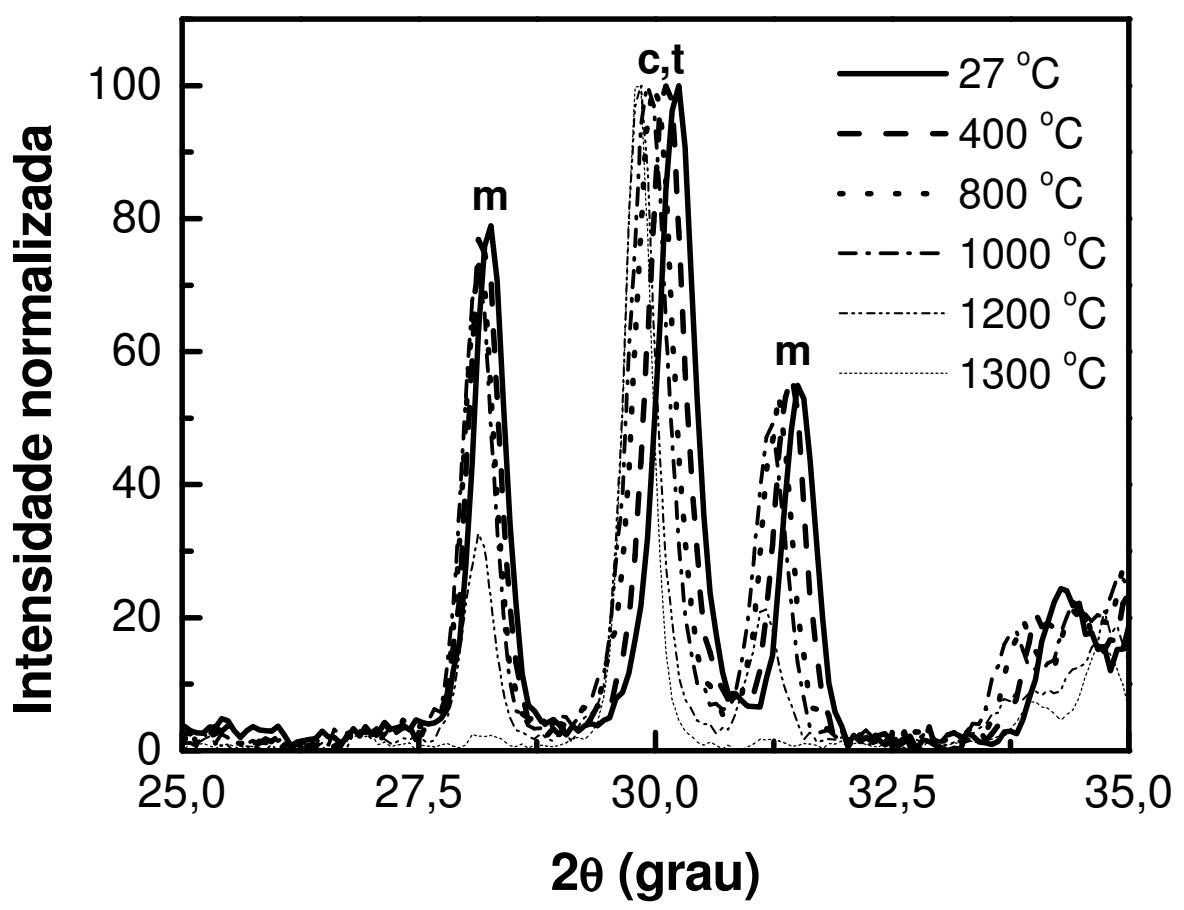

Figura 20: Difratogramas de raios $\mathrm{X}$ a altas temperaturas $\left(27^{\circ} \mathrm{C}-1300^{\circ} \mathrm{C}\right)$ do pó cerâmico de $\left(\mathrm{ZrO}_{2}: 8,6 \mathrm{~mol} \% \mathrm{MgO}\right)_{0,5}\left(\mathrm{ZrO}_{2}: 3 \mathrm{~mol} \% \mathrm{Y}_{2} \mathrm{O}_{3}\right)_{0,5}$. 


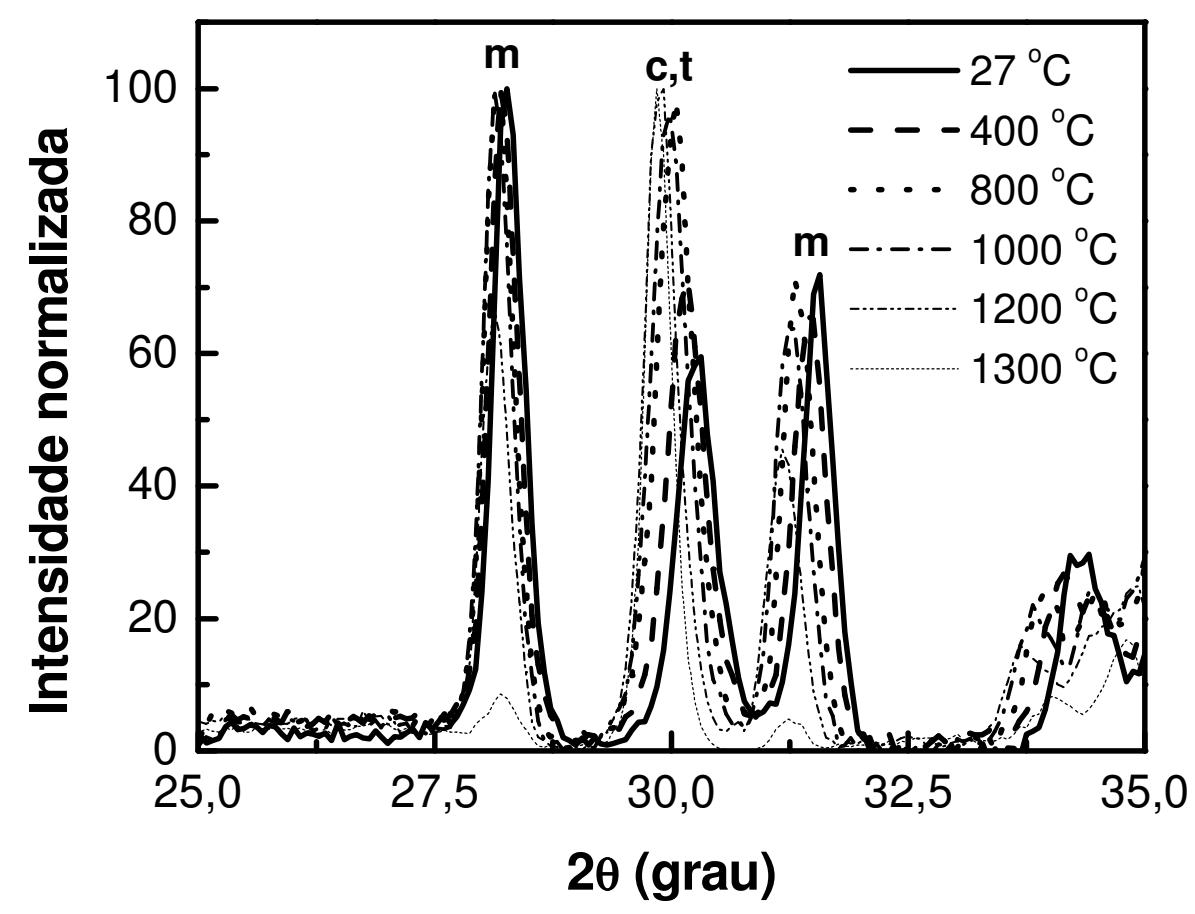

Figura 21: Difratogramas de raios $\mathrm{X}$ a altas temperaturas $\left(27^{\circ} \mathrm{C}-1300^{\circ} \mathrm{C}\right)$ do pó cerâmico de $\left(\mathrm{ZrO}_{2}: 8,6 \mathrm{~mol} \% \mathrm{MgO}\right)_{0,6}\left(\mathrm{ZrO}_{2}: 3 \mathrm{~mol} \% \mathrm{Y}_{2} \mathrm{O}_{3}\right)_{0,4}$.

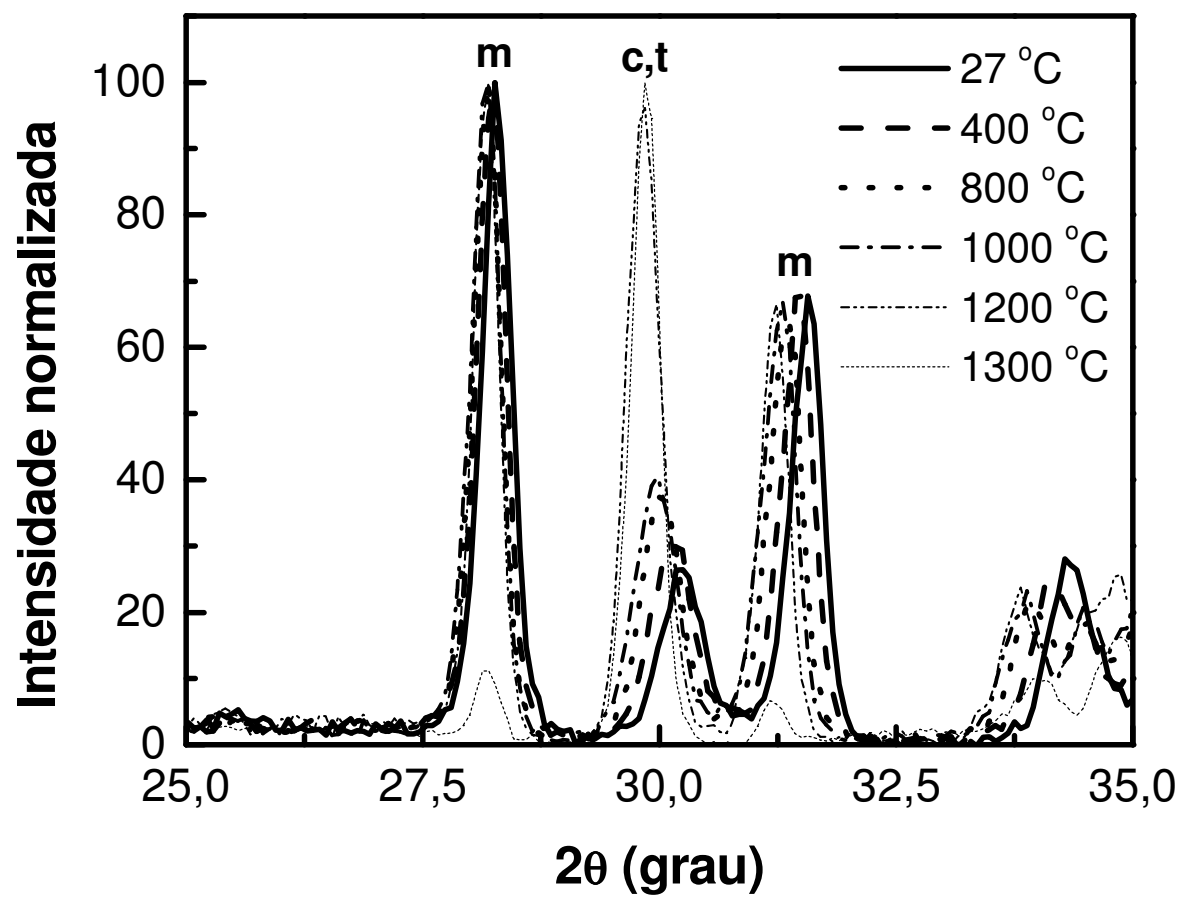

Figura 22: Difratogramas de raios $\mathrm{X}$ a altas temperaturas $\left(27^{\circ} \mathrm{C}-1300^{\circ} \mathrm{C}\right)$ do pó cerâmico de $\left(\mathrm{ZrO}_{2}: 8,6 \mathrm{~mol} \% \mathrm{MgO}\right)_{0,8}\left(\mathrm{ZrO}_{2}: 3 \mathrm{~mol} \% \mathrm{Y}_{2} \mathrm{O}_{3}\right)_{0,2}$. 


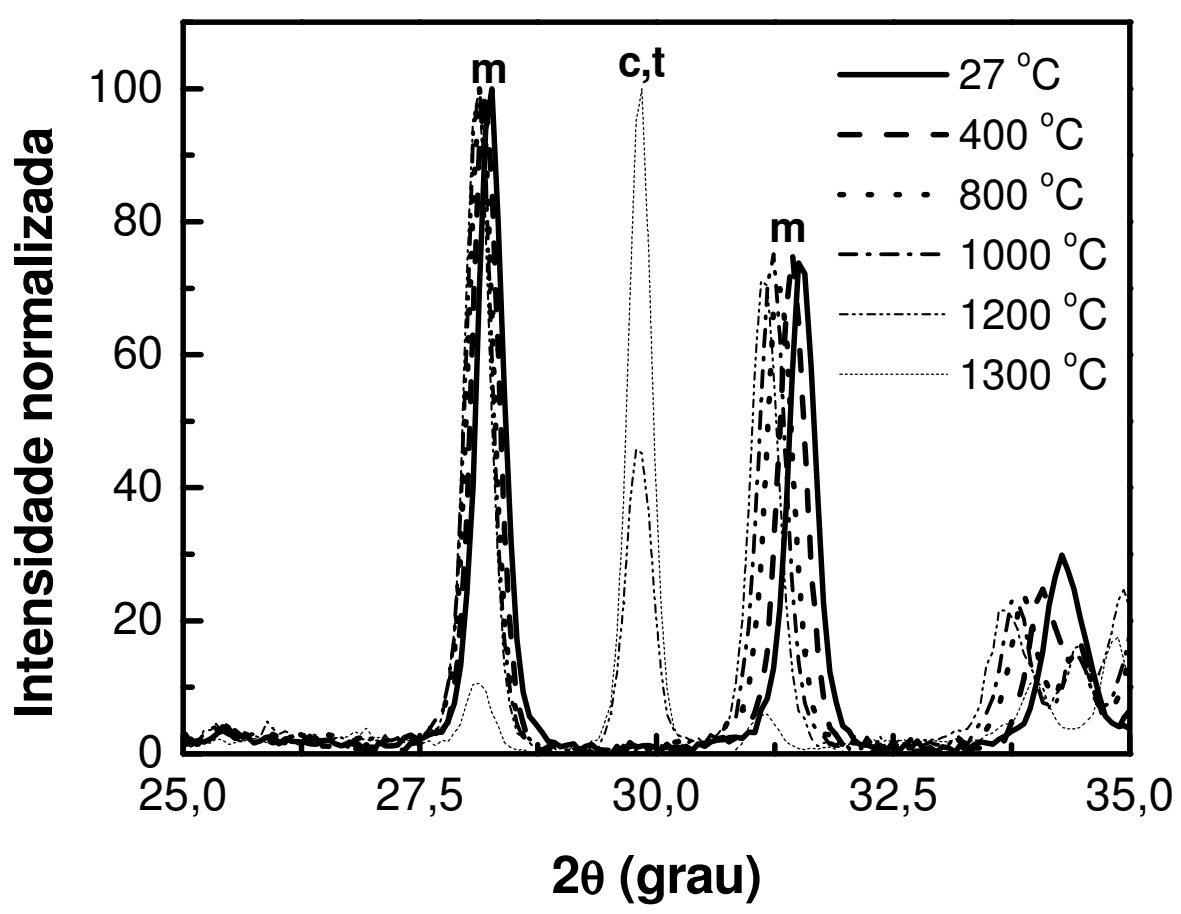

Figura 23: Difratogramas de raios $\mathrm{X}$ a altas temperaturas $\left(27^{\circ} \mathrm{C}-1300^{\circ} \mathrm{C}\right)$ do pó cerâmico de zircônia:magnésia $\left(\mathrm{ZrO}_{2}: 8,6 \mathrm{~mol} \% \mathrm{MgO}\right)$.

A fração volumétrica da fase monoclínica $\left(\mathrm{V}_{\mathrm{m}}\right)$ para os difratogramas de raios $\mathrm{X}$ obtidos na faixa de temperatura $27^{\circ} \mathrm{C}$ a $1300{ }^{\circ} \mathrm{C}$, foi calculada a partir da equação (14) ${ }^{[53]}$ :

$$
\mathrm{V}_{\mathrm{m}}=\frac{\mathrm{I}_{\mathrm{m}}(111)+\mathrm{I}_{\mathrm{m}}(\overline{11} 1)}{\mathrm{I}_{\mathrm{m}}(111)+\mathrm{I}_{\mathrm{m}}(\overline{11} 1)+\mathrm{I}_{\mathrm{c}, \mathrm{t}}(111)}
$$

$\mathrm{I}_{\mathrm{m}} \mathrm{e} \mathrm{I}_{\mathrm{c}, \mathrm{t}}$ são as intensidades relativas dos picos de amplitude máxima referentes às fases monoclínica e cúbica/tetragonal.

A Figura 24 mostra os teores da fase monoclínica em função da temperatura para os diferentes compósitos. Quanto maior o teor da zircônia:magnésia nos compósitos cerâmicos tratados termicamente até temperaturas próximas a $1000{ }^{\circ} \mathrm{C}$, maior é a fração volumétrica da fase monoclínica. Para temperaturas superiores a $1000{ }^{\circ} \mathrm{C}$, há uma mudança significativa na transformação de fases monoclínica $\rightarrow$ cúbica/tetragonal para as diferentes composições. 


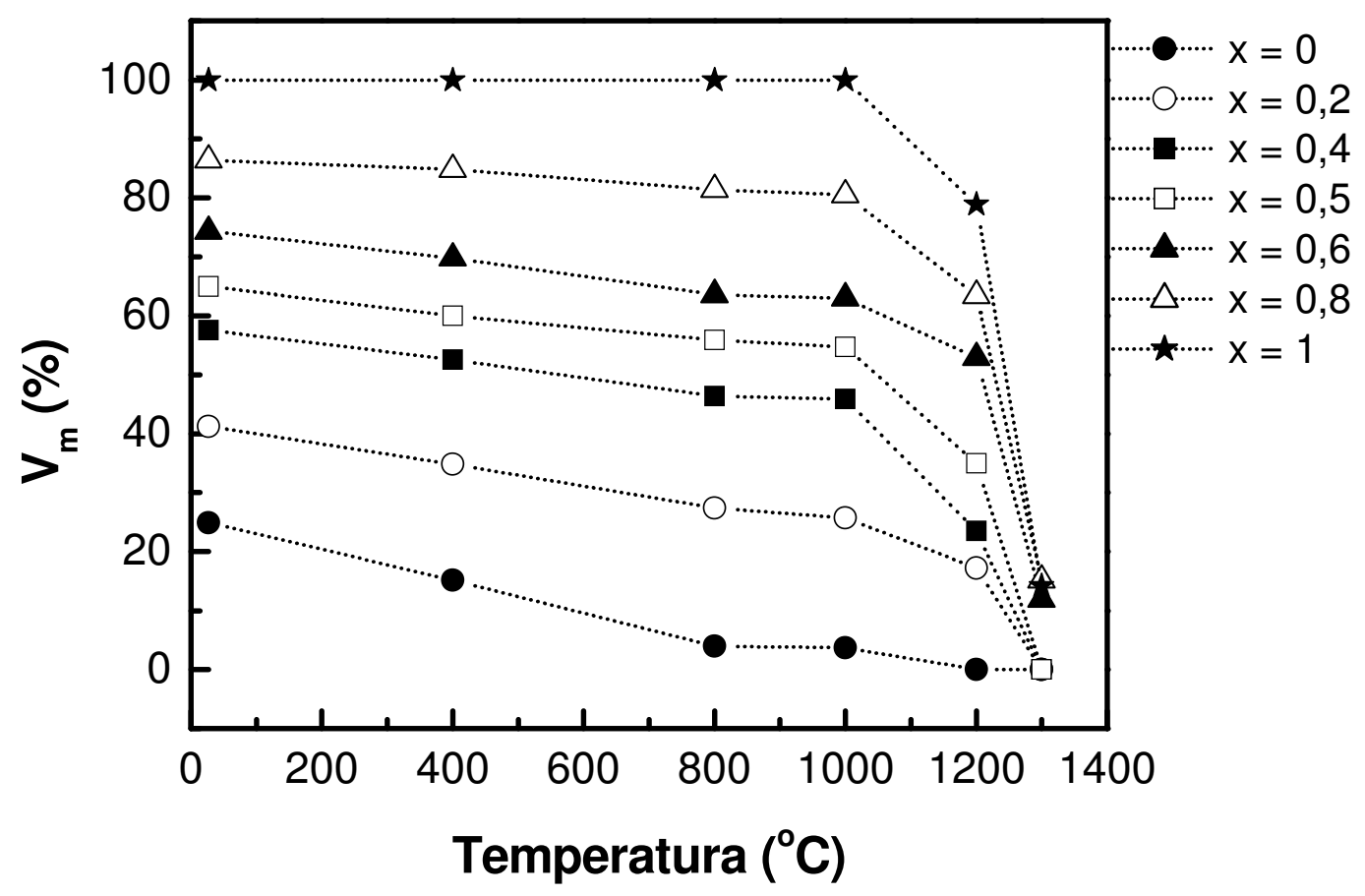

Figura 24: Valores do teor da fase monoclínica dos compósitos cerâmicos $\left(\mathrm{ZrO}_{2}\right.$ : 8,6 mol\% $\mathrm{MgO})_{\mathrm{x}}\left(\mathrm{ZrO}_{2}: 3 \mathrm{~mol} \% \mathrm{Y}_{2} \mathrm{O}_{3}\right)_{1-\mathrm{x}}$.

Portanto, a retração dos compósitos cerâmicos, na Figura 16, está principalmente relacionada ao processo de sinterização do material, tendo também uma contribuição devida à transformação de fases monoclínica $\rightarrow$ cúbica/tetragonal da zircônia. No resfriamento, a aproximadamente $580{ }^{\circ} \mathrm{C}$ para a composição $\mathrm{x}=0,2$, a $675^{\circ} \mathrm{C}$ para $\mathrm{x}=0,5$ e a $720{ }^{\circ} \mathrm{C}$ para $\mathrm{x}=0,8$, é observada uma histerese térmica. Esta histerese está relacionada com a transformação de fase cúbica/tetragonal $\rightarrow$ monoclínica da fração remanescente da zircônia que não foi estabilizada durante a sinterização. Esta histerese térmica já foi observada em temperaturas próximas à observada neste estudo ${ }^{[1,6]}$.

Com base neste resultado, foi escolhida a temperatura de $1500{ }^{\circ} \mathrm{C}$ para a sinterização dos compósitos cerâmicos, para garantir uma boa densificação e a formação majoritária das fases cúbica/tetragonal. 


\subsubsection{Difração de raios $\mathrm{X}$ e refinamento da estrutura cristalina pelo método de Rietveld}

É conhecida a dificuldade de distinguir a fase cúbica da fase tetragonal na zircônia ${ }^{[54]}$. Apesar de neste trabalho ser suficiente conhecer que os compósitos cerâmicos são parcialmente estabilizados (monoclínica e cúbica e/ou tetragonal), já que a condutividade de eletrólitos sólidos que apresentam a fase cúbica ou tetragonal é muito maior que a dos com fase monoclínica ${ }^{[49]}$, foi feita uma análise quantitativa de fases pelo método de Rietveld.

Os resultados obtidos para os compósitos cerâmicos $\left(\mathrm{ZrO}_{2}: 8,6 \mathrm{~mol} \% \mathrm{MgO}\right)_{\mathrm{x}}\left(\mathrm{ZrO}_{2}: 3\right.$ mol\% $\left.\mathrm{Y}_{2} \mathrm{O}_{3}\right)_{1-\mathrm{x}}, 0 \leq \mathrm{x} \leq 1$, podem ser vistos nas Figuras 25 a 31 e Tabelas 2 a 28.

Resultados do refinamento para $\mathrm{ZrO}_{2}: 3$ mol\% $\mathrm{Y}_{2} \mathrm{O}_{3}$.

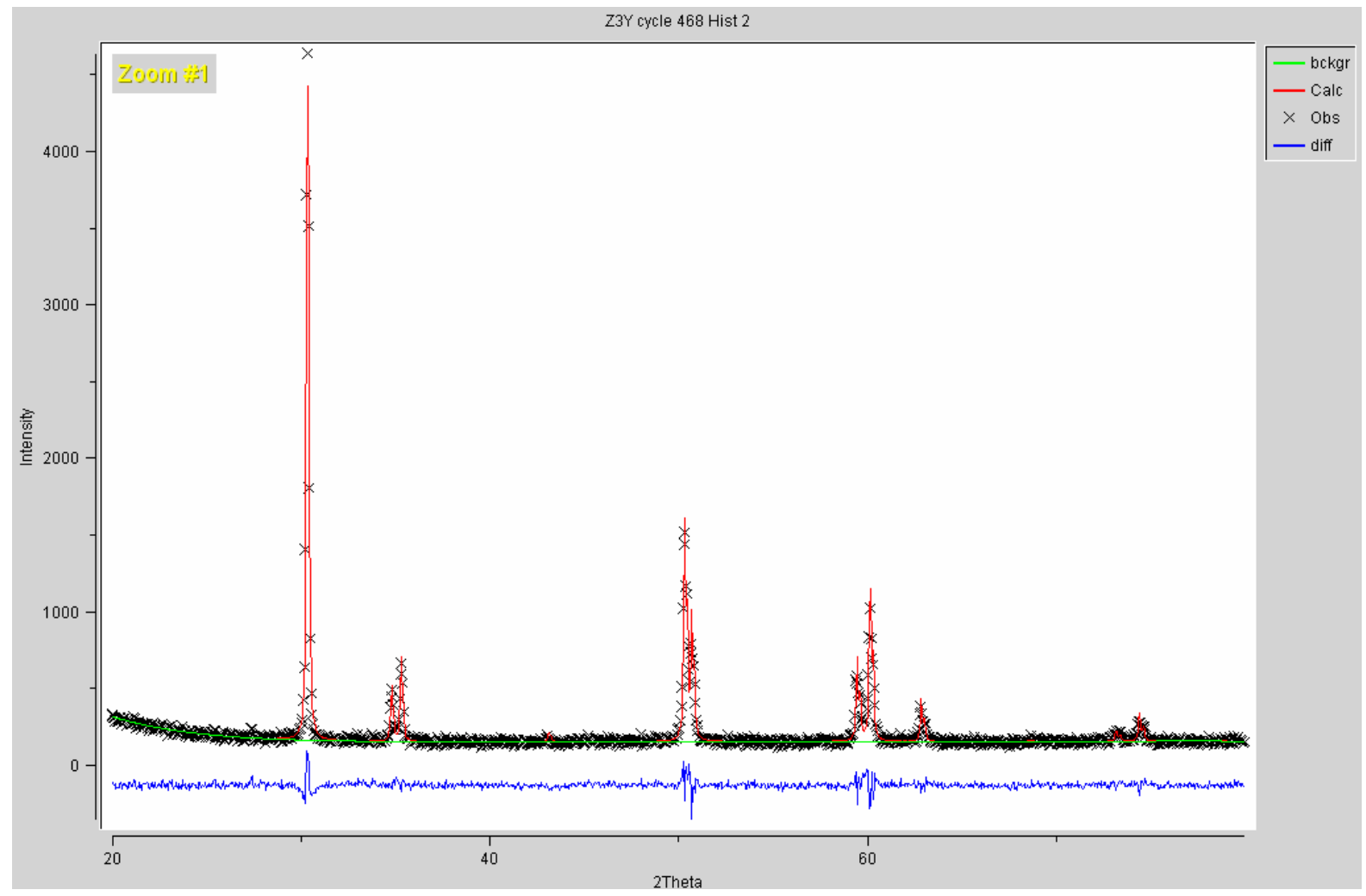

Figura 25: Padrões de difração calculado e observado para $\mathrm{ZrO}_{2}: 3$ mol\% $\mathrm{Y}_{2} \mathrm{O}_{3}$. 
Tabela 2: Valores estruturais teóricos e experimentais da fase tetragonal $\mathrm{ZrO}_{2}: 3 \mathrm{~mol} \% \mathrm{Y}_{2} \mathrm{O}_{3}$.

\begin{tabular}{|c|c|c|}
\hline & Teórico & Experimental \\
\hline Grupo espacial & \multicolumn{2}{|c|}{$\mathrm{P} 42 / \mathrm{nmcZ}$} \\
\hline $\begin{array}{c}\text { Parâmetros } \\
\text { de rede }\end{array}$ & $\begin{array}{c}\mathrm{a}=\mathrm{b}=3,6292(3) \AA \\
\mathrm{c}=5,1973(9) \AA\end{array}$ & $\begin{array}{c}\mathrm{a}=\mathrm{b}=3,6105(1) \AA \\
\mathrm{c}=5,1791(2) \AA\end{array}$ \\
\hline Volume da cela & $68,45 \AA^{3}$ & $67,514(5) \AA^{3}$ \\
\hline Densidade & $5,98 \mathrm{~g} / \mathrm{cm}^{3}$ & $6,061 \mathrm{~g} / \mathrm{cm}^{3}$ \\
\hline
\end{tabular}

Tabela 3: Porcentagem de fases (\%) de $\mathrm{ZrO}_{2}: 3 \mathrm{~mol} \% \mathrm{Y}_{2} \mathrm{O}_{3}$.

\begin{tabular}{|c|c|c|}
\hline Tetragonal & Cúbica & Monoclínica \\
\hline 100 & 0 & 0 \\
\hline
\end{tabular}

Resultados do refinamento para $\left(\mathrm{ZrO}_{2}: 8,6 \mathrm{~mol} \% \mathrm{MgO}_{0,2}\left(\mathrm{ZrO}_{2}: 3 \mathrm{~mol}_{\%} \mathrm{Y}_{2} \mathrm{O}_{3}\right)_{0,8}\right.$.

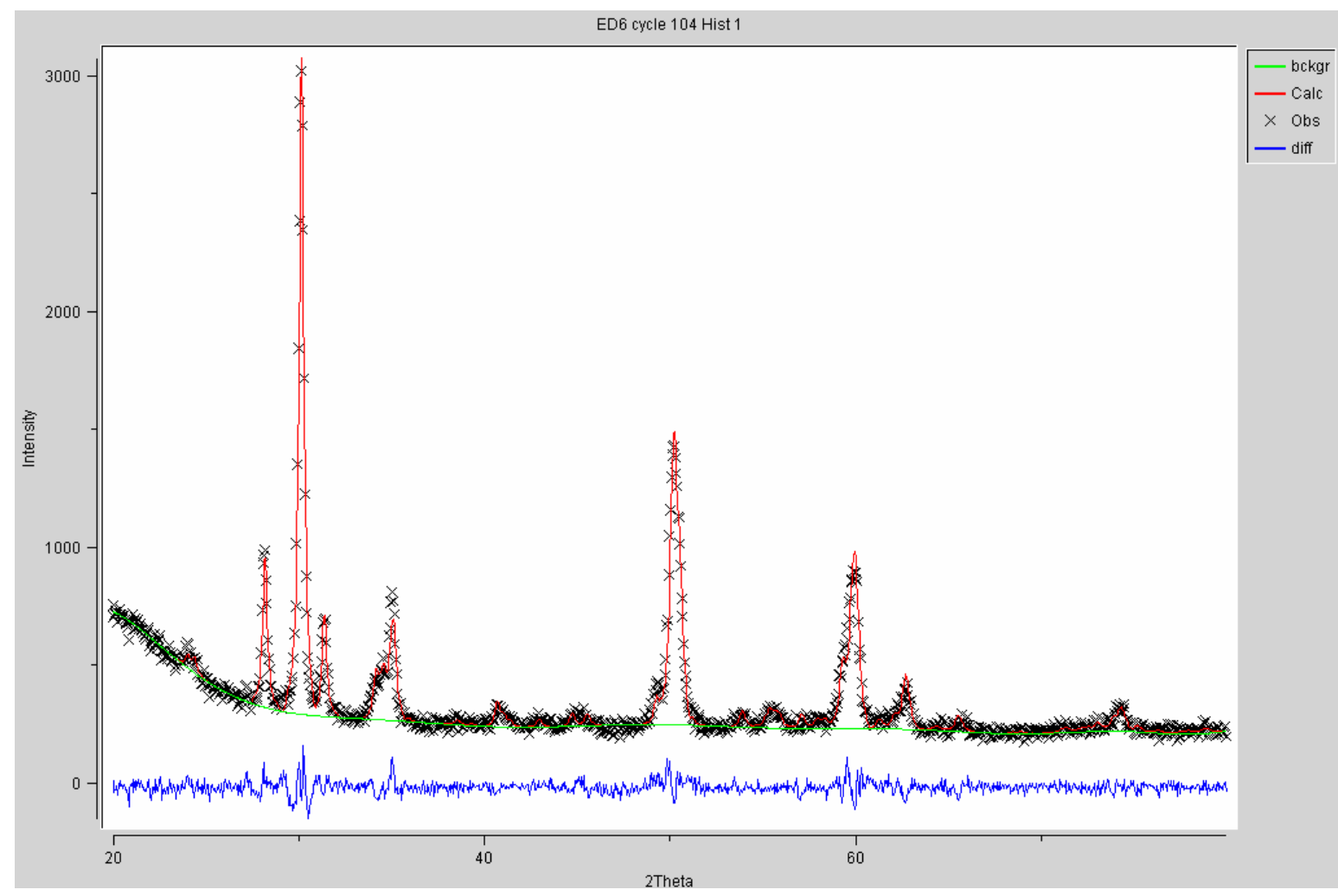

Figura 26: Padrões de difração calculado e observado para $\left(\mathrm{ZrO}_{2}: 8,6 \mathrm{~mol} \% \mathrm{MgO}\right)_{0,2}\left(\mathrm{ZrO}_{2}: 3\right.$ $\left.\mathrm{mol} \% \mathrm{Y}_{2} \mathrm{O}_{3}\right)_{0,8}$. 
Tabela 4: Valores estruturais teóricos e experimentais da fase tetragonal para $\left(\mathrm{ZrO}_{2}: 8,6 \mathrm{~mol} \% \mathrm{MgO}\right)_{0,2}\left(\mathrm{ZrO}_{2}: 3 \mathrm{~mol} \% \mathrm{Y}_{2} \mathrm{O}_{3}\right)_{0,8}$.

\begin{tabular}{|c|c|c|}
\hline & Teórico & Experimental \\
\hline Grupo espacial & \multicolumn{2}{|c|}{$\mathrm{P} 42 / \mathrm{nmcZ}$} \\
\hline $\begin{array}{c}\text { Parâmetros } \\
\text { de rede }\end{array}$ & $\begin{array}{c}\mathrm{a}=\mathrm{b}=3,6292(3) \AA \\
\mathrm{c}=5,1973(9) \AA\end{array}$ & $\begin{array}{c}\mathrm{a}=\mathrm{b}=3,6075(3) \AA \\
\mathrm{c}=5,1778(9) \AA\end{array}$ \\
\hline Volume da cela & $68,45 \AA^{3}$ & $67,38(1) \AA^{3}$ \\
\hline Densidade & $5,98 \mathrm{~g} / \mathrm{cm}^{3}$ & $6,073 \mathrm{~g} / \mathrm{cm}^{3}$ \\
\hline
\end{tabular}

Tabela 5: Valores estruturais teóricos e experimentais da fase cúbica para $\left(\mathrm{ZrO}_{2}: 8,6 \mathrm{~mol} \% \mathrm{MgO}\right)_{0,2}\left(\mathrm{ZrO}_{2}: 3 \mathrm{~mol} \% \mathrm{Y}_{2} \mathrm{O}_{3}\right)_{0,8}$.

\begin{tabular}{|c|c|c|}
\hline & Teórico & Experimental \\
\hline Grupo espacial & \multicolumn{2}{|c|}{ Fm-3m } \\
\hline Parâmetros de rede & $\mathrm{a}=\mathrm{b}=\mathrm{c}=5,135(9) \AA$ & $\mathrm{a}=\mathrm{b}=\mathrm{c}=5,1255(6) \AA$ \\
\hline Volume da cela & $135,4 \AA^{3}$ & $134,65(4) \AA^{3}$ \\
\hline Densidade & $6,04 \mathrm{~g} / \mathrm{cm}^{3}$ & $6,078 \mathrm{~g} / \mathrm{cm}^{3}$ \\
\hline
\end{tabular}

Tabela 6: Valores estruturais teóricos e experimentais da fase monoclínica para $\left(\mathrm{ZrO}_{2}: 8,6 \mathrm{~mol} \% \mathrm{MgO}\right)_{0,2}\left(\mathrm{ZrO}_{2}: 3 \mathrm{~mol} \% \mathrm{Y}_{2} \mathrm{O}_{3}\right)_{0,8}$.

\begin{tabular}{|c|c|c|}
\hline & Teórico & Experimental \\
\hline Grupo espacial & \multicolumn{2}{|c|}{$\mathrm{P} 121 / \mathrm{c} 1$} \\
\hline Parâmetros & $\mathrm{a}=5,146(7) \AA$ & $\mathrm{a}=5,158(1) \AA$ \\
de rede & $\mathrm{b}=5,205(1) \AA$ & $\mathrm{b}=5,205(1) \AA$ \\
& $\mathrm{c}=5,313(6) \AA$ & $\mathrm{c}=5,308(1) \AA$ \\
\hline Volume da cela & $140,52 \AA^{3}$ & $140,81(5) \AA^{3}$ \\
\hline Densidade & $5,82 \mathrm{~g} / \mathrm{cm}^{3}$ & $5,812 \mathrm{~g} / \mathrm{cm}^{3}$ \\
\hline
\end{tabular}

Tabela 7: Porcentagem de fases $(\%)$ de $\left(\mathrm{ZrO}_{2}: 8,6 \mathrm{~mol} \% \mathrm{MgO}\right)_{0,2}\left(\mathrm{ZrO}_{2}: 3 \mathrm{~mol} \% \mathrm{Y}_{2} \mathrm{O}_{3}\right)_{0,8}$.

\begin{tabular}{|c|c|c|}
\hline Monoclínica & Tetragonal & Cúbica \\
\hline 31,7 & 43,3 & 25,0 \\
\hline
\end{tabular}


Resultados do refinamento de $\left(\mathrm{ZrO}_{2}: 8,6 \text { mol\% } \mathrm{MgO}\right)_{0,4}\left(\mathrm{ZrO}_{2}: 3 \mathrm{~mol} \% \mathrm{Y}_{2} \mathrm{O}_{3}\right)_{0,6}$.

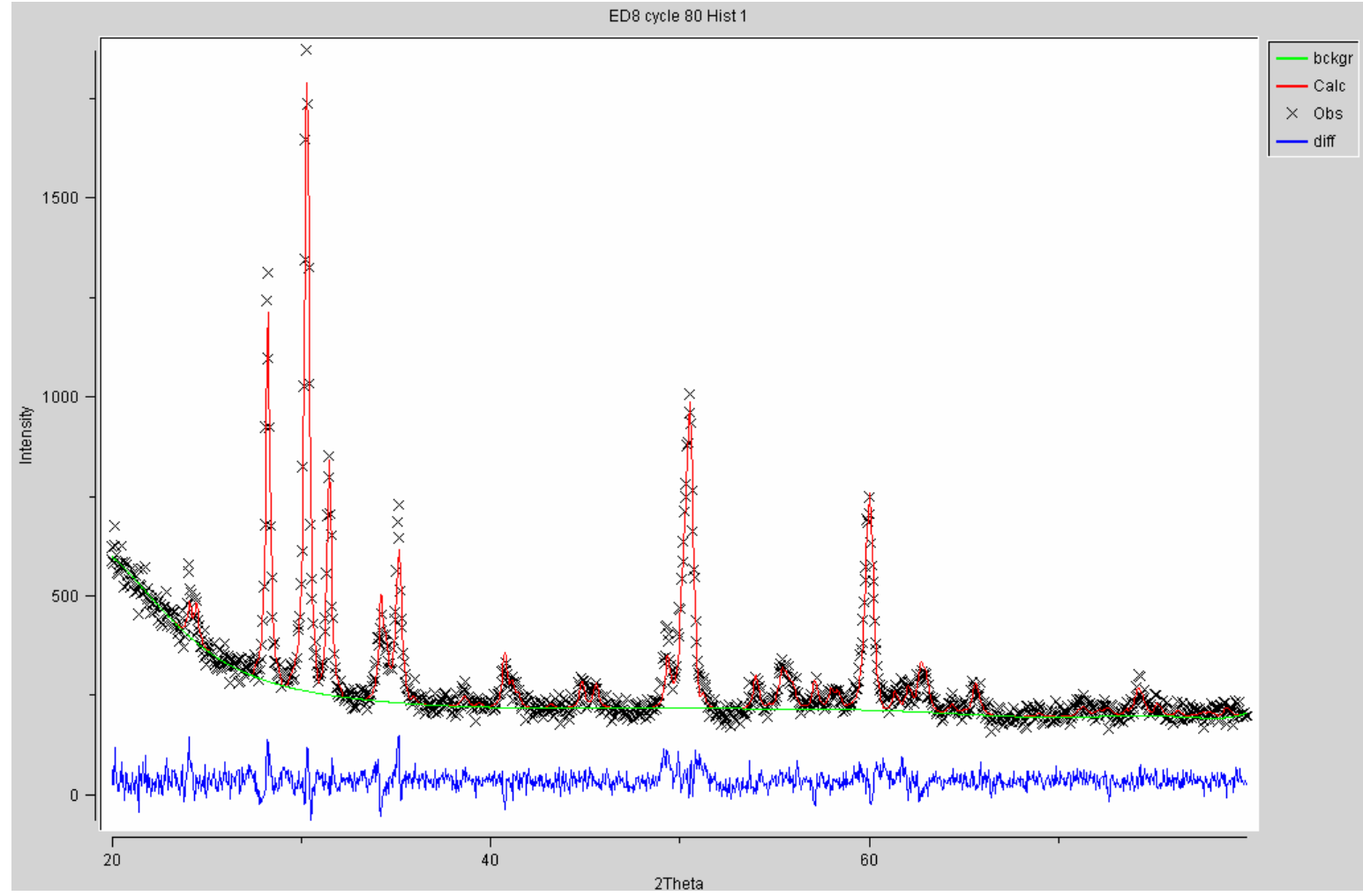

Figura 27: Padrões de difração calculado e observado para $\left(\mathrm{ZrO}_{2}: 8,6 \mathrm{~mol} \% \mathrm{MgO}\right)_{0,4}\left(\mathrm{ZrO}_{2}: 3\right.$ $\left.\mathrm{mol} \% \mathrm{Y}_{2} \mathrm{O}_{3}\right)_{0,6}$.

Tabela 8: Valores estruturais teóricos e experimentais da fase tetragonal para $\left(\mathrm{ZrO}_{2}: 8,6 \mathrm{~mol} \% \mathrm{MgO}\right)_{0,4}\left(\mathrm{ZrO}_{2}: 3 \mathrm{~mol} \% \mathrm{Y}_{2} \mathrm{O}_{3}\right)_{0,6}$.

\begin{tabular}{|c|c|c|}
\hline & Teórico & Experimental \\
\hline Grupo espacial & \multicolumn{2}{|c|}{$\mathrm{P} 42 / \mathrm{nmcZ}$} \\
\hline $\begin{array}{c}\text { Parâmetros } \\
\text { de rede }\end{array}$ & $\begin{array}{c}\mathrm{a}=\mathrm{b}=3,6292(3) \AA \\
\mathrm{c}=5,1973(9) \AA\end{array}$ & $\begin{array}{c}\mathrm{a}=\mathrm{b}=3,619(1) \AA \\
\mathrm{c}=5,142(2) \AA\end{array}$ \\
\hline Volume da cela & $68,45 \AA^{3}$ & $67,38(6) \AA^{3}$ \\
\hline Densidade & $5,98 \mathrm{~g} / \mathrm{cm}^{3}$ & $6,073 \mathrm{~g} / \mathrm{cm}^{3}$ \\
\hline
\end{tabular}

Tabela 9: Valores estruturais teóricos e experimentais da fase cúbica para $\left(\mathrm{ZrO}_{2}: 8,6 \mathrm{~mol} \% \mathrm{MgO}\right)_{0,4}\left(\mathrm{ZrO}_{2}: 3 \mathrm{~mol} \% \mathrm{Y}_{2} \mathrm{O}_{3}\right)_{0,6}$.

\begin{tabular}{|c|c|c|}
\hline & Teórico & Experimental \\
\hline Grupo espacial & \multicolumn{2}{|c|}{ Fm-3m } \\
\hline Parâmetros de rede & $\mathrm{a}=\mathrm{b}=\mathrm{c}=5,135(9) \AA$ & $\mathrm{a}=\mathrm{b}=\mathrm{c}=5,1102(8) \AA$ \\
\hline Volume da cela & $135,4 \AA^{3}$ & $133,45(6) \AA^{3}$ \\
\hline Densidade & $6,04 \mathrm{~g} / \mathrm{cm}^{3}$ & $6,133 \mathrm{~g} / \mathrm{cm}^{3}$ \\
\hline
\end{tabular}


Tabela 10: Valores estruturais teóricos e experimentais da fase monoclínica para $\left(\mathrm{ZrO}_{2}: 8,6 \mathrm{~mol} \% \mathrm{MgO}\right)_{0,4}\left(\mathrm{ZrO}_{2}: 3 \mathrm{~mol} \% \mathrm{Y}_{2} \mathrm{O}_{3}\right)_{0,6}$.

\begin{tabular}{|c|c|c|}
\hline & Teórico & Experimental \\
\hline Grupo espacial & \multicolumn{2}{|c|}{$\mathrm{P} 121 / \mathrm{c} 1$} \\
\hline Parâmetros & $\mathrm{a}=5,146(7) \AA$ & $\mathrm{a}=5,161(1) \AA$ \\
de rede & $\mathrm{b}=5,205(1) \AA$ & $\mathrm{b}=5,206(1) \AA$ \\
& $\mathrm{c}=5,313(6) \AA$ & $\mathrm{c}=5,313(1) \AA$ \\
\hline Volume da cela & $140,52 \AA^{3}$ & $141,00(6) \AA^{3}$ \\
\hline Densidade & $5,82 \mathrm{~g} / \mathrm{cm}^{3}$ & $5,804 \mathrm{~g} / \mathrm{cm}^{3}$ \\
\hline
\end{tabular}

Tabela 11: Porcentagem de fases $(\%)$ de $\left(\mathrm{ZrO}_{2}: 8,6 \mathrm{~mol} \% \mathrm{MgO}\right)_{0,4}\left(\mathrm{ZrO}_{2}: 3 \mathrm{~mol} \% \mathrm{Y}_{2} \mathrm{O}_{3}\right)_{0,6}$.

\begin{tabular}{|c|c|c|}
\hline Monoclínica & Tetragonal & Cúbica \\
\hline 52,0 & 18,2 & 29,8 \\
\hline
\end{tabular}

Resultados do refinamento para $\left(\mathrm{ZrO}_{2}: 8,6 \text { mol\% } \mathrm{MgO}\right)_{0,5}\left(\mathrm{ZrO}_{2}: 3 \mathrm{~mol} \% \mathrm{Y}_{2} \mathrm{O}_{3}\right)_{0,5}$.

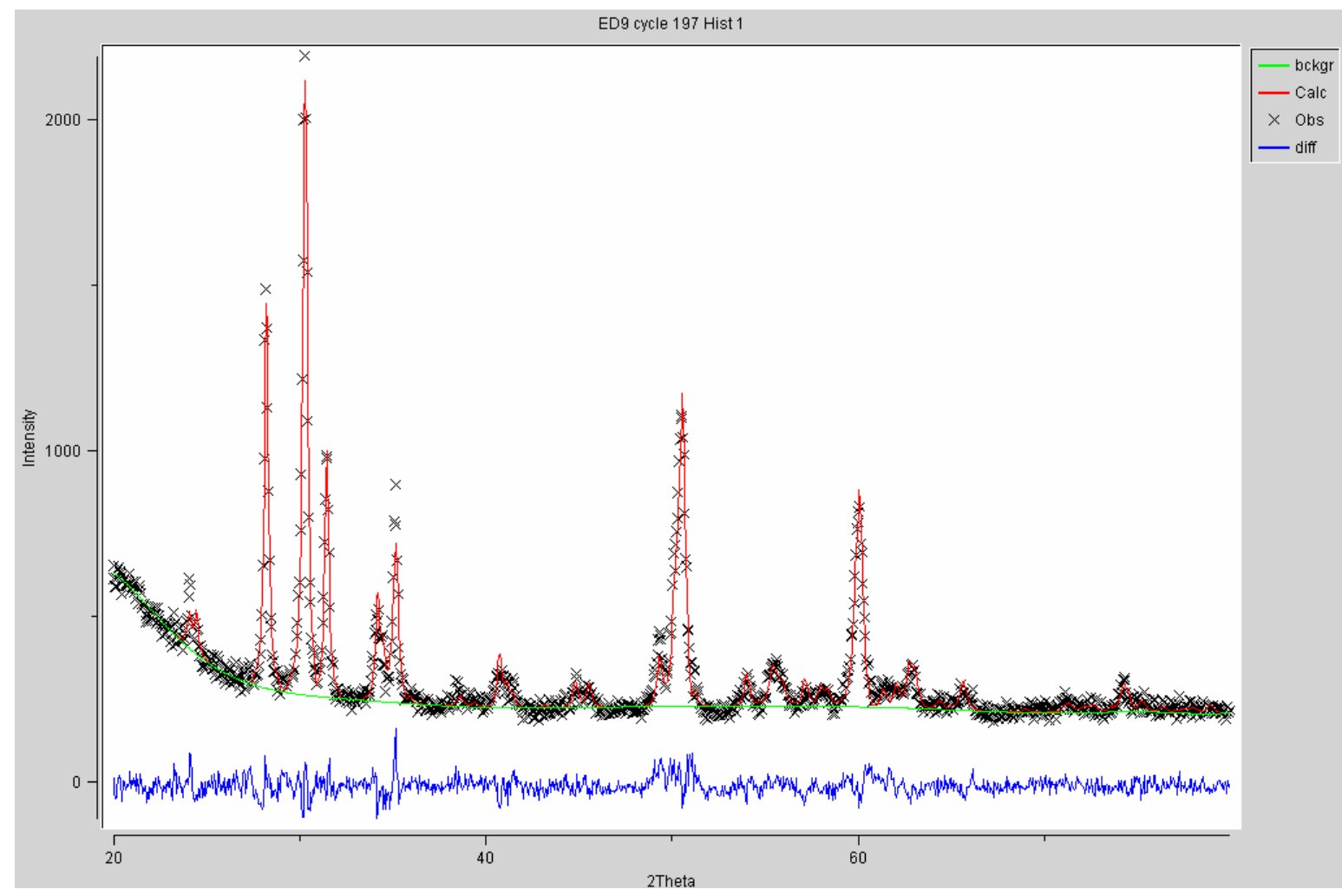

Figura 28: Padrões de difração calculado e observado para $\left(\mathrm{ZrO}_{2}: 8,6 \mathrm{~mol} \% \mathrm{MgO}\right)_{0,5}\left(\mathrm{ZrO}_{2}: 3\right.$ $\left.\mathrm{mol} \% \mathrm{Y}_{2} \mathrm{O}_{3}\right)_{0,5}$. 
Tabela 12: Valores estruturais teóricos e experimentais da fase tetragonal para $\left(\mathrm{ZrO}_{2}: 8,6 \mathrm{~mol} \% \mathrm{MgO}\right)_{0,5}\left(\mathrm{ZrO}_{2}: 3 \mathrm{~mol} \% \mathrm{Y}_{2} \mathrm{O}_{3}\right)_{0,5}$.

\begin{tabular}{|c|c|c|}
\hline & Teórico & Experimental \\
\hline Grupo espacial & \multicolumn{1}{|c|}{$\mathrm{P} 42 / \mathrm{nmcZ}$} \\
\hline $\begin{array}{c}\text { Parâmetros } \\
\text { de rede }\end{array}$ & $\begin{array}{c}\mathrm{a}=\mathrm{b}=3,6292(3) \AA \\
\mathrm{c}=5,1973(9) \AA\end{array}$ & $\begin{array}{c}\mathrm{a}=\mathrm{b}=3,617(1) \AA \\
\mathrm{c}=5,139(2) \AA\end{array}$ \\
\hline Volume da cela & $68,45 \AA^{3}$ & $67,24(4) \AA^{3}$ \\
\hline Densidade & $5,98 \mathrm{~g} / \mathrm{cm}^{3}$ & $6,086 \mathrm{~g} / \mathrm{cm}^{3}$ \\
\hline
\end{tabular}

Tabela 13: Valores estruturais teóricos e experimentais da fase cúbica para $\left(\mathrm{ZrO}_{2}: 8,6 \mathrm{~mol} \% \mathrm{MgO}\right)_{0,5}\left(\mathrm{ZrO}_{2}: 3 \mathrm{~mol} \% \mathrm{Y}_{2} \mathrm{O}_{3}\right)_{0,5}$.

\begin{tabular}{|c|c|c|}
\hline & Teórico & Experimental \\
\hline Grupo espacial & \multicolumn{2}{|c|}{$\mathrm{Fm}-3 \mathrm{~m}$} \\
\hline Parâmetros de rede & $\mathrm{a}=\mathrm{b}=\mathrm{c}=5,135(9) \AA$ & $\mathrm{a}=\mathrm{b}=\mathrm{c}=5,1049(4) \AA$ \\
\hline Volume da cela & $135,4 \AA^{3}$ & $133,03(3) \AA^{3}$ \\
\hline Densidade & $6,04 \mathrm{~g} / \mathrm{cm}^{3}$ & $6,152 \mathrm{~g} / \mathrm{cm}^{3}$ \\
\hline
\end{tabular}

Tabela 14: Valores estruturais teóricos e experimentais da fase monoclínica para $\left(\mathrm{ZrO}_{2}: 8,6 \mathrm{~mol} \% \mathrm{MgO}\right)_{0,5}\left(\mathrm{ZrO}_{2}: 3 \mathrm{~mol} \% \mathrm{Y}_{2} \mathrm{O}_{3}\right)_{0,5}$.

\begin{tabular}{|c|c|c|}
\hline & Teórico & Experimental \\
\hline Grupo espacial & \multicolumn{2}{|c|}{$\mathrm{P} 121 / \mathrm{c} 1$} \\
\hline Parâmetros & $\mathrm{a}=5,146(7) \AA$ & $\mathrm{a}=5,1570(9) \AA$ \\
de rede & $\mathrm{b}=5,205(1) \AA$ & $\mathrm{b}=5,204(1) \AA$ \\
& $\mathrm{c}=5,313(6) \AA$ & $\mathrm{c}=5,3128(9) \AA$ \\
\hline Volume da cela & $140,52 \AA^{3}$ & $140,80(4) \AA^{3}$ \\
\hline Densidade & $5,82 \mathrm{~g} / \mathrm{cm}^{3}$ & $5,813 \mathrm{~g} / \mathrm{cm}^{3}$ \\
\hline
\end{tabular}

Tabela 15: Porcentagem de fases $(\%)$ de $\left(\mathrm{ZrO}_{2}: 8,6 \mathrm{~mol} \% \mathrm{MgO}\right)_{0,5}\left(\mathrm{ZrO}_{2}: 3 \mathrm{~mol} \% \mathrm{Y}_{2} \mathrm{O}_{3}\right)_{0,5}$.

\begin{tabular}{|c|c|c|}
\hline Monoclínica & Tetragonal & Cúbica \\
\hline 53,1 & 15,1 & 31,8 \\
\hline
\end{tabular}


Resultados do refinamento para $\left(\mathrm{ZrO}_{2}: 8,6 \mathrm{~mol} \% \mathrm{MgO}\right)_{0,6}\left(\mathrm{ZrO}_{2}: 3 \mathrm{~mol} \% \mathrm{Y}_{2} \mathrm{O}_{3}\right)_{0,4 \text {. }}$

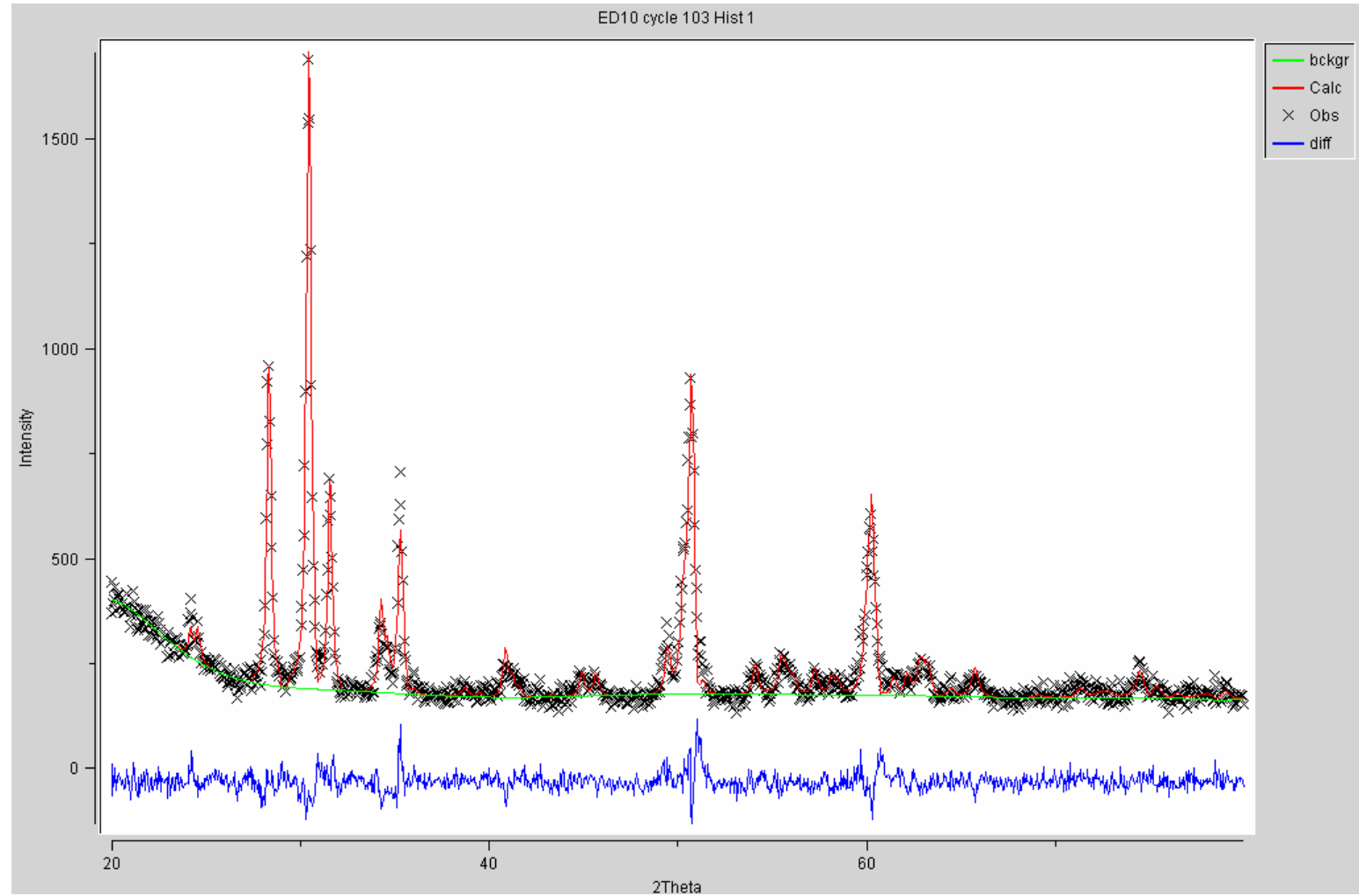

Figura 29: Padrões de difração calculado e observado para $\left(\mathrm{ZrO}_{2}: 8,6 \mathrm{~mol} \% \mathrm{MgO}\right)_{0,6}\left(\mathrm{ZrO}_{2}: 3\right.$ $\left.\mathrm{mol} \% \mathrm{Y}_{2} \mathrm{O}_{3}\right)_{0,4}$.

Tabela 16: Valores estruturais teóricos e experimentais da fase tetragonal para $\left(\mathrm{ZrO}_{2}: 8,6 \mathrm{~mol} \% \mathrm{MgO}\right)_{0,6}\left(\mathrm{ZrO}_{2}: 3 \mathrm{~mol} \% \mathrm{Y}_{2} \mathrm{O}_{3}\right)_{0,4}$.

\begin{tabular}{|c|c|c|}
\hline & Teórico & Experimental \\
\hline Grupo espacial & \multicolumn{2}{|c|}{$\mathrm{P} 42 / \mathrm{nmcZ}$} \\
\hline $\begin{array}{c}\text { Parâmetros } \\
\text { de rede }\end{array}$ & $\begin{array}{c}\mathrm{a}=\mathrm{b}=3,6292(3) \AA \\
\mathrm{c}=5,1973(9) \AA\end{array}$ & $\begin{array}{c}\mathrm{a}=\mathrm{b}=3,615(2) \AA \\
\mathrm{c}=5,128(5) \AA\end{array}$ \\
\hline Volume da cela & $68,45 \AA^{3}$ & $67,03(7) \AA^{3}$ \\
\hline Densidade & $5,98 \mathrm{~g} / \mathrm{cm}^{3}$ & $6,104 \mathrm{~g} / \mathrm{cm}^{3}$ \\
\hline
\end{tabular}

Tabela 17: Valores estruturais teóricos e experimentais da fase cúbica para $\left(\mathrm{ZrO}_{2}: 8,6 \mathrm{~mol} \% \mathrm{MgO}\right)_{0,6}\left(\mathrm{ZrO}_{2}: 3 \mathrm{~mol} \% \mathrm{Y}_{2} \mathrm{O}_{3}\right)_{0,4}$.

\begin{tabular}{|c|c|c|}
\hline & Teórico & Experimental \\
\hline Grupo espacial & \multicolumn{2}{|c|}{$\mathrm{Fm}-3 \mathrm{~m}$} \\
\hline Parâmetros de rede & $\mathrm{a}=\mathrm{b}=\mathrm{c}=5,135(9) \AA$ & $\mathrm{a}=\mathrm{b}=\mathrm{c}=5,0994(7) \AA$ \\
\hline Volume da cela & $135,4 \AA^{3}$ & $132,61(5) \AA^{3}$ \\
\hline Densidade & $6,04 \mathrm{~g} / \mathrm{cm}^{3}$ & $6,172 \mathrm{~g} / \mathrm{cm}^{3}$ \\
\hline
\end{tabular}


Tabela 18: Valores estruturais teóricos e experimentais da fase monoclínica para $\left(\mathrm{ZrO}_{2}: 8,6 \mathrm{~mol} \% \mathrm{MgO}\right)_{0,6}\left(\mathrm{ZrO}_{2}: 3 \mathrm{~mol} \% \mathrm{Y}_{2} \mathrm{O}_{3}\right)_{0,4}$.

\begin{tabular}{|c|c|c|}
\hline & Teórico & Experimental \\
\hline Grupo espacial & \multicolumn{2}{|c|}{$\mathrm{P} 121 / \mathrm{c} 1$} \\
\hline Parâmetros & $\mathrm{a}=5,146(7) \AA$ & $\mathrm{a}=5,156(1) \AA$ \\
de rede & $\mathrm{b}=5,205(1) \AA$ & $\mathrm{b}=5,201(1) \AA$ \\
& $\mathrm{c}=5,313(6) \AA$ & $\mathrm{c}=5,315(1) \AA$ \\
\hline Volume da cela & $140,52 \AA^{3}$ & $140,76(6) \AA^{3}$ \\
\hline Densidade & $5,82 \mathrm{~g} / \mathrm{cm}^{3}$ & $5,814 \mathrm{~g} / \mathrm{cm}^{3}$ \\
\hline
\end{tabular}

Tabela 19: Porcentagem de fases $(\%)$ de $\left(\mathrm{ZrO}_{2}: 8,6 \mathrm{~mol} \% \mathrm{MgO}\right)_{0,6}\left(\mathrm{ZrO}_{2}: 3 \mathrm{~mol} \% \mathrm{Y}_{2} \mathrm{O}_{3}\right)_{0,4}$.

\begin{tabular}{|c|c|c|}
\hline Monoclínica & Tetragonal & Cúbica \\
\hline 47,0 & 12,1 & 41,0 \\
\hline
\end{tabular}

Resultados do refinamento para $\left(\mathrm{ZrO}_{2}: 8,6 \text { mol\% } \mathrm{MgO}\right)_{0,8}\left(\mathrm{ZrO}_{2}: 3 \mathrm{~mol} \% \mathrm{Y}_{2} \mathrm{O}_{3}\right)_{0,2}$.

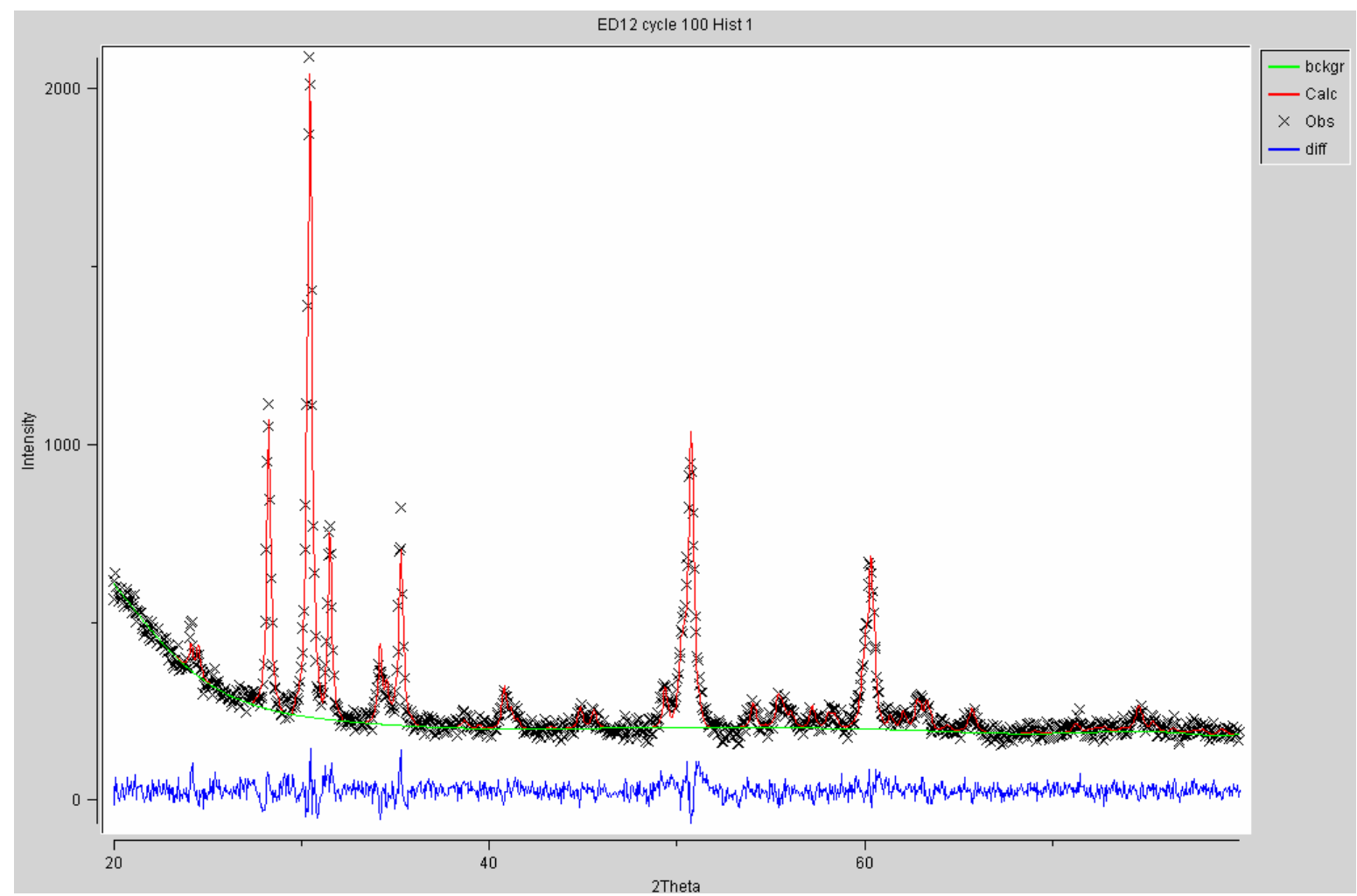

Figura 30: Padrões de difração calculado e observado para $\left(\mathrm{ZrO}_{2}: 8,6 \mathrm{~mol} \% \mathrm{MgO}\right)_{0,8}\left(\mathrm{ZrO}_{2}: 3\right.$ $\left.\operatorname{mol} \% \mathrm{Y}_{2} \mathrm{O}_{3}\right)_{0,2}$. 
Tabela 20: Valores estruturais teóricos e experimentais da fase tetragonal para $\left(\mathrm{ZrO}_{2}: 8,6 \mathrm{~mol} \% \mathrm{MgO}\right)_{0,8}\left(\mathrm{ZrO}_{2}: 3 \mathrm{~mol} \% \mathrm{Y}_{2} \mathrm{O}_{3}\right)_{0,2}$.

\begin{tabular}{|c|c|c|}
\hline & Teórico & Experimental \\
\hline Grupo espacial & \multicolumn{2}{|c|}{$\mathrm{P} 42 / \mathrm{nmcZ}$} \\
\hline $\begin{array}{c}\text { Parâmetros } \\
\text { de rede }\end{array}$ & $\begin{array}{c}\mathrm{a}=\mathrm{b}=3,6292(3) \AA \\
\mathrm{c}=5,1973(9) \AA\end{array}$ & $\begin{array}{c}\mathrm{a}=\mathrm{b}=3,608(1) \AA \\
\mathrm{c}=5,134(3) \AA\end{array}$ \\
\hline Volume da cela & $68,45 \AA^{3}$ & $66,85(6) \AA^{3}$ \\
\hline Densidade & $5,98 \mathrm{~g} / \mathrm{cm}^{3}$ & $6,121 \mathrm{~g} / \mathrm{cm}^{3}$ \\
\hline
\end{tabular}

Tabela 21: Valores estruturais teóricos e experimentais da fase cúbica para $\left(\mathrm{ZrO}_{2}: 8,6 \mathrm{~mol} \% \mathrm{MgO}\right)_{0,8}\left(\mathrm{ZrO}_{2}: 3 \mathrm{~mol} \% \mathrm{Y}_{2} \mathrm{O}_{3}\right)_{0,2}$.

\begin{tabular}{|c|c|c|}
\hline & Teórico & Experimental \\
\hline Grupo espacial & \multicolumn{2}{|c|}{$\mathrm{Fm}-3 \mathrm{~m}$} \\
\hline Parâmetros de rede & $\mathrm{a}=\mathrm{b}=\mathrm{c}=5,135(9) \AA$ & $\mathrm{a}=\mathrm{b}=\mathrm{c}=5,0885(6) \AA$ \\
\hline Volume da cela & $135,4 \AA^{3}$ & $131,75(4) \AA^{3}$ \\
\hline Densidade & $6,04 \mathrm{~g} / \mathrm{cm}^{3}$ & $6,212 \mathrm{~g} / \mathrm{cm}^{3}$ \\
\hline
\end{tabular}

Tabela 22: Valores estruturais teóricos e experimentais da fase monoclínica para $\left(\mathrm{ZrO}_{2}: 8,6 \mathrm{~mol} \% \mathrm{MgO}\right)_{0,8}\left(\mathrm{ZrO}_{2}: 3 \mathrm{~mol} \% \mathrm{Y}_{2} \mathrm{O}_{3}\right)_{0,2}$.

\begin{tabular}{|c|c|c|}
\hline & Teórico & Experimental \\
\hline Grupo espacial & \multicolumn{2}{|c|}{$\mathrm{P} 121 / \mathrm{c} 1$} \\
\hline Parâmetros & $\mathrm{a}=5,146(7) \AA$ & $\mathrm{a}=5,153(1) \AA$ \\
de rede & $\mathrm{b}=5,205(1) \AA$ & $\mathrm{b}=5,197(1) \AA$ \\
& $\mathrm{c}=5,313(6) \AA$ & $\mathrm{c}=5,318(1) \AA$ \\
\hline Volume da cela & $140,52 \AA^{3}$ & $140,64(5) \AA^{3}$ \\
\hline Densidade & $5,82 \mathrm{~g} / \mathrm{cm}^{3}$ & $5,819 \mathrm{~g} / \mathrm{cm}^{3}$ \\
\hline
\end{tabular}

Tabela 23: Porcentagem de fases $(\%)$ de $\left(\mathrm{ZrO}_{2}: 8,6 \mathrm{~mol} \% \mathrm{MgO}\right)_{0,8}\left(\mathrm{ZrO}_{2}: 3 \mathrm{~mol} \% \mathrm{Y}_{2} \mathrm{O}_{3}\right)_{0,2}$.

\begin{tabular}{|c|c|c|}
\hline Monoclínica & Tetragonal & Cúbica \\
\hline 43,0 & 10,2 & 46,8 \\
\hline
\end{tabular}


Resultados do refinamento para $\left(\mathrm{ZrO}_{2}: 8,6 \mathrm{~mol} \% \mathrm{MgO}\right)$.

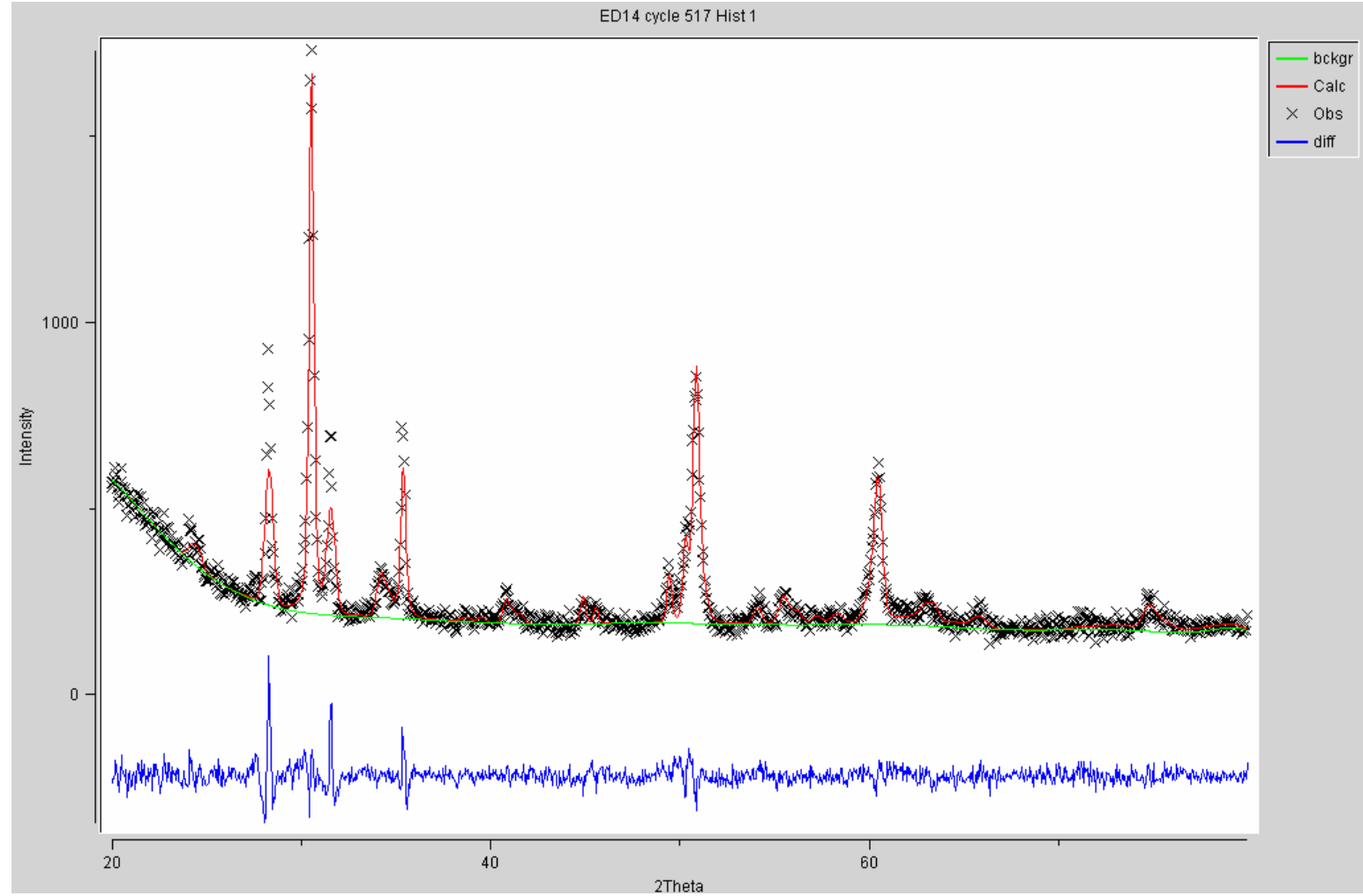

Figura 31: Padrões de difração calculado e observado para $\left(\mathrm{ZrO}_{2}: 8,6 \mathrm{~mol} \% \mathrm{MgO}\right)$.

Tabela 24: Valores estruturais teóricos e experimentais da fase tetragonal para $\mathrm{ZrO}_{2}: 8,6 \mathrm{~mol} \% \mathrm{MgO}$.

\begin{tabular}{|c|c|c|}
\hline & Teórico & Experimental \\
\hline Grupo espacial & \multicolumn{2}{|c|}{$\mathrm{P} 42 / \mathrm{nmcZ}$} \\
\hline $\begin{array}{c}\text { Parâmetros } \\
\text { de rede }\end{array}$ & $\mathrm{a}=\mathrm{b}=3,6292(3) \AA$ & $\mathrm{a}=\mathrm{b}=3,606(1) \AA$ \\
$\mathrm{c}=5,1973(9) \AA$ & $\mathrm{c}=5,097(6) \AA$ \\
\hline Volume da cela & $68,45 \AA^{3}$ & $66,31(6) \AA^{3}$ \\
\hline Densidade & $5,98 \mathrm{~g} / \mathrm{cm}^{3}$ & $6,174 \mathrm{~g} / \mathrm{cm}^{3}$ \\
\hline
\end{tabular}

Tabela 25: Valores estruturais teóricos e experimentais da fase cúbica para $\mathrm{ZrO}_{2}: 8,6 \mathrm{~mol} \% \mathrm{MgO}$.

\begin{tabular}{|c|c|c|}
\hline & Teórico & Experimental \\
\hline Grupo espacial & \multicolumn{2}{|c|}{$\mathrm{Fm}-3 \mathrm{~m}$} \\
\hline Parâmetros de rede & $\mathrm{a}=\mathrm{b}=\mathrm{c}=5,135(9) \AA$ & $\mathrm{a}=\mathrm{b}=\mathrm{c}=5,0788(6) \AA$ \\
\hline Volume da cela & $135,4 \AA^{3}$ & $131,00(5) \AA^{3}$ \\
\hline Densidade & $6,04 \mathrm{~g} / \mathrm{cm}^{3}$ & $6,248 \mathrm{~g} / \mathrm{cm}^{3}$ \\
\hline
\end{tabular}


Tabela 26: Valores estruturais teóricos e experimentais da fase monoclínica para $\mathrm{ZrO}_{2}: 8,6 \mathrm{~mol} \% \mathrm{MgO}$.

\begin{tabular}{|c|c|c|}
\hline & Teórico & Experimental \\
\hline Grupo espacial & \multicolumn{2}{|c|}{$\mathrm{P} 121 / \mathrm{c} 1$} \\
\hline Parâmetros & $\mathrm{a}=5,146(7) \AA$ & $\mathrm{a}=5,150(1) \AA$ \\
de rede & $\mathrm{b}=5,205(1) \AA$ & $\mathrm{b}=5,197(1) \AA$ \\
& $\mathrm{c}=5,313(6) \AA$ & $\mathrm{c}=5,319(1) \AA$ \\
\hline Volume da cela & $140,52 \AA^{3}$ & $140,57(6) \AA^{3}$ \\
\hline Densidade & $5,82 \mathrm{~g} / \mathrm{cm}^{3}$ & $5,822 \mathrm{~g} / \mathrm{cm}^{3}$ \\
\hline
\end{tabular}

Tabela 27: Porcentagem de fases (\%) de $\mathrm{ZrO}_{2}: 8,6 \mathrm{~mol} \% \mathrm{MgO}$.

\begin{tabular}{|c|c|c|}
\hline Monoclínica & Tetragonal & Cúbica \\
\hline 44,4 & 11,8 & 43,8 \\
\hline
\end{tabular}

Tabela 28: Resíduos obtidos no refinamento de $\left(\mathrm{ZrO}_{2}: 8,6 \mathrm{~mol} \% \mathrm{MgO}\right)_{\mathrm{x}}\left(\mathrm{ZrO}_{2}: 3 \mathrm{~mol} \% \mathrm{Y}_{2} \mathrm{O}_{3}\right)_{1-\mathrm{x}}$

\begin{tabular}{|c|c|c|}
\hline $\mathbf{x}$ & $\chi^{\mathbf{2}}$ & $\mathbf{R}_{\mathbf{w p}}$ \\
\hline 0 & 1,696 & 9,12 \\
\hline 0,2 & 1,806 & 7,15 \\
\hline 0,4 & 1,640 & 7,36 \\
\hline 0,5 & 1,881 & 7,63 \\
\hline 0,6 & 1,822 & 8,7 \\
\hline 0,8 & 1,604 & 7,53 \\
\hline 1 & 1,563 & 7,67 \\
\hline
\end{tabular}

Os resíduos obtidos nos refinamentos para todas as amostras mostram uma boa aproximação entre os padrões calculados e os observados. A partir do refinamento da estrutura cristalina pelo método de Rietveld foi possível separar as fases cúbica e tetragonal e quantificar seus teores relativos. 
Os valores obtidos de cada fase nos compósitos cerâmicos $\left(\mathrm{ZrO}_{2}: 8,6 \mathrm{~mol} \% \mathrm{MgO}\right)_{\mathrm{x}}\left(\mathrm{ZrO}_{2}\right.$ : $\left.3 \mathrm{~mol} \% \mathrm{Y}_{2} \mathrm{O}_{3}\right)_{1-\mathrm{x}}, 0 \leq \mathrm{x} \leq 1$, podem ser vistos na Figura 32.

A mistura da zircônia:ítria com zircônia:magnésia seguida de sinterização a $1500{ }^{\circ} \mathrm{C}$ proporciona a estabilização parcial das fases monoclínica, tetragonal e cúbica nos compósitos cerâmicos. O teor da fase tetragonal diminui com o aumento da zircônia:magnésia, enquanto que o teor da fase cúbica aumenta.

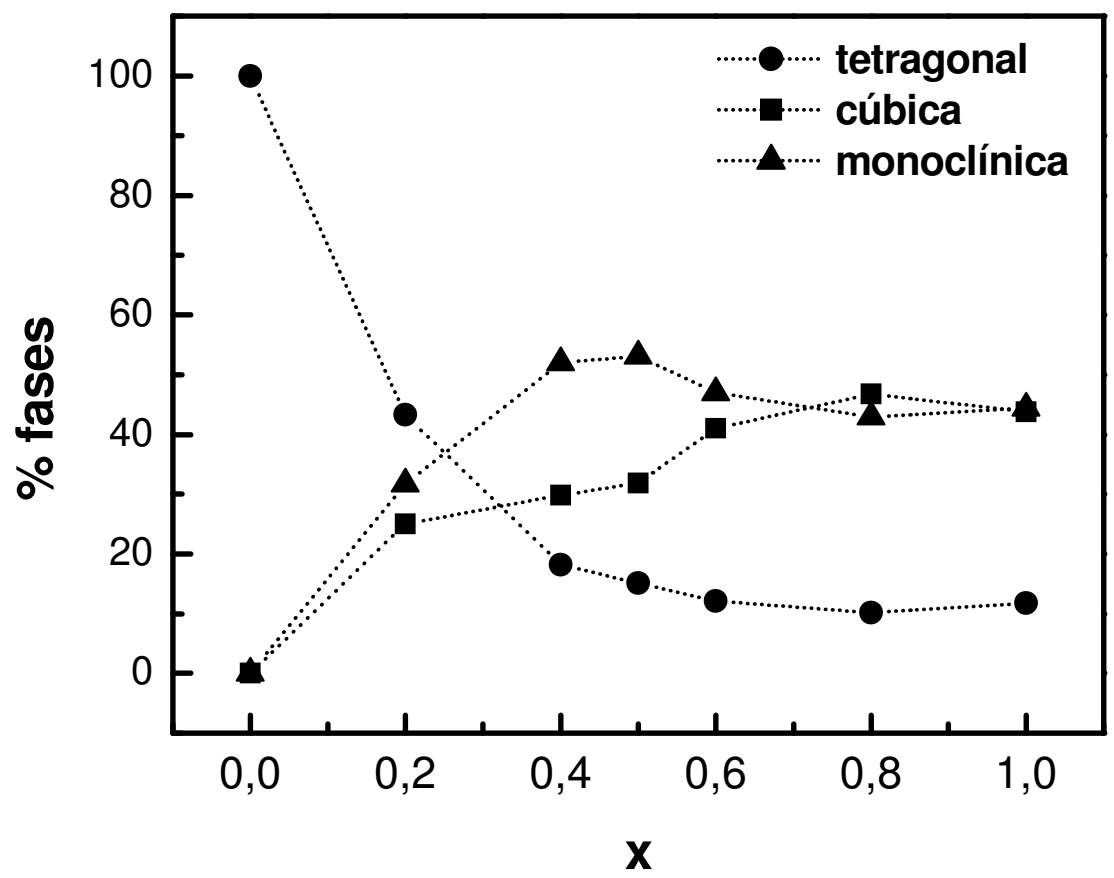

Figura 32: Porcentagem das fases tetragonal, cúbica e monoclínica nos compósitos cerâmicos $\left(\mathrm{ZrO}_{2}: 8,6 \mathrm{~mol} \% \mathrm{MgO}\right)_{\mathrm{x}}\left(\mathrm{ZrO}_{2}: 3 \mathrm{~mol} \% \mathrm{Y}_{2} \mathrm{O}_{3}\right)_{1-\mathrm{x}}, 0 \leq \mathrm{x} \leq 1$.

A zircônia parcialmente estabilizada apresenta menor coeficiente de expansão térmica do que a zircônia totalmente estabilizada, contribuindo para uma melhor resistência ao choque térmico ${ }^{[1,5]}$. Isto é conseguido pela diminuição da expansão volumétrica que ocorre na transformação de fase monoclínica $\rightarrow$ cúbica/tetragonal durante o aquecimento ${ }^{[5,39]}$.

O coeficiente de expansão térmica da zircônia:magnésia pode ser reduzido por meio de tratamentos térmicos, diminuindo a variação volumétrica (monoclínica $\rightarrow$ tetragonal) que ocorre a uma temperatura próxima a $1170{ }^{\circ} \mathrm{C}$ durante o aquecimento ${ }^{[39]}$. 
A variação volumétrica associada com a transformação de fases tem um papel importante na resistência ao choque térmico de eletrólitos sólidos à base de zircônia.

Uma das principais propriedades que um eletrólito sólido deve apresentar para ser utilizado em sensores de oxigênio na indústria siderúrgica, além da alta condutividade iônica para permitir a detecção de baixos teores de oxigênio, é uma elevada resistência ao choque térmico. Deste modo, as características da variação volumétrica dos compósitos cerâmicos serão mostradas a seguir por análise de dilatometria.

\subsubsection{Comportamento térmico}

Durante os processos metalúrgicos, o sensor é rapidamente imerso no aço a temperaturas na faixa $1500{ }^{\circ} \mathrm{C}-1700{ }^{\circ} \mathrm{C}$. Essa condição de trabalho proporciona uma mudança brusca de temperatura no eletrólito sólido. A resistência ao choque térmico do eletrólito sólido é um parâmetro importante para garantir um adequado desempenho do sensor de oxigênio.

Com isso, neste trabalho, as mesmas amostras utilizadas anteriormente para análise de dilatometria, foram submetidas novamente a um mesmo ciclo de aquecimento e resfriamento descritos para as amostras a verde, para verificar o comportamento dos compósitos cerâmicos sob choque térmico, conforme a Figura 33.

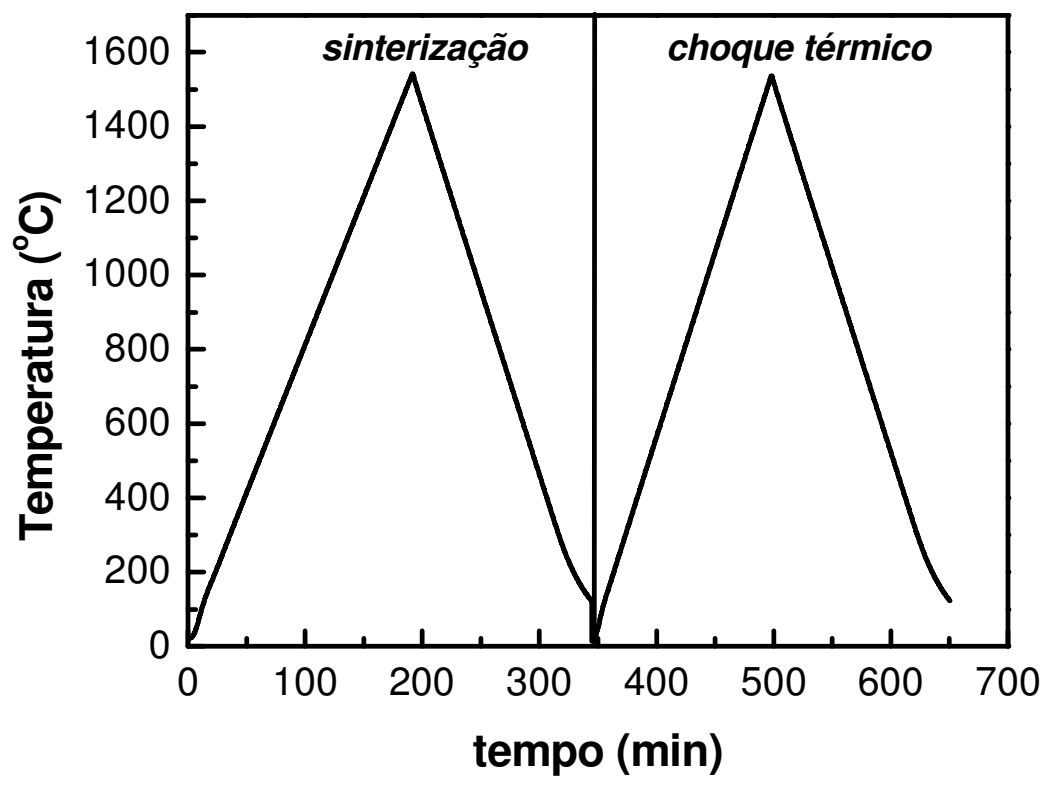

Figura 33: Ciclos de aquecimento e resfriamento durante o processo de sinterização e comportamento ao choque térmico. 
A Figura 34 mostra a retração linear em função da temperatura dos compósitos cerâmicos sinterizados $\left(\mathrm{ZrO}_{2}: 8,6 \mathrm{~mol} \% \mathrm{MgO}\right)_{\mathrm{x}}\left(\mathrm{ZrO}_{2}: 3 \mathrm{~mol} \% \mathrm{Y}_{2} \mathrm{O}_{3}\right)_{1-\mathrm{x}}, \mathrm{x}=0,2,0,5$ e 0,8.

Os gráficos da retração linear, avaliados após sinterização dos compósitos de zircônia:magnésia e zircônia:ítria, apresentam comportamento semelhante ao descrito anteriormente para o eletrólito sólido de zircônia:magnésia, usado em sensores de oxigênio ${ }^{\text {[39] }}$.

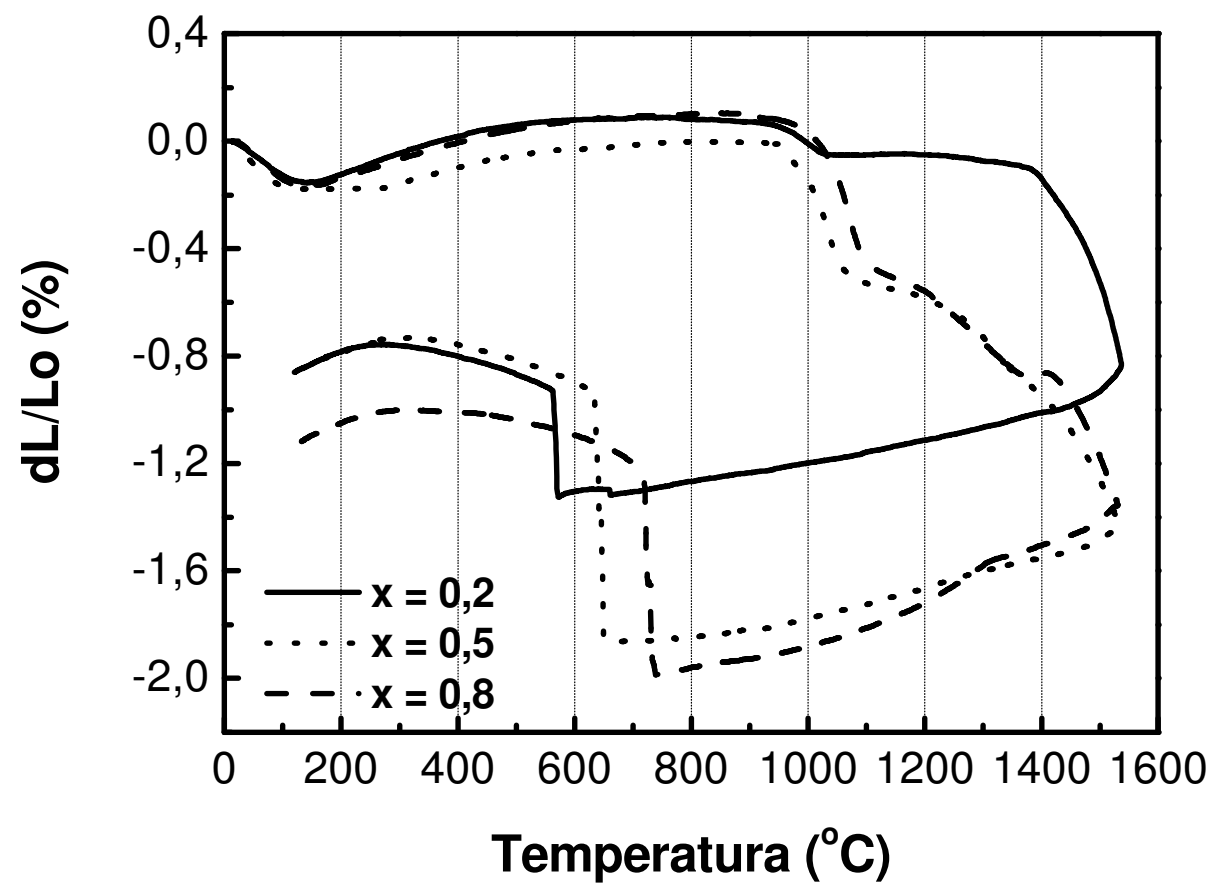

Figura 34: Análise de dilatometria dos compactos cerâmicos sinterizados $\left(\mathrm{ZrO}_{2}: 8,6\right.$ mol\% $\mathrm{MgO})_{\mathrm{x}}\left(\mathrm{ZrO}_{2}: 3 \mathrm{~mol} \% \mathrm{Y}_{2} \mathrm{O}_{3}\right)_{1-\mathrm{x}}, \mathrm{x}=0,2,0,5$ e 0,8 .

A composição $\mathrm{x}=0,2$ é a que apresenta a menor variação volumétrica (aproximadamente $0,1 \%$ ) associada às transformações cristalográficas de fases que ocorrem em cerâmicas à base de zircônia (monoclínica $\rightarrow$ tetragonal) ${ }^{[1,50,55]}$ na faixa de $930{ }^{\circ} \mathrm{C}$ a $1030{ }^{\circ} \mathrm{C}$, enquanto que as composições $\mathrm{x}=0,5$ e 0,8 apresentaram variação volumétrica de aproximadamente $0,5 \%$ e $0,8 \%$, respectivamente.

Portanto, entre as composições estudadas por dilatometria, o compósito cerâmico $\left(\mathrm{ZrO}_{2}\right.$ : 8,6 mol\% $\mathrm{MgO})_{0,2}\left(\mathrm{ZrO}_{2}: 3 \mathrm{~mol} \% \mathrm{Y}_{2} \mathrm{O}_{3}\right)_{0,8}$ é o que apresenta uma menor variação volumétrica, podendo estar relacionada a um melhor comportamento de resistência ao choque térmico. 
Ainda durante o aquecimento, na faixa de $1030{ }^{\circ} \mathrm{C}$ a $1550{ }^{\circ} \mathrm{C}$, há uma continuidade da retração linear para todas as composições, relacionada à sinterização do material.

No resfriamento, a aproximadamente $580{ }^{\circ} \mathrm{C}$ para a composição $\mathrm{x}=0,2$, a $650{ }^{\circ} \mathrm{C}$ para $\mathrm{x}=0,5$ e a $740{ }^{\circ} \mathrm{C}$ para $\mathrm{x}=0,8$, há uma histerese, relacionada com a transformação de fase cúbica/tetragonal $\rightarrow$ monoclínica.

\subsubsection{Densidade aparente}

Os valores da densidade aparente $\left(\rho_{\mathrm{a}}\right)$ para os compósitos cerâmicos $\left(\mathrm{ZrO}_{2}: 8,6 \mathrm{~mol} \%\right.$ $\mathrm{MgO})_{\mathrm{x}}\left(\mathrm{ZrO}_{2}: 3 \mathrm{~mol} \% \mathrm{Y}_{2} \mathrm{O}_{3}\right)_{1-\mathrm{x}}, 0 \leq \mathrm{x} \leq 1$ sinterizados a $1500{ }^{\circ} \mathrm{C}$, obtidos pelo método de Arquimedes, são apresentados na Tabela 35. A densidade teórica $\left(\rho_{t}\right)$ para cada amostra, foi determinada por meio da média ponderada das densidades das fases cúbica, tetragonal e monoclínica, obtidas pelo método de Rietveld (Tabelas na seção 3.2.2).

Tabela 29: Valores da densidade teórica e de densidade aparente dos compósitos $\left(\mathrm{ZrO}_{2}: 8,6 \mathrm{~mol} \% \mathrm{MgO}\right)_{\mathrm{x}}\left(\mathrm{ZrO}_{2}: 3 \mathrm{~mol} \% \mathrm{Y}_{2} \mathrm{O}_{3}\right)_{1-\mathrm{x}}$.

\begin{tabular}{cccc}
\hline $\mathbf{x}$ & $\begin{array}{c}\boldsymbol{\rho}_{\mathbf{t}} \\
\left(\mathbf{g} / \mathbf{c m}^{\mathbf{3}}\right)\end{array}$ & $\begin{array}{c}\boldsymbol{\rho}_{\mathbf{a}} \\
\left(\mathbf{g} / \mathbf{c m}^{\mathbf{3}}\right)\end{array}$ & $\boldsymbol{\%} \boldsymbol{\rho}_{\mathbf{t}}$ \\
\hline 0 & 6,06 & 6,04 & \\
\hline 0,2 & 5,99 & 5,89 & 99,7 \\
0,4 & 5,95 & 5,79 & 98,3 \\
0,5 & 5,96 & 5,76 & 97,3 \\
0,6 & 6,00 & 5,75 & 96,6 \\
0,8 & 6,03 & 5,74 & 95,8 \\
1 & 6,05 & 5,69 & 95,2 \\
\hline
\end{tabular}

Todos os compactos cerâmicos apresentam valores de densidade aparente superiores a 94\% da densidade teórica. A densificação atingida é suficiente para que o material possa ser utilizado como eletrólito sólido em sensores de oxigênio, evitando que durante o funcionamento do sensor, moléculas de oxigênio do ambiente sob medida difundam pelos poros do eletrólito 
sólido e seja menor a concentração de íons $\mathrm{O}^{2-}$ na interface eletrodo/eletrólito sólido, conforme a equação (15).

$$
O_{2}(\text { gás })+4 e^{-}(\text {eletrodo }) \leftrightarrow 2 O^{2-}(\text { eletrólito })
$$

\subsubsection{Microscopia eletrônica de varredura}

A Figura 35 mostra as micrografias das superfícies de fratura dos compactos sinterizados a $1500{ }^{\circ} \mathrm{C} / 1 \mathrm{~h}$, com um aumento de 4000 vezes. A adição da zircônia:ítria à matriz de zircônia:magnésia não modifica a morfologia e o tamanho médio de grão. Todas amostras apresentam superfície de fratura de modo intergranular com pequenos grãos, típico da zircônia parcialmente estabilizada, além da baixa porosidade para todas as composições, estando de acordo com os valores de densidade aparente obtidos pelo método de Arquimedes.

A condutividade elétrica dos contornos de grão (intergranular) aumenta com o aumento do tamanho de grão ${ }^{[56-58]}$, pois quanto maior o tamanho de grão, menor será a densidade de contornos de grão deste material e, consequentemente, menor será a fração de regiões bloqueadoras. Medidas de condutividade elétrica por meio de espectroscopia de impedância mostram que o crescimento de grãos diminui a resistência intergranular devido à diminuição da fração de bloqueadores ${ }^{[6]}$. Portanto, neste trabalho o tamanho de grão não deve interferir significativamente nas propriedades elétricas dos compósitos cerâmicos. 


$$
\mathrm{x}=0
$$

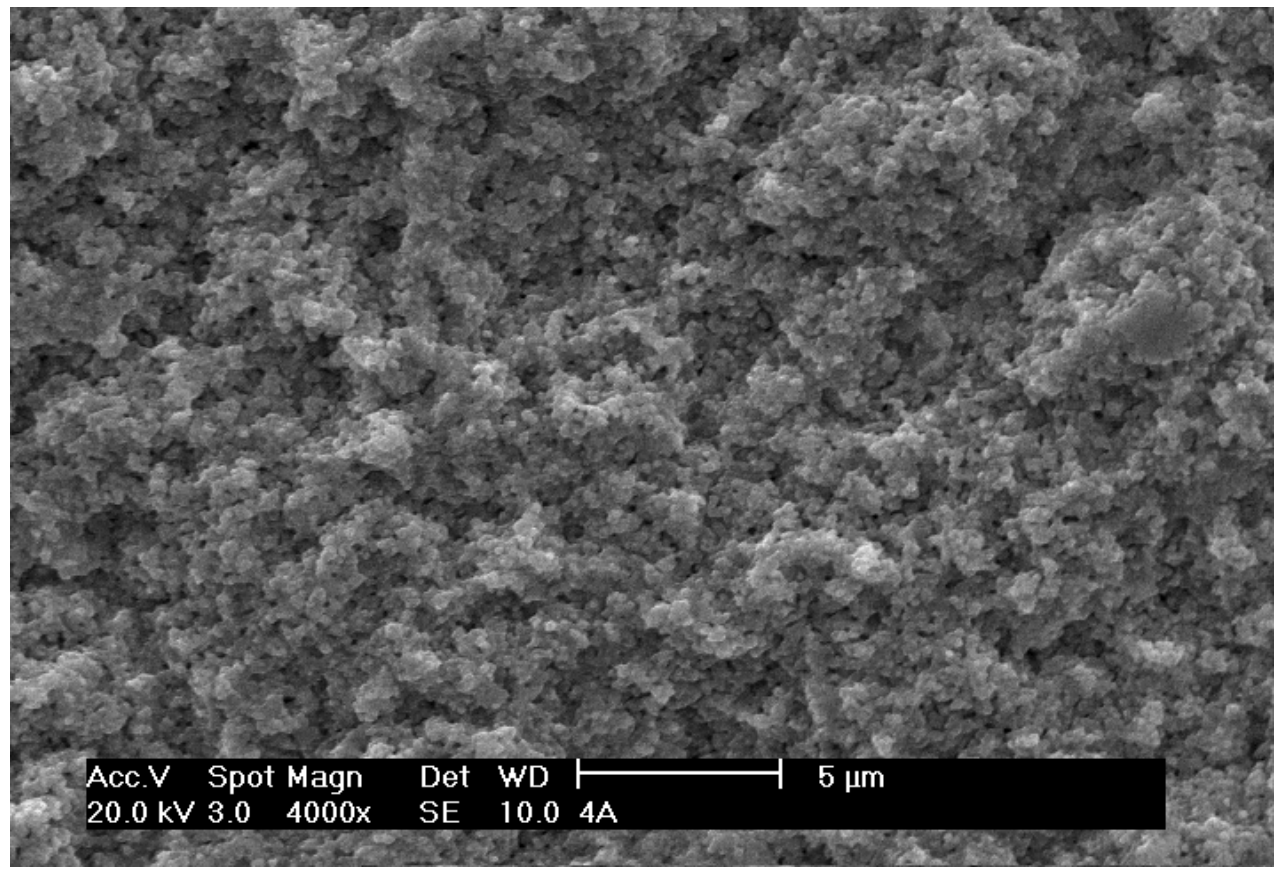

$$
\mathrm{x}=0,2
$$

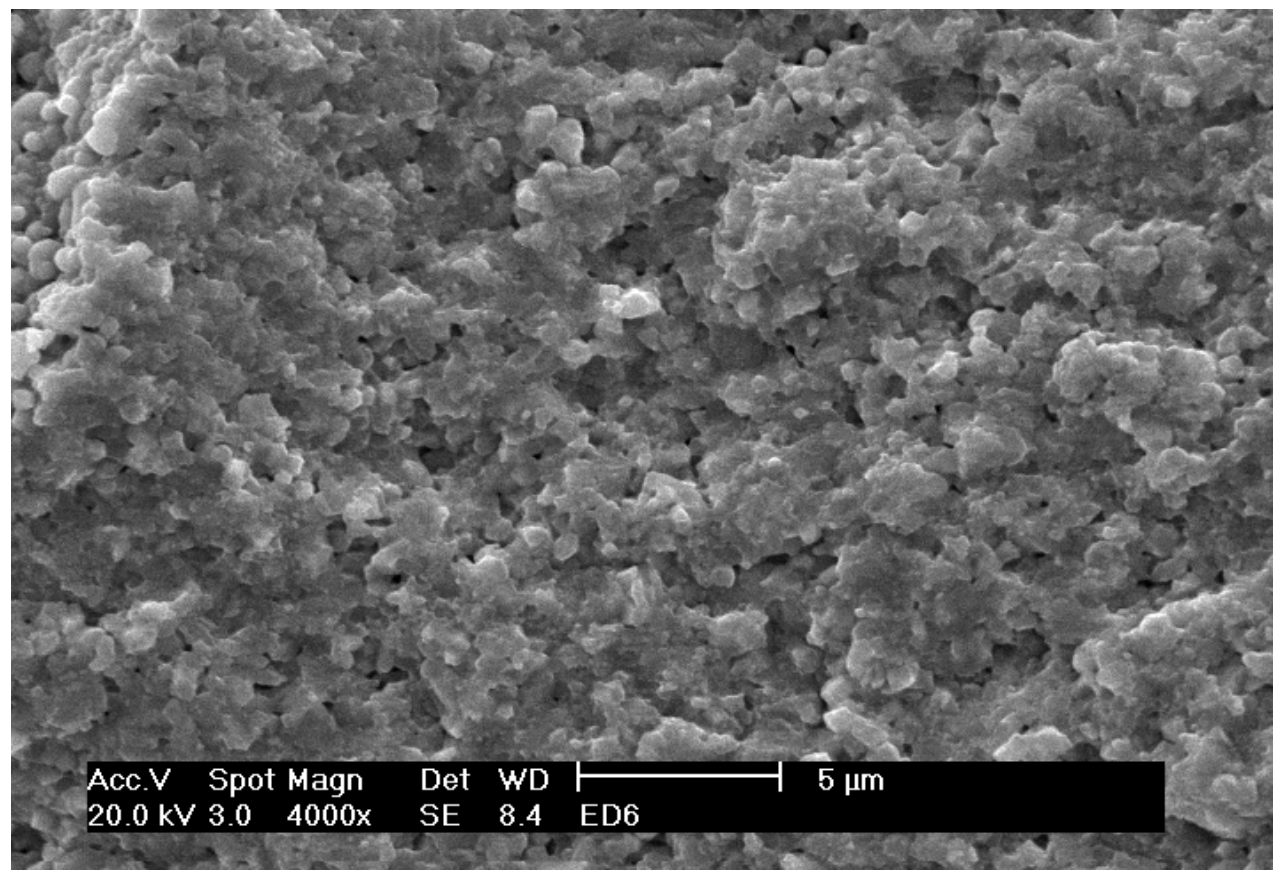

Figura 35: Micrografias obtidas por microscopia eletrônica de varredura das superfícies de fratura dos compósitos cerâmicos $\left(\mathrm{ZrO}_{2}: 8,6 \mathrm{~mol} \% \mathrm{MgO}\right)_{\mathrm{x}}\left(\mathrm{ZrO}_{2}: 3 \mathrm{~mol} \% \mathrm{Y}_{2} \mathrm{O}_{3}\right)_{1-\mathrm{x}}, \mathrm{x}=0$ e 0,2. 
$\mathrm{x}=0,4$

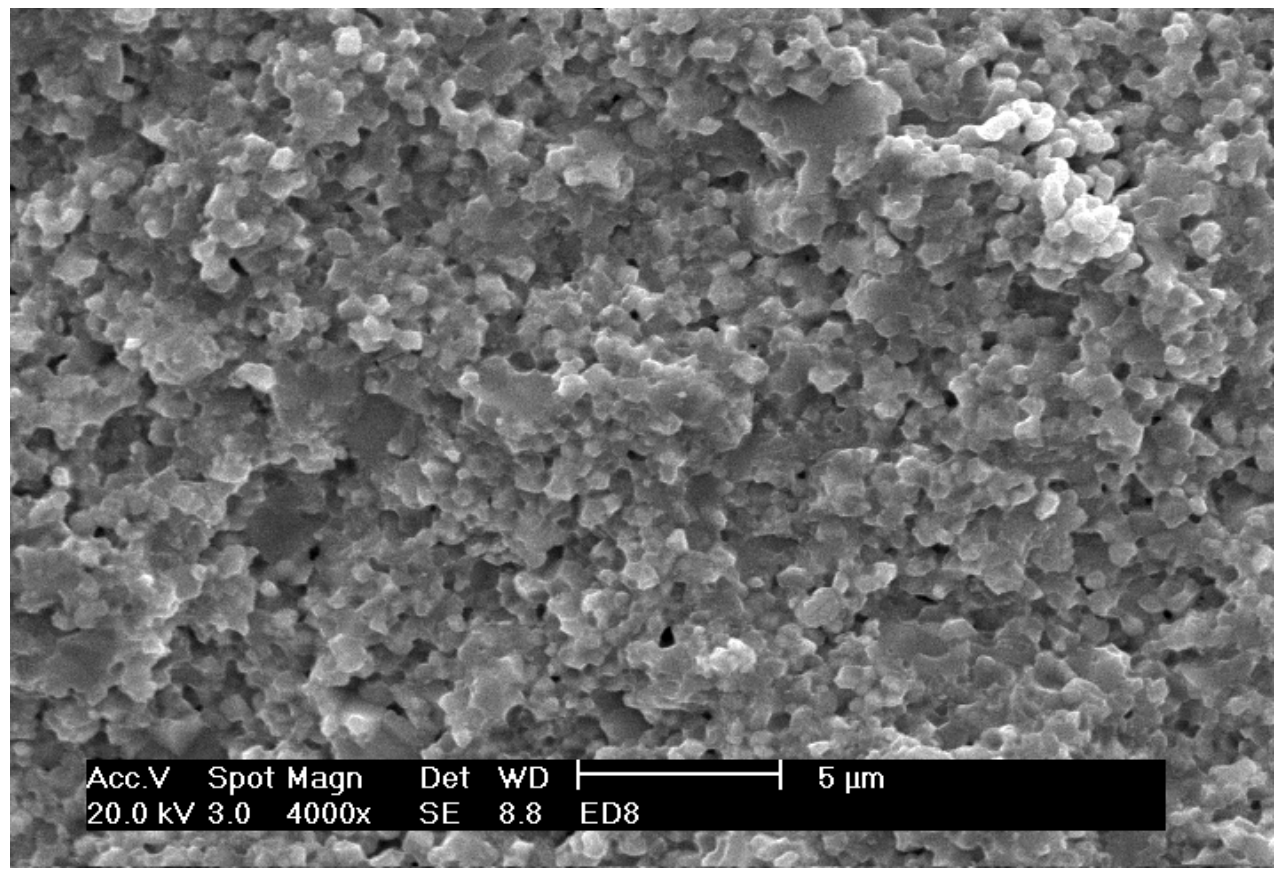

$$
\mathrm{x}=0,5
$$

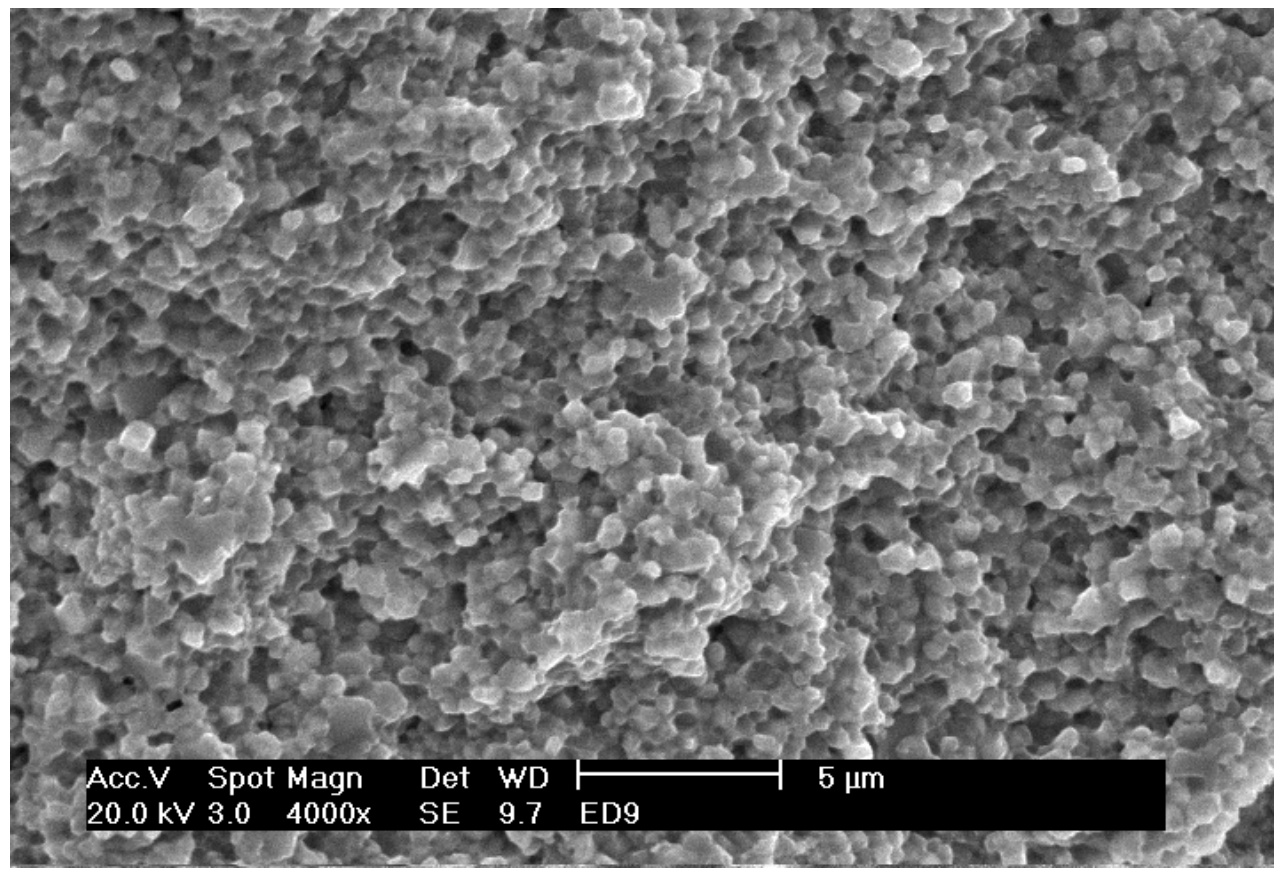

Figura 35 (cont): Micrografias obtidas por microscopia eletrônica de varredura das superfícies de fratura dos compósitos cerâmicos $\left(\mathrm{ZrO}_{2}: 8,6 \mathrm{~mol} \% \mathrm{MgO}\right)_{\mathrm{x}}\left(\mathrm{ZrO}_{2}: 3 \mathrm{~mol} \% \mathrm{Y}_{2} \mathrm{O}_{3}\right)_{1-\mathrm{x}}, \mathrm{x}=0,4 \mathrm{e}$ 0,5 . 


$$
x=0,6
$$

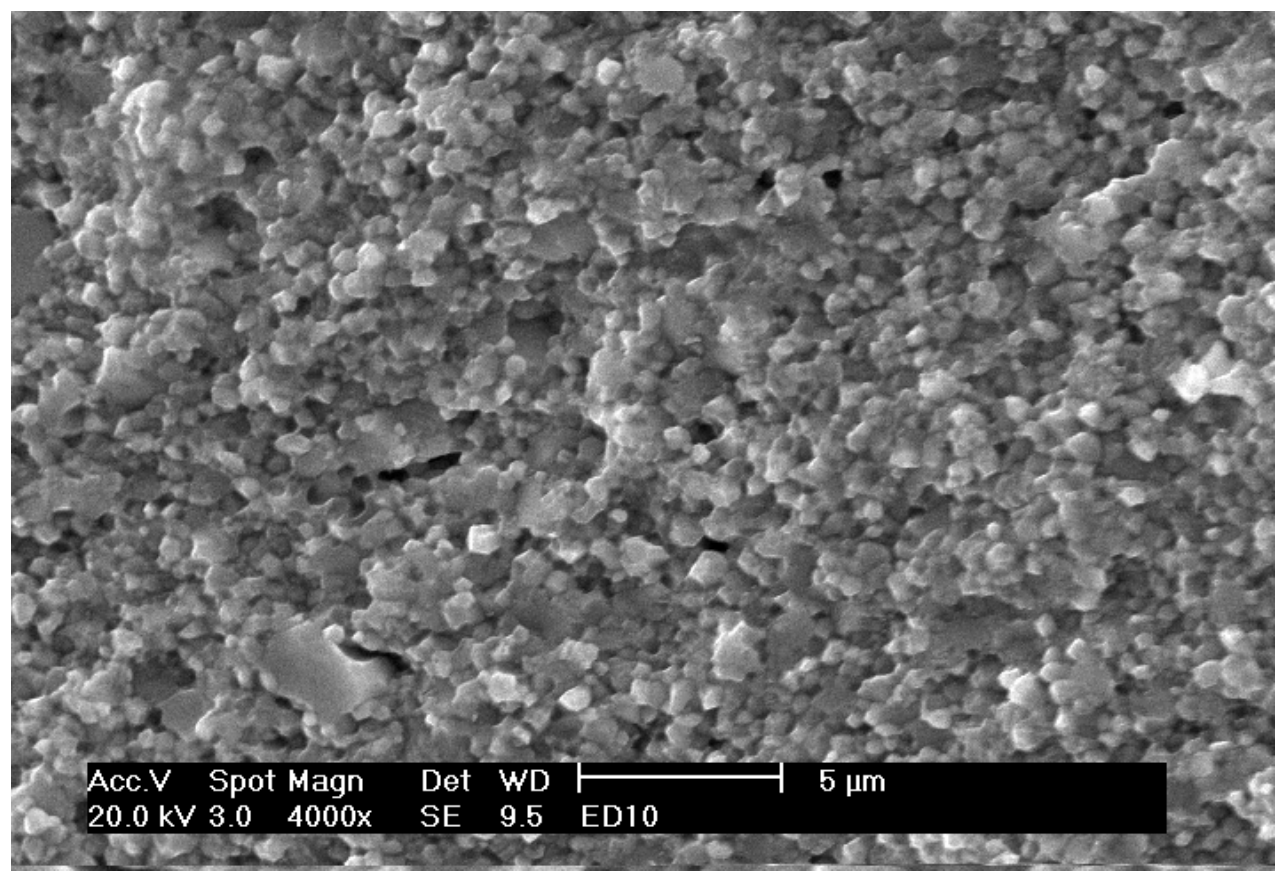

$$
\mathrm{x}=0,8
$$

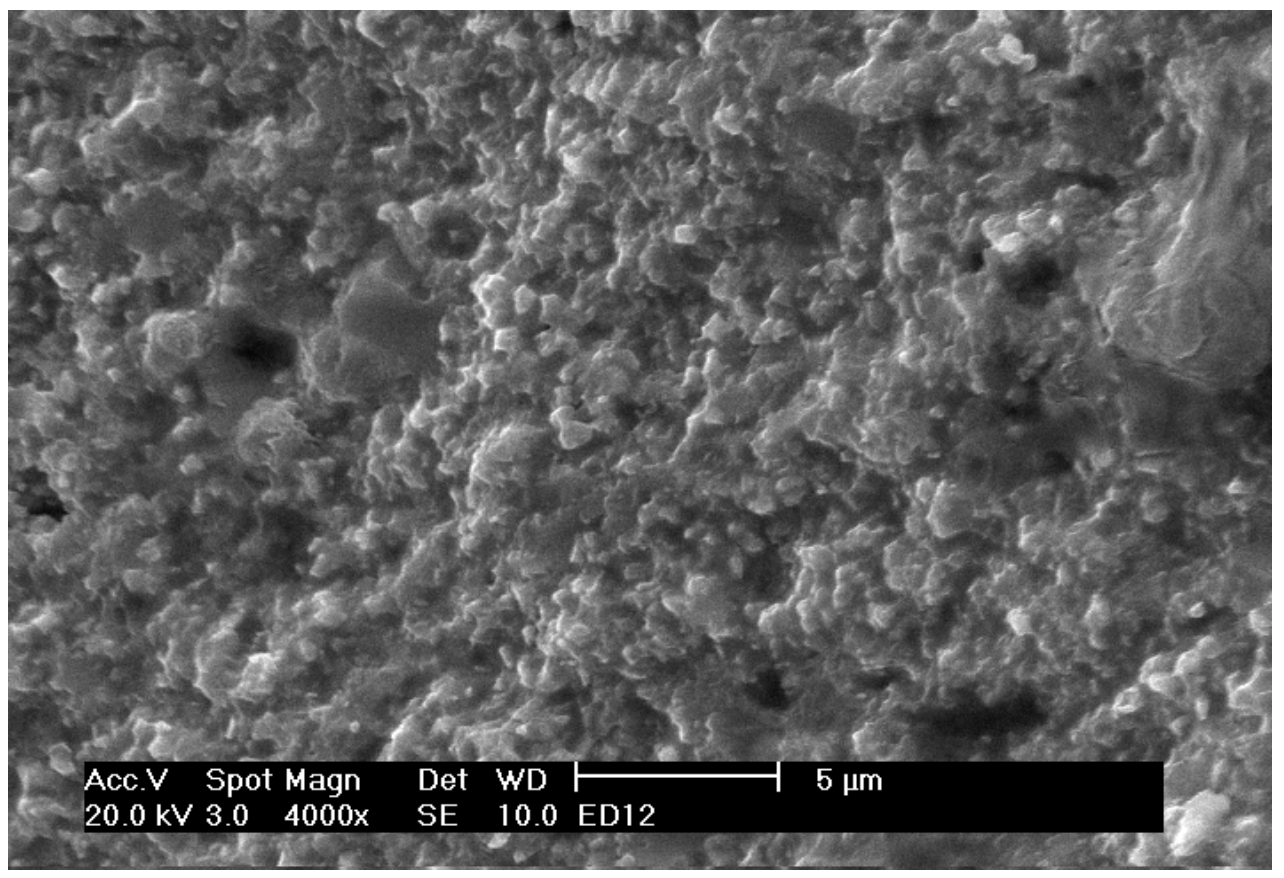

Figura 35 (cont): Micrografias obtidas por microscopia eletrônica de varredura das superfícies de fratura dos compósitos cerâmicos $\left(\mathrm{ZrO}_{2}: 8,6 \mathrm{~mol} \% \mathrm{MgO}\right)_{\mathrm{x}}\left(\mathrm{ZrO}_{2}: 3 \mathrm{~mol} \% \mathrm{Y}_{2} \mathrm{O}_{3}\right)_{1-\mathrm{x}}, \mathrm{x}=0,6 \mathrm{e}$ 0,8 . 


$$
\mathrm{x}=1
$$

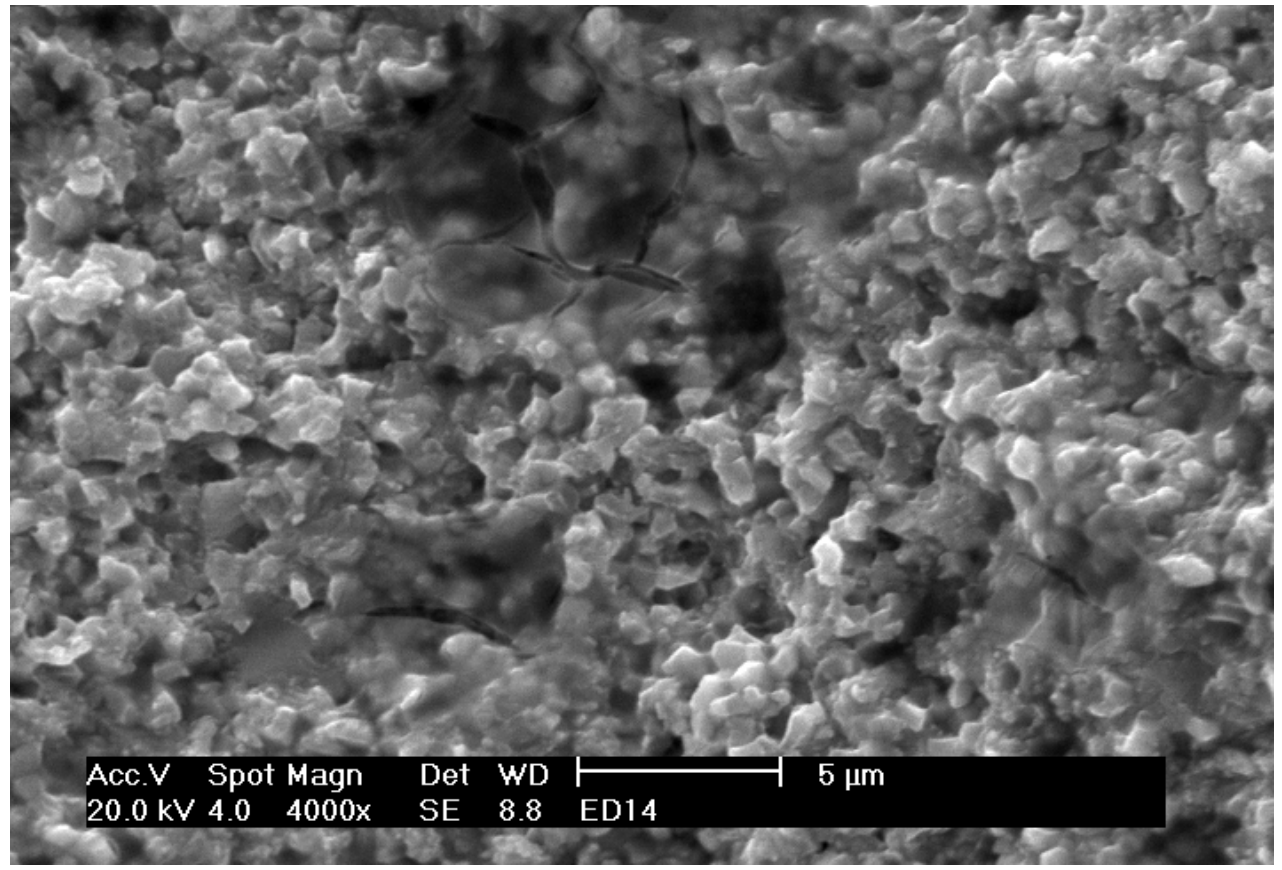

Figura 35 (cont): Micrografia obtida por microscopia eletrônica de varredura das superfícies de fratura dos compósitos cerâmicos $\left(\mathrm{ZrO}_{2}: 8,6 \mathrm{~mol} \% \mathrm{MgO}\right)_{\mathrm{x}}\left(\mathrm{ZrO}_{2}: 3 \mathrm{~mol} \% \mathrm{Y}_{2} \mathrm{O}_{3}\right)_{1-\mathrm{x}}, \mathrm{x}=1$.

\subsubsection{Espectroscopia de impedância}

Os diagramas de impedância das células eletroquímicas $\left(\mathrm{Ag} /\left(\mathrm{ZrO}_{2}: 8,6 \mathrm{~mol} \% \mathrm{MgO}\right)_{\mathrm{x}}\right.$ $\left.\left(\mathrm{ZrO}_{2}: 3 \mathrm{~mol} \% \mathrm{Y}_{2} \mathrm{O}_{3}\right)_{1-\mathrm{x}} / \mathrm{Ag}\right)$ medidos em aproximadamente $430{ }^{\circ} \mathrm{C}$ são mostrados na Figura 36.

Inicialmente, observa-se que a adição da zircônia:ítria na matriz de zircônia:magnésia modifica tanto o semicírculo de baixas freqüências (BF), relacionado á resistividade devida aos efeitos do bloqueio dos portadores de carga nos contornos de grão (ou resistividade intergranular), quanto o de altas frequiências (AF), relacionado às propriedades intragranulares, além de diminuir a resistividade total dos compósitos cerâmicos. Este é um resultado esperado, pois um dos objetivos propostos neste trabalho é o de melhorar a condutividade elétrica da matriz zircônia:magnésia pela adição da zircônia:ítria e, consequentemente melhorar a resposta elétrica (força eletromotriz - fem) gerada no sensor de oxigênio constituído pelo compósito cerâmico.

Os diagramas de impedância das amostras com concentração relativa até $\mathrm{x}=0,5$ mostram dois semicírculos bem definidos: um em altas freqüências, relacionado às propriedades 
intragranulares, e um em baixas frequiências, relacionado às propriedades intergranulares. Para concentrações acima de $\mathrm{x}=0,5$ há uma variação na forma dos diagramas de impedância: uma diminuição no semicírculo de alta freqüência e uma crescente superposição entre os semicírculos de baixa e alta frequiência.

A fase monoclínica pode ser considerada uma fase isolante em comparação com as fases cúbica e tetragonal e sua presença em eletrólitos sólidos à base de zircônia promove um aumento no bloqueio dos íons oxigênio, aumentando a resistividade elétrica ${ }^{[13]}$. Sua contribuição no diagrama de espectroscopia de impedância resulta em um semicírculo deformado devido à superposição de sua contribuição (um semicírculo) com os semicírculos devidos às contribuições intragranular e intergranular ${ }^{[13]}$. Assim, os diagramas de impedância de eletrólitos sólidos cerâmicos à base de zircônia estabilizada com magnésia que contém a fase monoclínica são complexos porque, além dos semicírculos devidos às contribuições intergranular e intragranular, tem-se à contribuição resistiva da fase monoclínica (fase bloqueante) ${ }^{[13,59]}$.

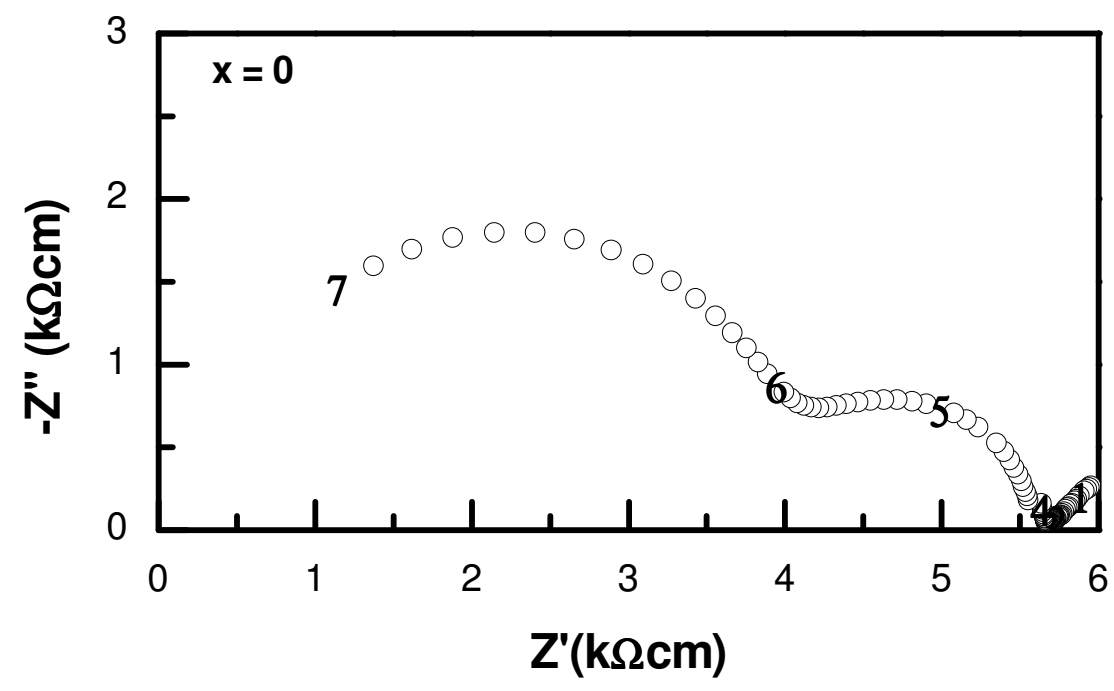

Figura 36: Diagrama de impedância de $\left(\mathrm{ZrO}_{2}: 8,6 \mathrm{~mol} \% \mathrm{MgO}\right)_{\mathrm{x}}\left(\mathrm{ZrO}_{2}: 3 \mathrm{~mol} \% \mathrm{Y}_{2} \mathrm{O}_{3}\right)_{1-\mathrm{x}}, \mathrm{x}=0$ medido a aproximadamente $430{ }^{\circ} \mathrm{C}$. 

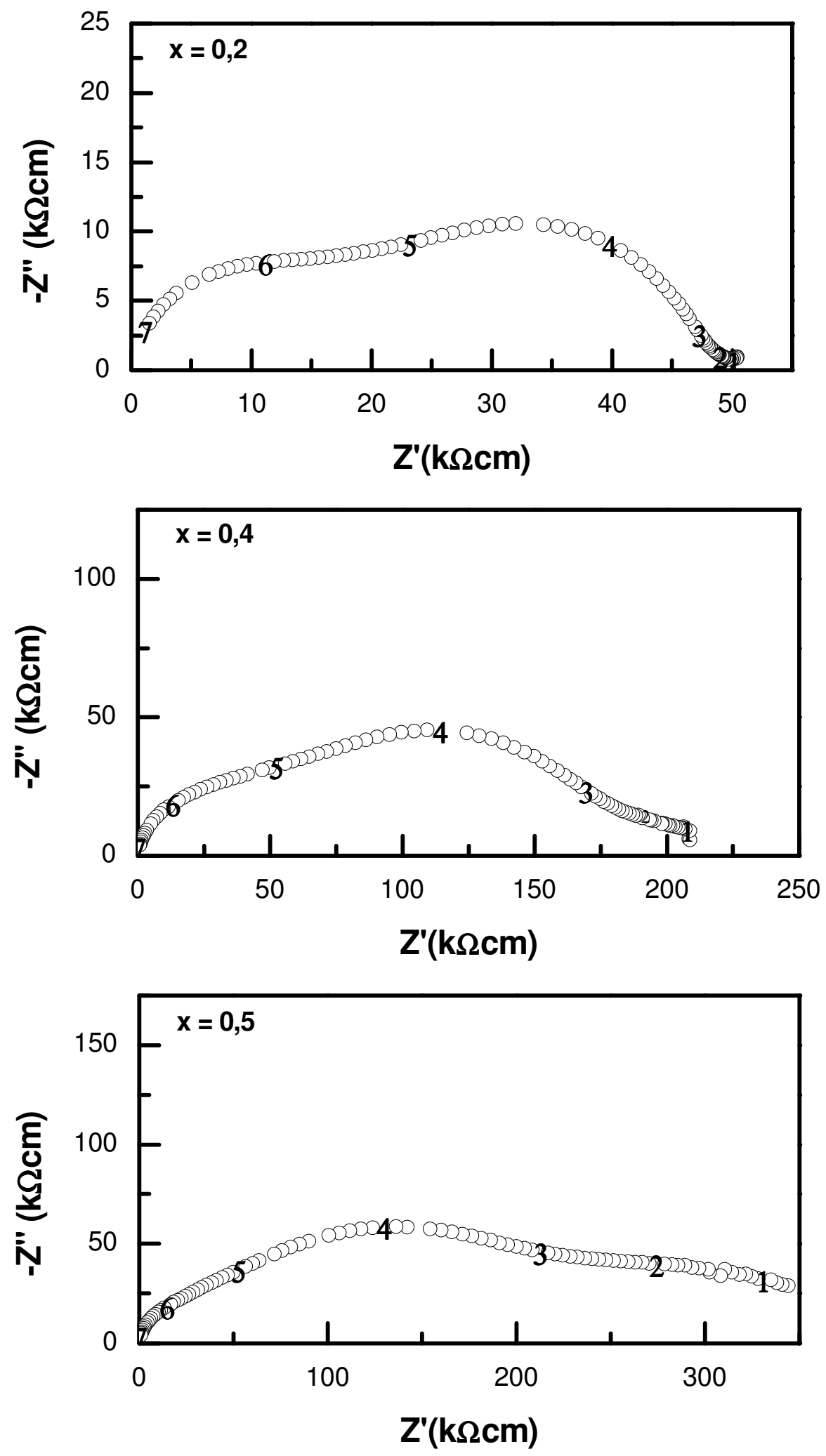

Figura 36 (cont): Diagramas de impedância de $\left(\mathrm{ZrO}_{2}: 8,6 \mathrm{~mol} \% \mathrm{MgO}\right)_{\mathrm{x}}\left(\mathrm{ZrO}_{2}: 3 \mathrm{~mol} \% \mathrm{Y}_{2} \mathrm{O}_{3}\right)_{1-\mathrm{x}}$, $\mathrm{x}=0,2,0,4 \mathrm{e} 0,5$, medidos a aproximadamente $430^{\circ} \mathrm{C}$. 

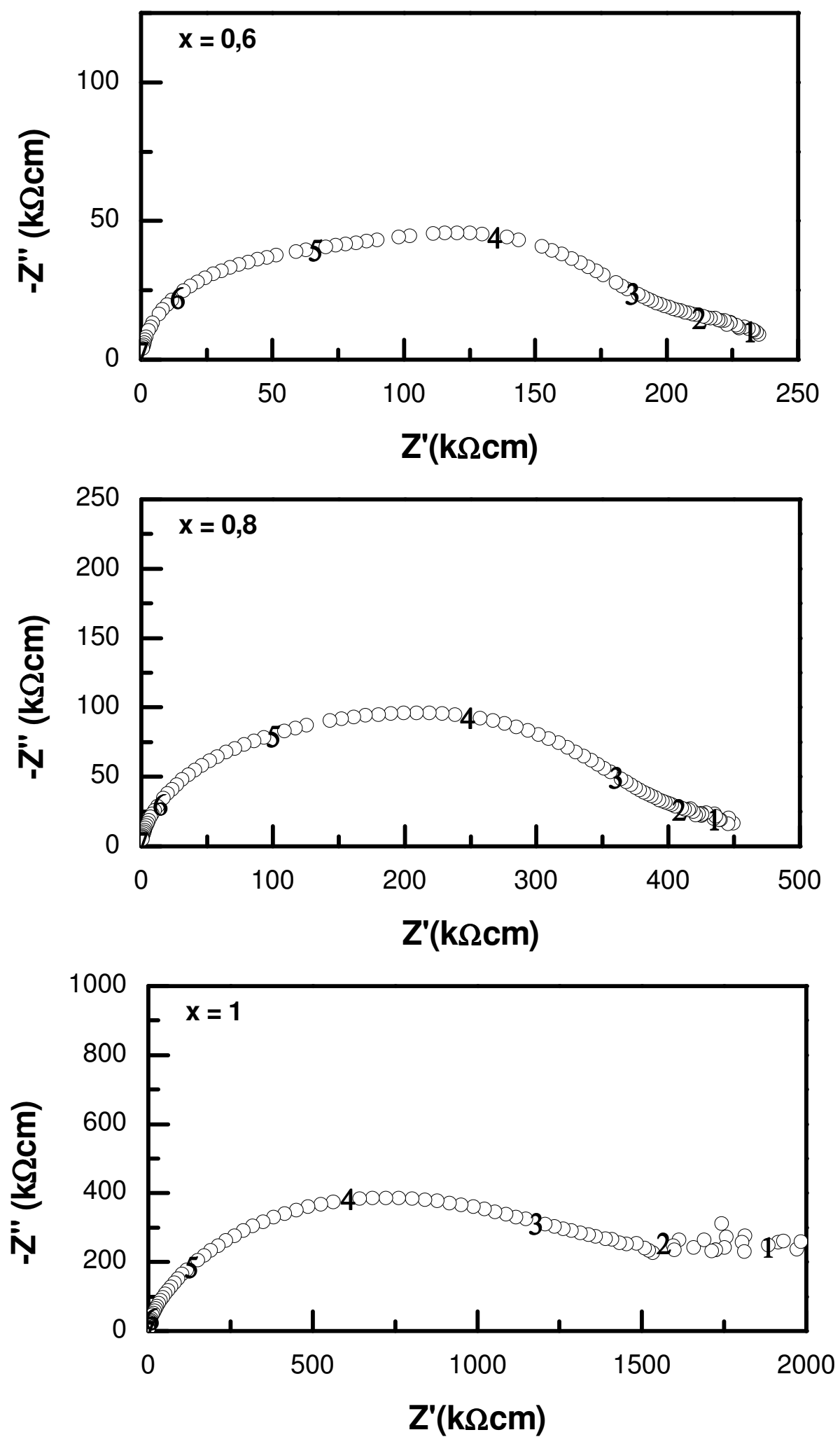

Figura 36 (cont): Diagramas de impedância de $\left(\mathrm{ZrO}_{2}: 8,6 \mathrm{~mol} \% \mathrm{MgO}\right)_{\mathrm{x}}\left(\mathrm{ZrO}_{2}: 3 \mathrm{~mol} \% \mathrm{Y}_{2} \mathrm{O}_{3}\right)_{1-\mathrm{x}}$, $\mathrm{x}=0,6,0,8$ e 1 , medidos a aproximadamente $430{ }^{\circ} \mathrm{C}$. 
Para uma melhor visualização do efeito da adição da zircônia:ítria à matriz de zircônia:magnésia, os diagramas de impedância das composições $\mathrm{x}=0,2,0,5,0,8$ e 1 são apresentados em um único gráfico (Figura 37). A adição da zircônia:ítria promove a diminuição da resistividade total dos compósitos cerâmicos.

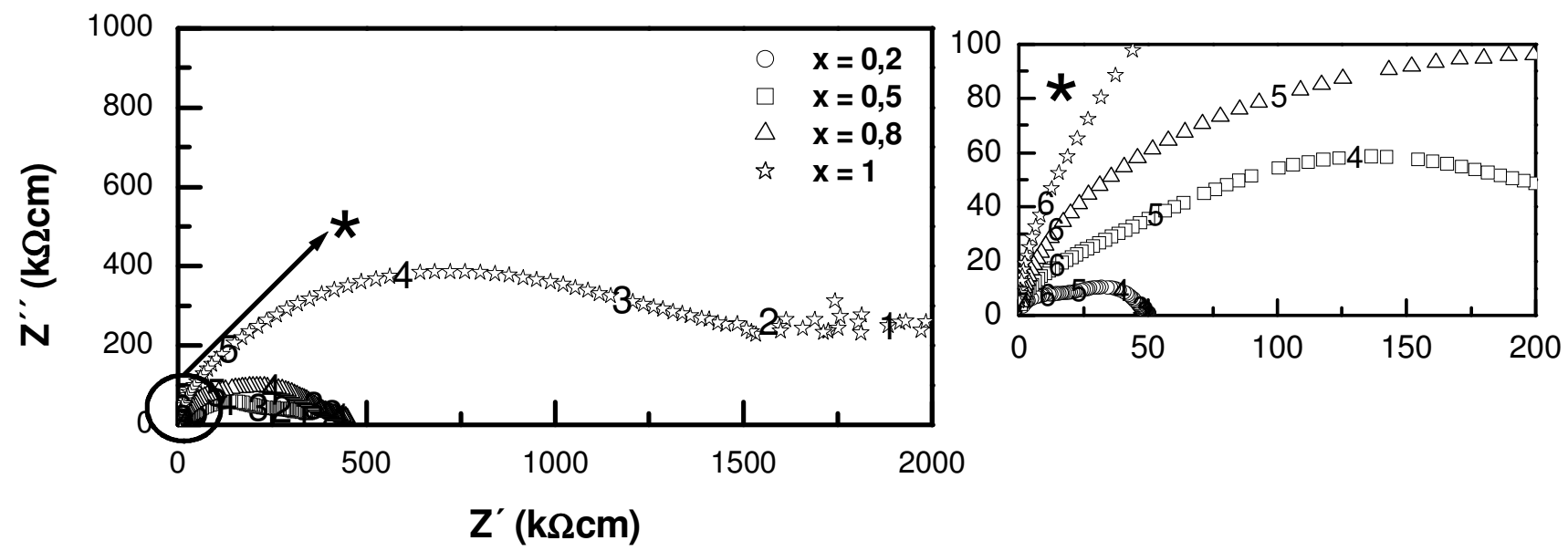

Figura 37: Diagramas de impedância de $\left(\mathrm{ZrO}_{2}: 8,6 \mathrm{~mol} \% \mathrm{MgO}\right)_{\mathrm{x}}\left(\mathrm{ZrO}_{2}: 3 \mathrm{~mol} \% \mathrm{Y}_{2} \mathrm{O}_{3}\right)_{1-\mathrm{x}}, \mathrm{x}=0,2$, $0,5,0,8$ e 1 , medidos a aproximadamente $430{ }^{\circ} \mathrm{C}$.

Os diagramas de impedância foram deconvoluídos (é feito o ajuste de um semicírculo a altas frequiências passando pela origem; é feita a subtração deste semicírculo do diagrama complexo; é ajustado um semicírculo no diagrama resultante da subtração. Os valores de resistência intragranular e intergranular são obtidos destes semicírculos ajustados), e a variação das componentes da resistividade elétrica intragranular $(\mathrm{AF})$, intergranular $(\mathrm{BF})$ e total $(\mathrm{AF}+\mathrm{BF})$ dos compósitos cerâmicos pode ser vista na Figura 38.

Os resultados mostram que quanto maior a concentração da zircônia:magnésia no compósito cerâmico, maior é a resistividade intragranular, intergranular e total. Esse efeito pode ser explicado pela degradação da condutividade elétrica, devido à presença da fase bloqueante (monoclínica) existente em amostras com alto teor de zircônia:magnésia ${ }^{[13]}$, como já mencionado anteriormente. 


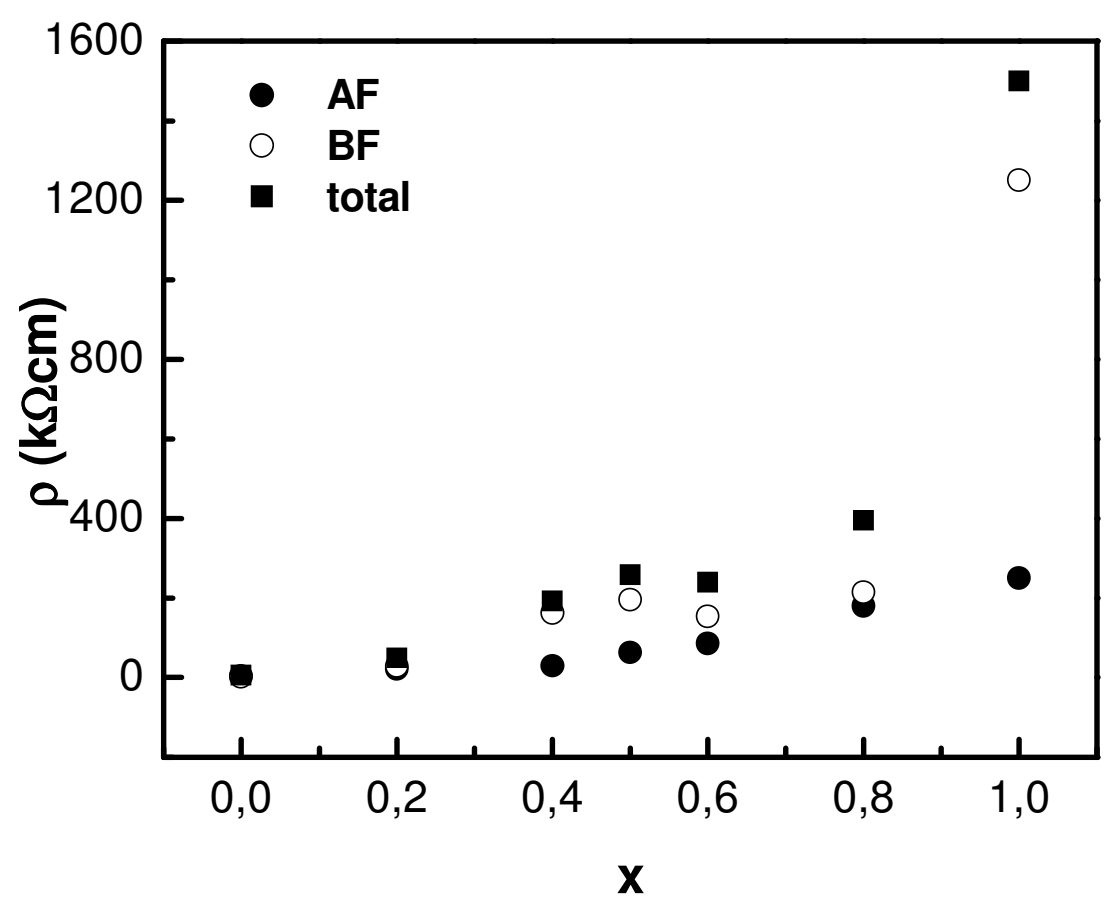

Figura 38: Resistividade elétrica intragranular (AF), intergranular (BF) e total de $\left(\mathrm{ZrO}_{2}: 8,6\right.$ $\mathrm{mol} \% \mathrm{MgO})_{\mathrm{x}}\left(\mathrm{ZrO}_{2}: 3 \mathrm{~mol} \% \mathrm{Y}_{2} \mathrm{O}_{3}\right)_{1-\mathrm{x}}$.

\subsection{Testes nos compósitos cerâmicos na forma de tubo}

Para simular o funcionamento do sensor de oxigênio utilizando como eletrólitos sólidos compósitos cerâmicos na forma de tubos e como eletrodo de referência $\mathrm{Cr}-\mathrm{Cr}_{2} \mathrm{O}_{3}$ (usado em sensores comerciais) e $\mathrm{Ni}-\mathrm{NiO}$ (resultados satisfatórios vem sendo reportados ${ }^{[60,61]}$ ), foram realizados vários testes e os resultados obtidos serão mostrados a seguir.

\section{Teste 1: Comportamento da força eletromotriz com a temperatura}

O primeiro teste realizado foi o da estabilização da força eletromotriz (E) em função da temperatura. Para essa medida foi utilizado o compósito $\left(\mathrm{ZrO}_{2}: 8,6 \mathrm{~mol} \% \mathrm{MgO}\right)_{0,5}\left(\mathrm{ZrO}_{2}: 3\right.$ mol\% $\left.\mathrm{Y}_{2} \mathrm{O}_{3}\right)_{0,5}$, tendo ar como eletrodo de referência. $\mathrm{O}$ estudo foi feito na faixa $500{ }^{\circ} \mathrm{C}$ $1000^{\circ} \mathrm{C}$, Figura 39 .

Na faixa de $900{ }^{\circ} \mathrm{C}-1000{ }^{\circ} \mathrm{C}$ a fem se mantém constante e próxima de zero, mostrando que a diferença da pressão parcial de oxigênio entre a superfície externa e interna da célula 
ar/Pt/compósito cerâmico/Pt/ar é nula. Com base neste resultado, foi escolhida a temperatura de $1000{ }^{\circ} \mathrm{C}$ para as medidas elétricas (fem x tempo) dos compósitos sob atmosfera de argônio. Esta atmosfera foi escolhida por conter baixo teor de oxigênio $(<1 \mathrm{ppm})$, que já daria uma indicação da capacidade sensorial do compósito cerâmico.

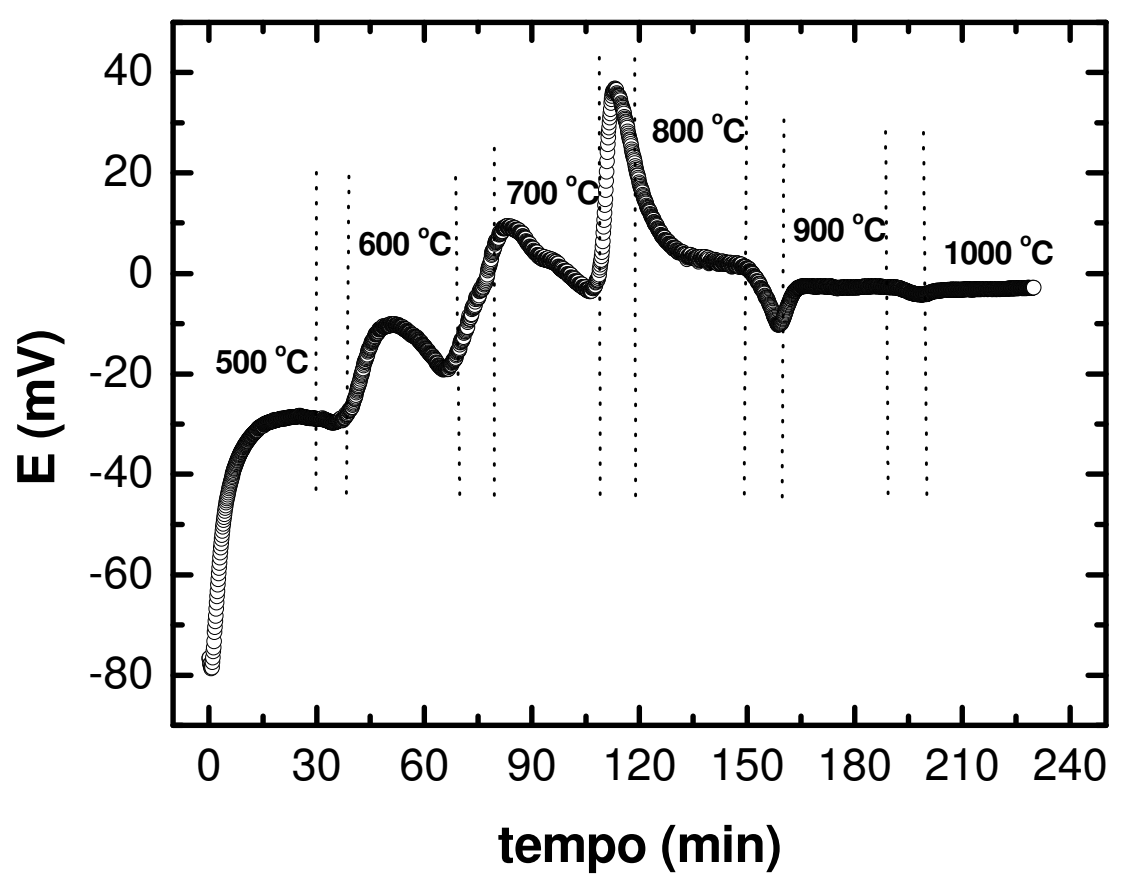

Figura 39: Dependência da fem com a temperatura do compósito cerâmico $\left(\mathrm{ZrO}_{2}\right.$ : 8,6 mol\% $\mathrm{MgO})_{0,5}\left(\mathrm{ZrO}_{2}: 3 \text { mol\% } \mathrm{Y}_{2} \mathrm{O}_{3}\right)_{0,5}$; eletrodo de referência: ar.

\section{Teste 2: Tempo de resposta}

A partir da análise do comportamento térmico por dilatometria (composições com menor variação volumétrica), foram escolhidos para a medida do tempo de resposta os compósitos $\left(\mathrm{ZrO}_{2}: 8 \mathrm{~mol} \% \mathrm{MgO}\right)_{\mathrm{x}}\left(\mathrm{ZrO}_{2}: 3 \mathrm{~mol} \% \mathrm{Y}_{2} \mathrm{O}_{3}\right)_{1-\mathrm{x}}, \mathrm{x}=0,2$ e 0,5 , e como eletrodo de referência uma mistura Ni-NiO.

Os resultados obtidos para os compósitos cerâmicos de composição $\mathrm{x}=0,2$ e 0,5 podem ser vistos nas Figuras 40 e 41, assim como a avaliação do tempo de resposta.

Os compósitos cerâmicos apresentam comportamento semelhante, alta variação e boa reprodutibilidade do sinal elétrico. Quando o gás é pulsado, o módulo da fem é $19 \mathrm{mV}$ para a 
composição $\mathrm{x}=0,2$ e $18 \mathrm{mV}$ para $\mathrm{x}=0,5$, com o mesmo tempo de resposta de aproximadamente $40 \mathrm{~s}$ (tempo decorrido entre a variação do sinal elétrico no momento em que o gás é pulsado e da sua estabilização em atmosfera de argônio). Após a interrupção da passagem do gás, a fem volta ao seu valor original com tempo de recuperação (tempo decorrido para a estabilização do sinal elétrico após a interrupção do gás) de $130 \mathrm{~s}$ para a composição $\mathrm{x}=0,2$ e de $100 \mathrm{~s}$ para $\mathrm{x}=0,5$, mostrando assim que a medida da resposta elétrica é reprodutiva.

O tempo de resposta a $1600{ }^{\circ} \mathrm{C}$ do eletrólito sólido de zircônia:magnésia na forma de tubo, tendo como eletrodo de referência às misturas $\mathrm{Cr}-\mathrm{Cr}_{2} \mathrm{O}_{3}{ }^{[39]}$ e $\mathrm{Mo}-\mathrm{MoO}_{2}{ }^{[25]}$, é de aproximadamente 6-10s e 6s, respectivamente. O tempo de resposta obtido neste trabalho deverá ser menor que $40 \mathrm{~s}$, com o aumento da temperatura de funcionamento do sensor de oxigênio.

Como os compósitos cerâmicos com $\mathrm{x}=0,2$ e 0,5 apresentaram comportamento elétrico semelhante, foram escolhidos para o estudo do comportamento elétrico em função da pressão parcial de oxigênio, o compósito cerâmico de composição $\mathrm{x}=0,5$ e o eletrólito sólido com a mesma composição do encontrado em sensores comerciais $(\mathrm{x}=1)$, tendo como eletrodo de referência uma mistura $\mathrm{Cr}-\mathrm{Cr}_{2} \mathrm{O}_{3}$.
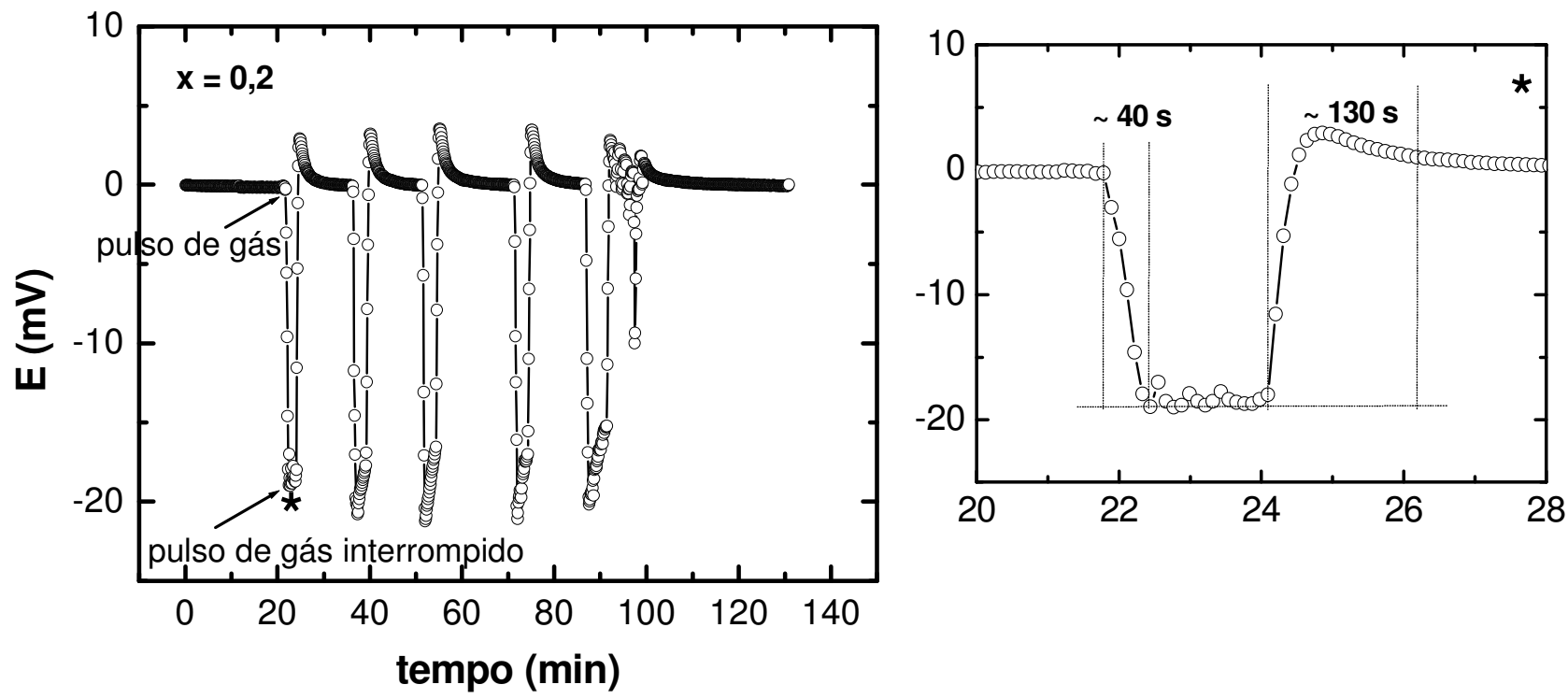

Figura 40: Dependência da fem com o tempo de resposta para o compósito cerâmico $\left(\mathrm{ZrO}_{2}: 8,6\right.$ $\operatorname{mol} \% \mathrm{MgO})_{0,2}\left(\mathrm{ZrO}_{2}: 3 \mathrm{~mol} \% \mathrm{Y}_{2} \mathrm{O}_{3}\right)_{0,8}$ sob pulsos de argônio a $1000{ }^{\circ} \mathrm{C}$. 


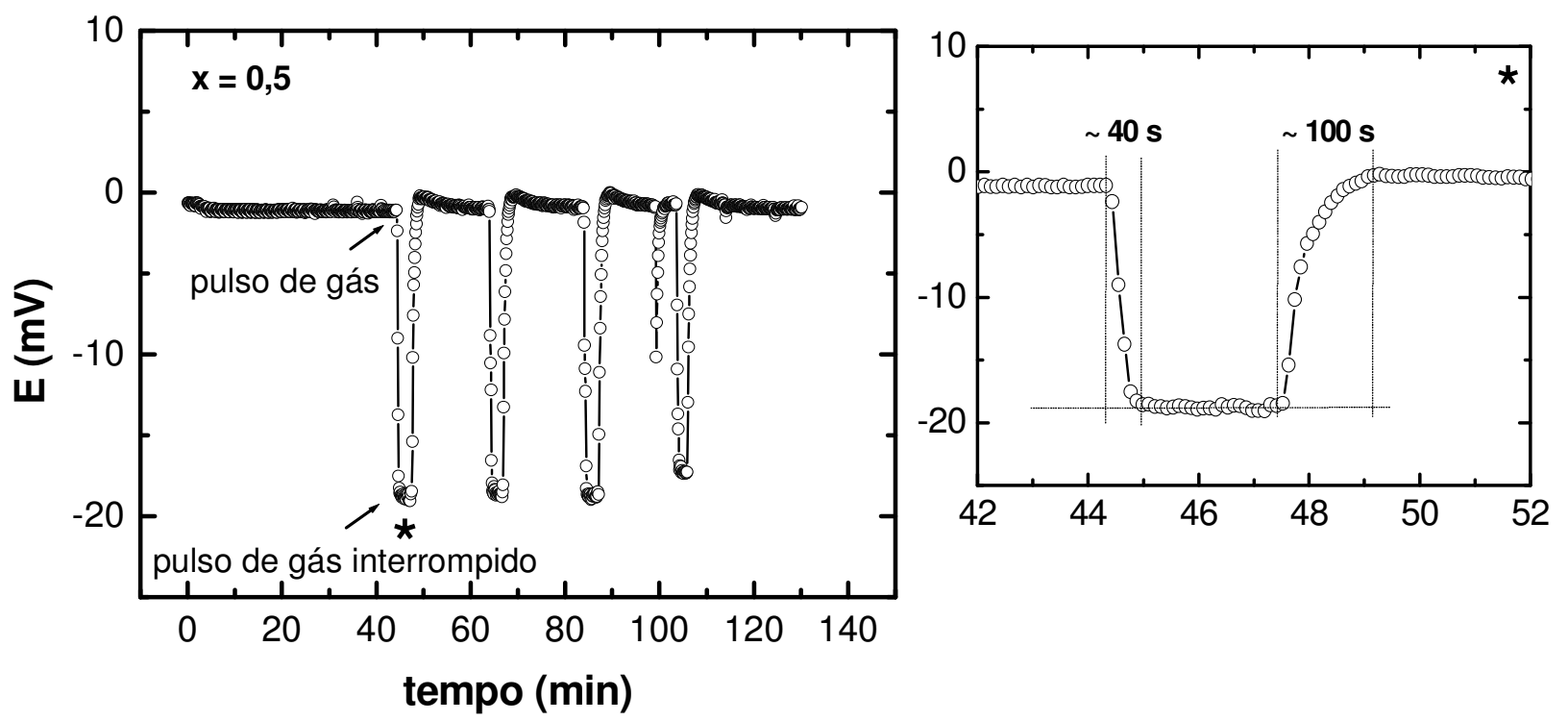

Figura 41: Dependência da fem com o tempo de resposta para o compósito cerâmico $\left(\mathrm{ZrO}_{2}: 8,6\right.$ $\mathrm{mol} \% \mathrm{MgO})_{0,5}\left(\mathrm{ZrO}_{2}: 3 \mathrm{~mol} \% \mathrm{Y}_{2} \mathrm{O}_{3}\right)_{0,5}$ sob pulsos de argônio a $1000{ }^{\circ} \mathrm{C}$.

Teste 3: Comportamento da força eletromotriz e do tempo de resposta com a pressão parcial de oxigênio

Este teste tem como objetivo avaliar o comportamento elétrico do compósito cerâmico em função do teor de oxigênio, comparando os resultados com os do eletrólito sólido com a mesma composição do encontrado em sensores comerciais.

Os resultados obtidos para $\left(\mathrm{ZrO}_{2}: 8,6 \mathrm{~mol} \% \mathrm{MgO}\right)_{\mathrm{x}}\left(\mathrm{ZrO}_{2}: 3 \mathrm{~mol} \% \mathrm{Y}_{2} \mathrm{O}_{3}\right)_{1-\mathrm{x}}, \mathrm{x}=0,5$ e 1 , são mostrados na Figura 42. Os dois sensores apresentam comportamento semelhante; respondem às diferentes quantidades de oxigênio introduzido, com tempo de resposta de $30 \mathrm{~s}$.

Este é o primeiro resultado importante deste trabalho, do ponto de vista tecnológico. Mostra ser possível construir sensores de oxigênio com compósitos à base de zircônia, que apresentam resposta elétrica reprodutiva a $1000{ }^{\circ} \mathrm{C}$. 


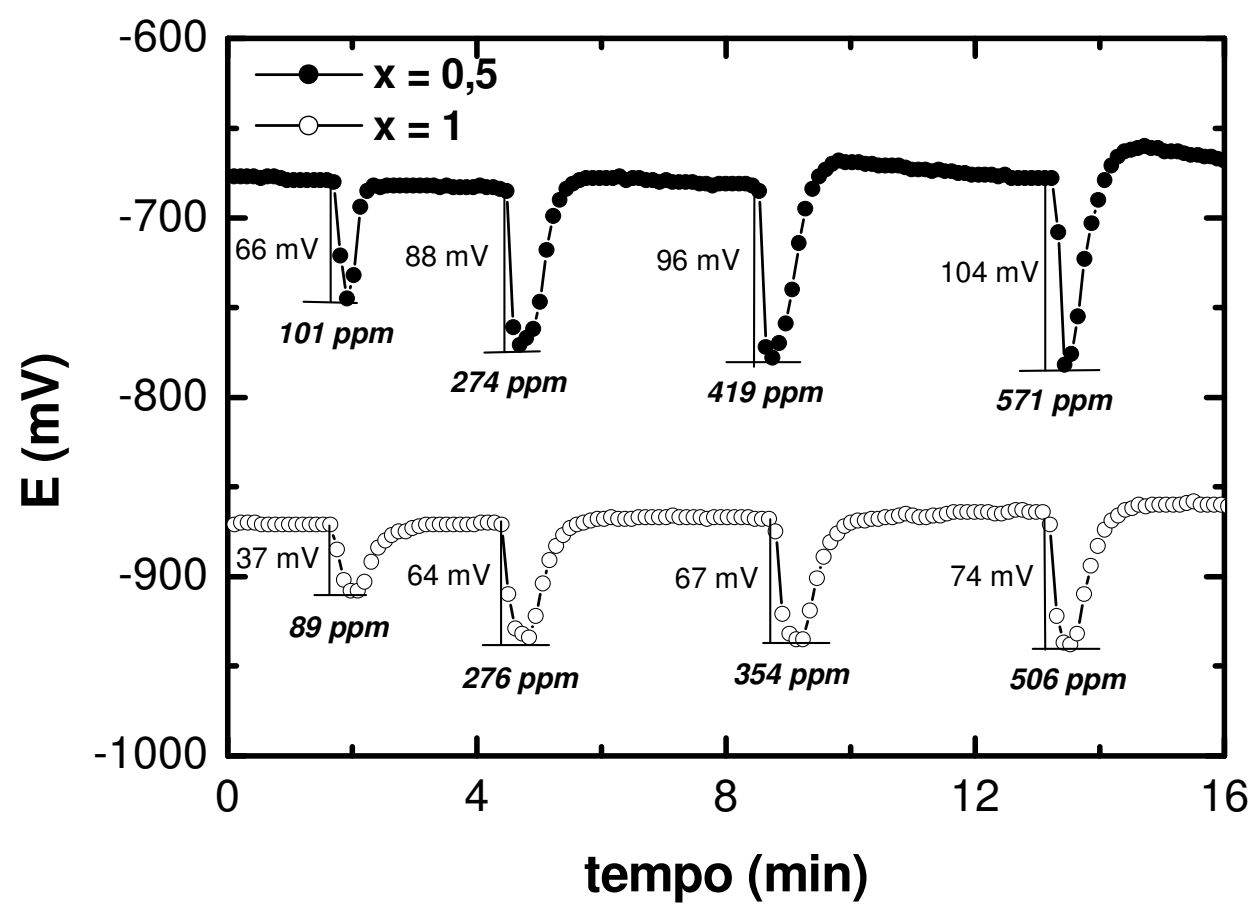

Figura 42: Comportamento da fem de $\left(\mathrm{ZrO}_{2}: 8,6 \mathrm{~mol} \% \mathrm{MgO}\right)_{\mathrm{x}}\left(\mathrm{ZrO}_{2}: 3 \mathrm{~mol} \% \mathrm{Y}_{2} \mathrm{O}_{3}\right)_{1-\mathrm{x}}, \mathrm{x}=0,5 \mathrm{e}$ 1 em função da $\mathrm{pO}_{2}$.

A Figura 43 mostra a dependência da alteração da fem com os diferentes teores de oxigênio (80 - 600 ppm) introduzidos. A dependência com a quantidade de oxigênio, está de acordo com a lei de Nernst. Os valores da alteração da fem obtidos para o compósito cerâmico $(\mathrm{x}=0,5)$ são maiores que os obtidos para a composição comercial $(\mathrm{x}=1)$. Este comportamento se deve ao aumento da condutividade elétrica com a adição de zircônia:ítria à matriz de zircônia:magnésia, como foi mostrado anteriormente na caracterização elétrica por espectroscopia de impedância (Figura 36).

Este resultado mostra o bom funcionamento do sensor de oxigênio construído com compósito cerâmico $\left(\mathrm{ZrO}_{2}: 8,6 \mathrm{~mol} \% \mathrm{MgO}\right)_{0,5}\left(\mathrm{ZrO}_{2}: 3 \mathrm{~mol} \% \mathrm{Y}_{2} \mathrm{O}_{3}\right)_{0,5}$. 


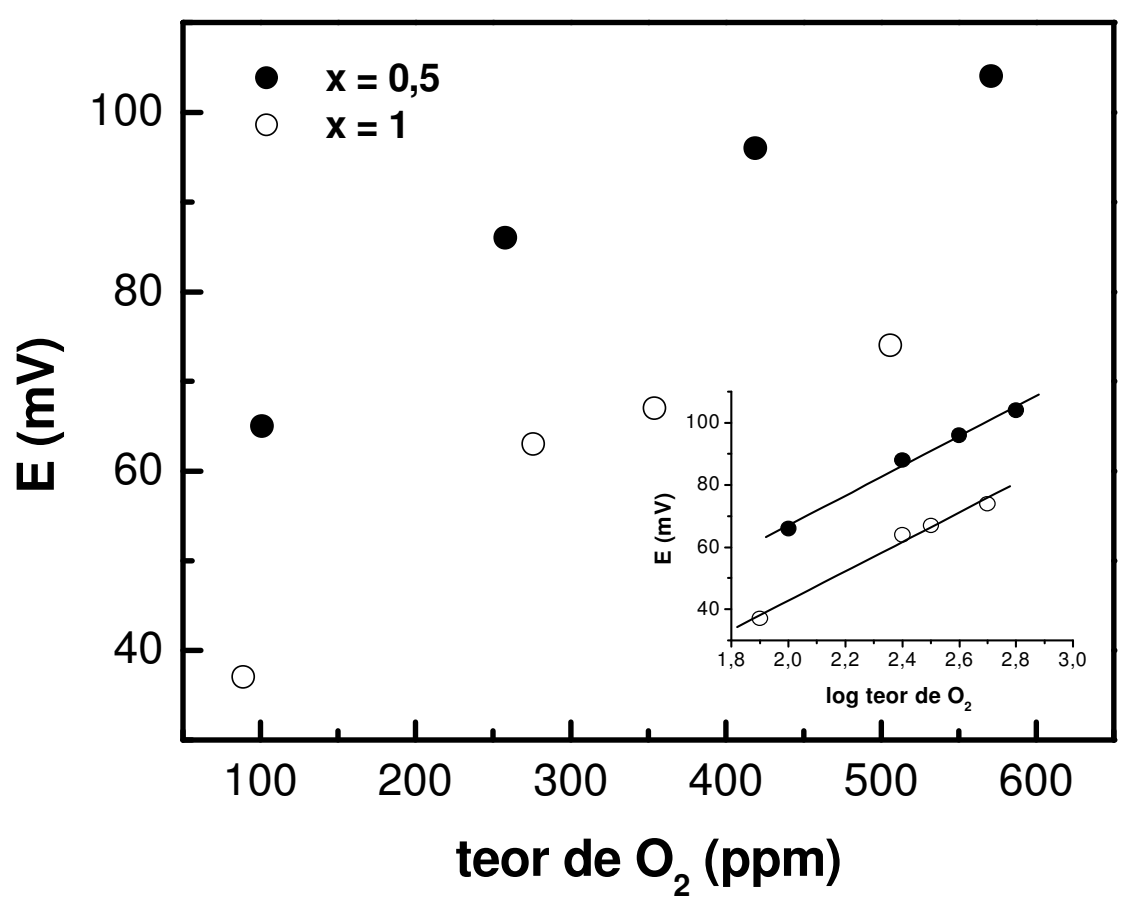

Figura 43: Dependência da fem com a $\mathrm{pO}_{2}$ de $\left(\mathrm{ZrO}_{2}: 8,6 \mathrm{~mol} \% \mathrm{MgO}\right)_{\mathrm{x}}\left(\mathrm{ZrO}_{2}: 3 \mathrm{~mol} \% \mathrm{Y}_{2} \mathrm{O}_{3}\right)_{1-\mathrm{x}}$, $\mathrm{x}=0,5$ e 1. Figura inserida: lei de de Nernst.

A partir da equação (11) da Introdução, são calculados os valores de E em função do teor de oxigênio para cerâmicas à base de zircônia. A pressão parcial de oxigênio da referência $\mathrm{Cr}-\mathrm{Cr}_{2} \mathrm{O}_{3}$ a $1000{ }^{\circ} \mathrm{C}$ é $8,2 \times 10^{-23}$ atm, este valor foi obtido pela equação (16) ${ }^{[62]}$ :

$$
\mathrm{pO}_{2}\left(\mathrm{Cr}+\mathrm{Cr}_{2} \mathrm{O}_{3}\right)=\exp \left(20,357-\frac{90661}{\mathrm{~T}}\right)
$$

Os valores de E obtidos experimentalmente são mostrados na Figura 44 em função dos valores calculados a partir da equação (11).

A dependência linear está de acordo com a Lei de Nernst. Os valores experimentais são menores que os calculados. A diferença entre os valores calculados e experimentais $(\sim 0,4 \mathrm{~V})$ é explicada devido ao efeito da montagem experimental (terminais elétricos, eletrodos, cimento) e ao tempo de exposição de $30 \mathrm{~s}$, que pode não ter sido suficiente para o equilíbrio químico do sistema. Assim sendo, a equação de Nernst para esse sistema será: 


$$
\mathrm{E}_{\text {experimental }}=\mathrm{Eo}+\left(\frac{\mathrm{RT}}{4 \mathrm{~F}}\right) \ln \left(\frac{\mathrm{pO}_{2}{ }^{(1)}}{\mathrm{pO}_{2}{ }^{(2)}}\right)
$$

Eo: constante dependente dos efeitos da montagem experimental, neste trabalho $\sim 0,4 \mathrm{~V}$.

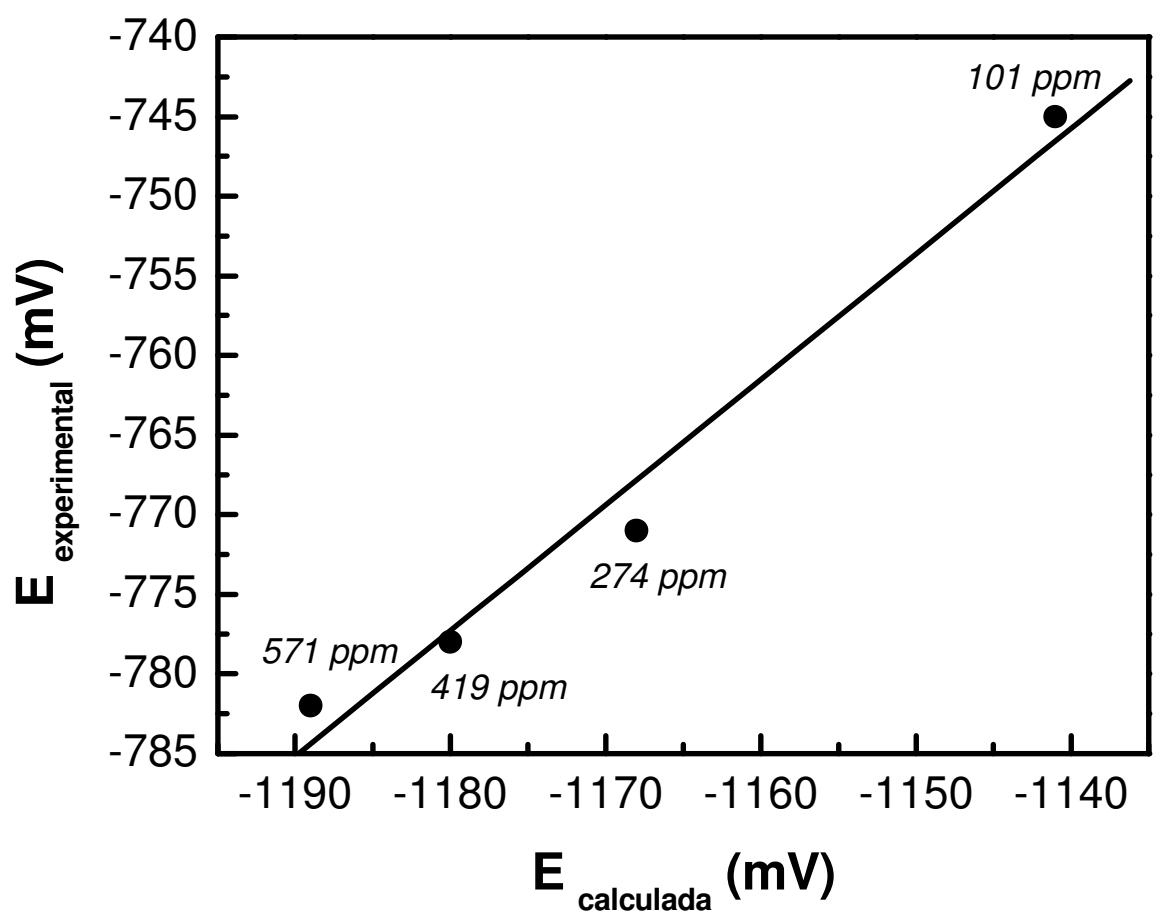

Figura 44: Dependência da fem medida com o calculado em sensores construídos com compósito cerâmico $\left(\mathrm{ZrO}_{2}: 8,6 \mathrm{~mol} \% \mathrm{MgO}\right)_{0,5}\left(\mathrm{ZrO}_{2}: 3 \mathrm{~mol} \% \mathrm{Y}_{2} \mathrm{O}_{3}\right)_{0,5}$.

\section{Teste 4: Comportamento da resistividade elétrica com a pressão parcial de oxigênio}

As medidas de condutividade elétrica em função da pressão parcial de oxigênio são muito importantes, pois os resultados podem definir as possíveis aplicações de materiais em dispositivos eletroquímicos. Estas medidas permitem estudar o regime de ionicidade de um condutor iônico, determinando a faixa de pressão parcial de oxigênio em que a condutividade iônica permanece constante, já que as condutividades eletrônica e iônica variam de maneira diferente com a temperatura e a composição da atmosfera em equilíbrio com o material.

Neste trabalho foi feito um estudo do comportamento da resistividade elétrica dos compósitos cerâmicos em função da pressão parcial de oxigênio. Os diagramas de impedância 
dos tubos cerâmicos medidos a $620^{\circ} \mathrm{C}$ em diferentes atmosferas de oxigênio (1 a 860 ppm), são mostrados na Figura 45.

Inicialmente todos os diagramas apresentam um semicírculo bem definido a altas freqüências relacionado às propriedades do sólido e um a baixas freqüências relacionado à resposta do eletrodo. A adição de zircônia:ítria na matriz de zircônia:magnésia modifica os semicírculos de altas freqüências relacionados às propriedades do material. Por outro lado, observa-se uma modificação (diminuição) na região de baixas frequiências. A resposta do eletrodo está associada à cinética da reação eletrodo/oxigênio $\left(1 / 2 \mathrm{O}_{2}+2 \mathrm{e}^{-} \leftrightarrow \mathrm{O}^{2-}\right)$ que depende da quantidade de gás $\mathrm{O}_{2}$ presente nas interfaces.
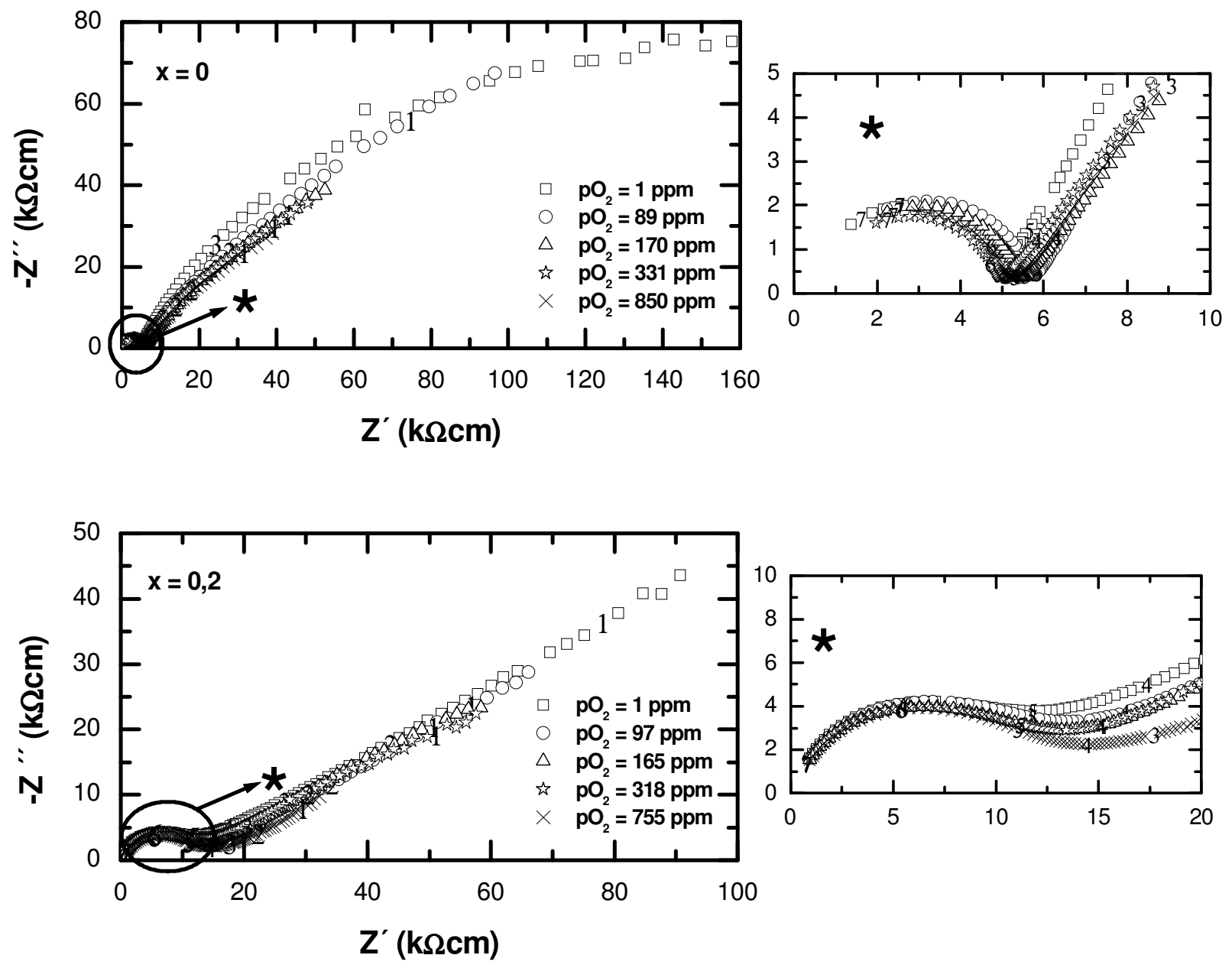

Figura 45: Diagramas de impedância dos compactos cerâmicos sinterizados, na forma de tubo, $\left(\mathrm{ZrO}_{2}: 8,6 \mathrm{~mol} \% \mathrm{MgO}\right)_{\mathrm{x}}\left(\mathrm{ZrO}_{2}: 3 \mathrm{~mol} \% \mathrm{Y}_{2} \mathrm{O}_{3}\right)_{1-\mathrm{x}}, \mathrm{x}=0$ e 0,2 medidos a $620{ }^{\circ} \mathrm{C}$ sob diferentes teores de oxigênio (1 a 860 ppm). 

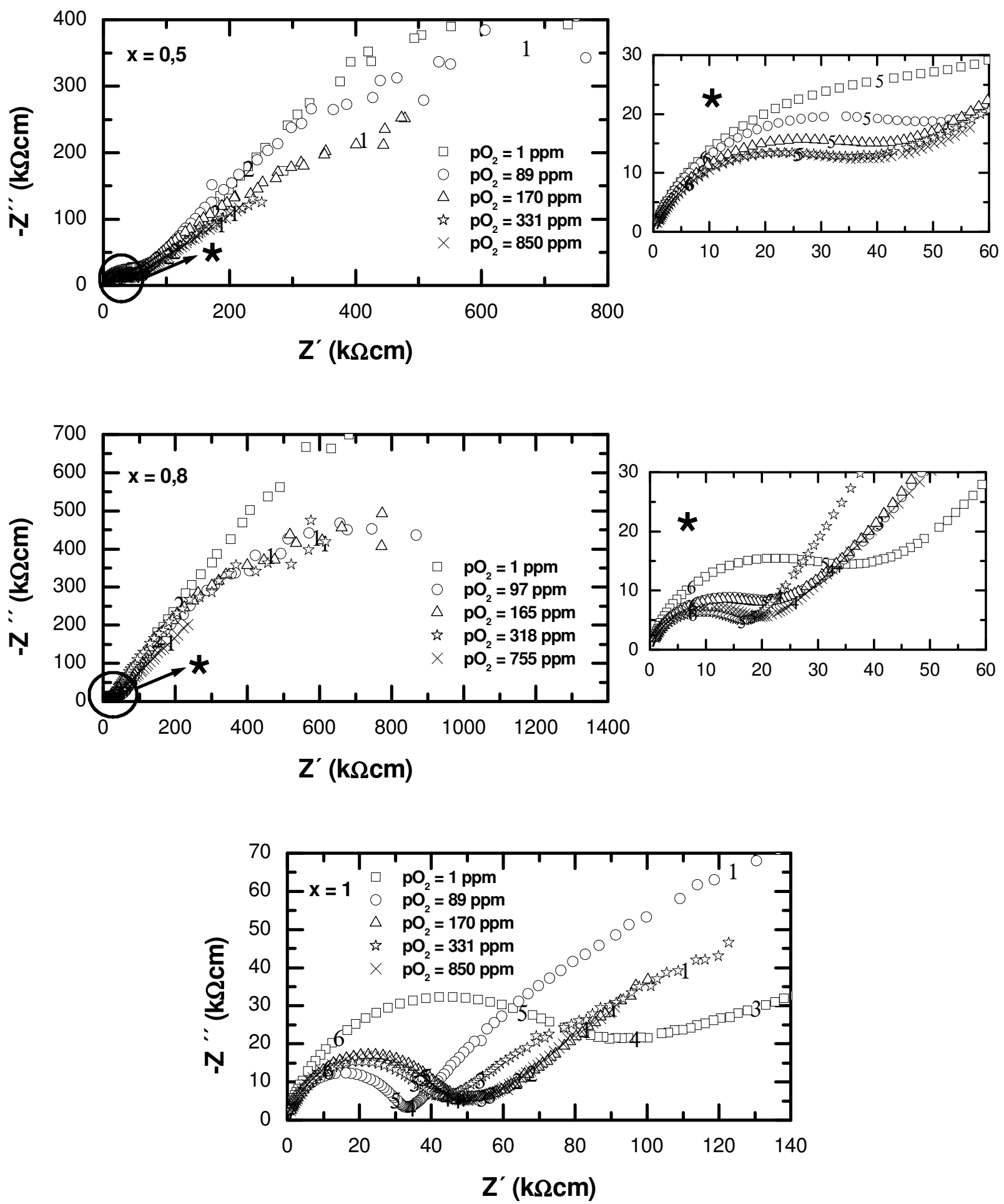

Figura 45 (cont): Diagramas de impedância dos compactos cerâmicos sinterizados, na forma de tubo, $\left(\mathrm{ZrO}_{2}: 8,6 \mathrm{~mol} \% \mathrm{MgO}\right)_{\mathrm{x}}\left(\mathrm{ZrO}_{2}: 3 \mathrm{~mol} \% \mathrm{Y}_{2} \mathrm{O}_{3}\right)_{1-\mathrm{x}}, \mathrm{x}=0,5,0,8$ e 1 , medidos a $620{ }^{\circ} \mathrm{C}$ sob diferentes teores de oxigênio ( 1 a 860 ppm). 
Uma análise detalhada dos diagramas de impedância (Figura 45) mostra que estes diagramas são mais facilmente deconvoluídos considerando um semicírculo a altas frequiências (material) e uma reta para baixas freqüências (resposta do eletrodo). Os valores obtidos da resistividade elétrica das amostras em função do teor de oxigênio são mostrados na Figura 46.

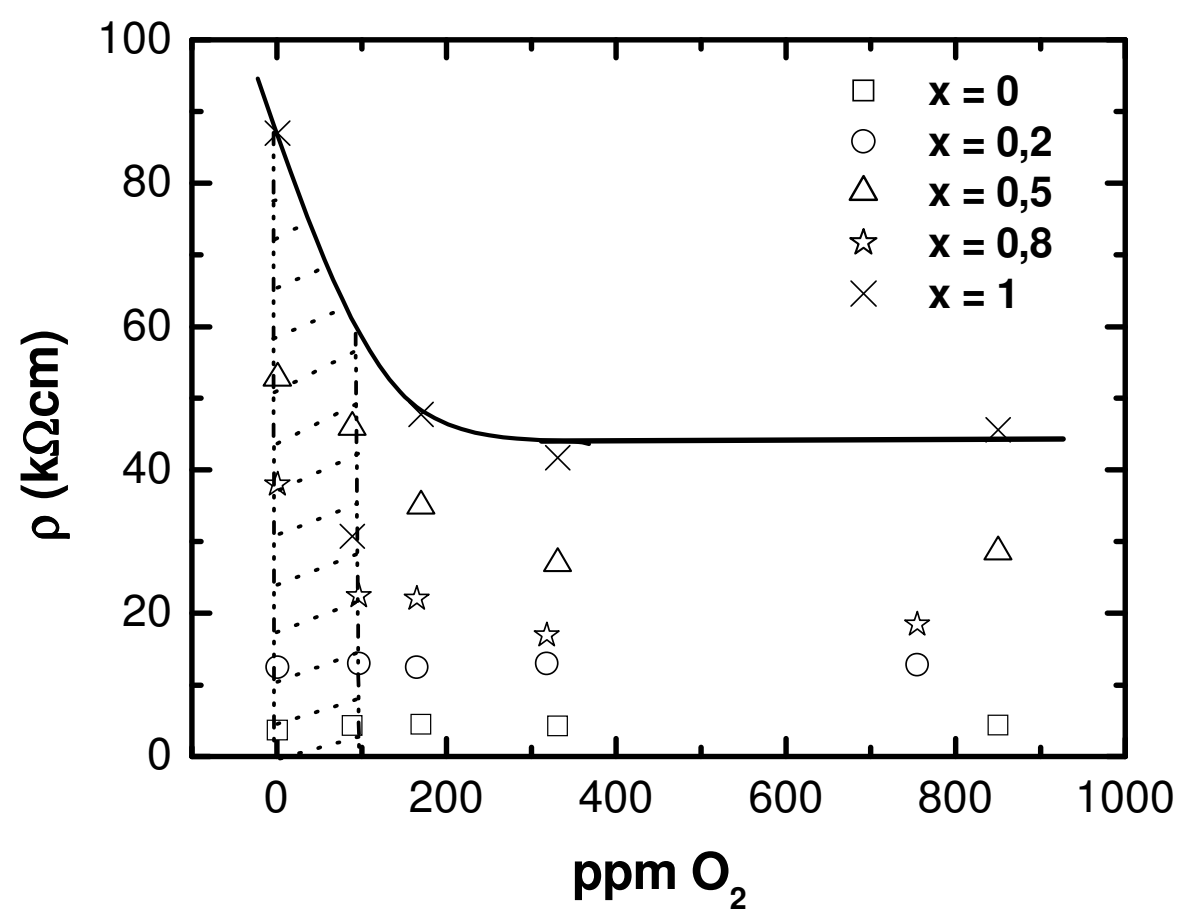

Figura 46: Valores da resistividade dos compósitos $\left(\mathrm{ZrO}_{2}: 8,6 \mathrm{~mol} \% \mathrm{MgO}\right)_{\mathrm{x}}\left(\mathrm{ZrO}_{2}: 3 \mathrm{~mol} \%\right.$ $\left.\mathrm{Y}_{2} \mathrm{O}_{3}\right)_{1-\mathrm{x}}, \mathrm{x}=0,0,2,0,5,0,8$ e 1, em função da pressão parcial de oxigênio.

A resistividade elétrica das amostras com $\mathrm{x}=0$ e 0,2 é independente do teor de oxigênio. Esta observação está de acordo com as propriedades de um condutor puramente iônico ${ }^{[48]}$. Nesta temperatura e nesta faixa de $\mathrm{pO}_{2}$, a resistividade elétrica depende somente da concentração de vacâncias de oxigênio, que se mantém constante sob diferentes teores de oxigênio. A resistividade elétrica para o compósito cerâmico $\mathrm{x}=0,8$ diminui até aproximadamente 97 ppm, se mantendo constante a partir deste valor. O compósito cerâmico com $x=0,5$ e a amostra de zircônia:magnésia apresentam o mesmo comportamento: a resistividade diminui até aproximadamente 330 ppm, mantendo-se constante a partir deste valor. Esse comportamento está 
relacionado à contribuição eletrônica na resistividade elétrica na zircônia:magnésia a baixas pressões parciais de oxigênio. O eletrólito sólido de zircônia:magnésia apresenta condutividade eletrônica tipo-n sob baixas pressões parciais de oxigênio, resultando na permeação química do oxigênio através do eletrólito sólido, causando polarização na interface eletrodo/eletrólito e diminuição da fem ${ }^{[24]}$.

A parte hachurada na Figura 46 mostra a região de baixas pressões parciais de oxigênio (1-97 ppm). A adição de $80 \%$ em peso de $\mathrm{ZrO}_{2}: 3$ mol\% $\mathrm{Y}_{2} \mathrm{O}_{3}(\mathrm{x}=0,2)$ promove uma melhora da resistividade elétrica total de $85 \%$ em 1 ppm até $78 \%$ em 97 ppm.

Este resultado mostra a possibilidade de usar o compósito cerâmico $\left(\mathrm{ZrO}_{2}:\right.$ 8,6 mol\% $\mathrm{MgO})_{0,2}\left(\mathrm{ZrO}_{2}: 3 \mathrm{~mol} \% \mathrm{Y}_{2} \mathrm{O}_{3}\right)_{0,8}$ como eletrólito sólido em sensores de oxigênio para aplicações que envolvam baixo teor de oxigênio (<50 ppm).

A partir deste resultado foi feito um estudo do comportamento da resistividade elétrica em baixo teor de oxigênio (3-60 ppm), do compósito $\left(\mathrm{ZrO}_{2}: 8,6 \mathrm{~mol} \% \mathrm{MgO}\right)_{0,2}\left(\mathrm{ZrO}_{2}: 3 \mathrm{~mol} \%\right.$ $\left.\mathrm{Y}_{2} \mathrm{O}_{3}\right)_{0,8}$, utilizando os eletrodos de referência $\mathrm{Cr}-\mathrm{Cr}_{2} \mathrm{O}_{3}$ e Ni-NiO. Os diagramas de impedância com $\mathrm{Cr}-\mathrm{Cr}_{2} \mathrm{O}_{3}$ e Ni-NiO são mostrados nas Figuras 47 e 48, respectivamente.

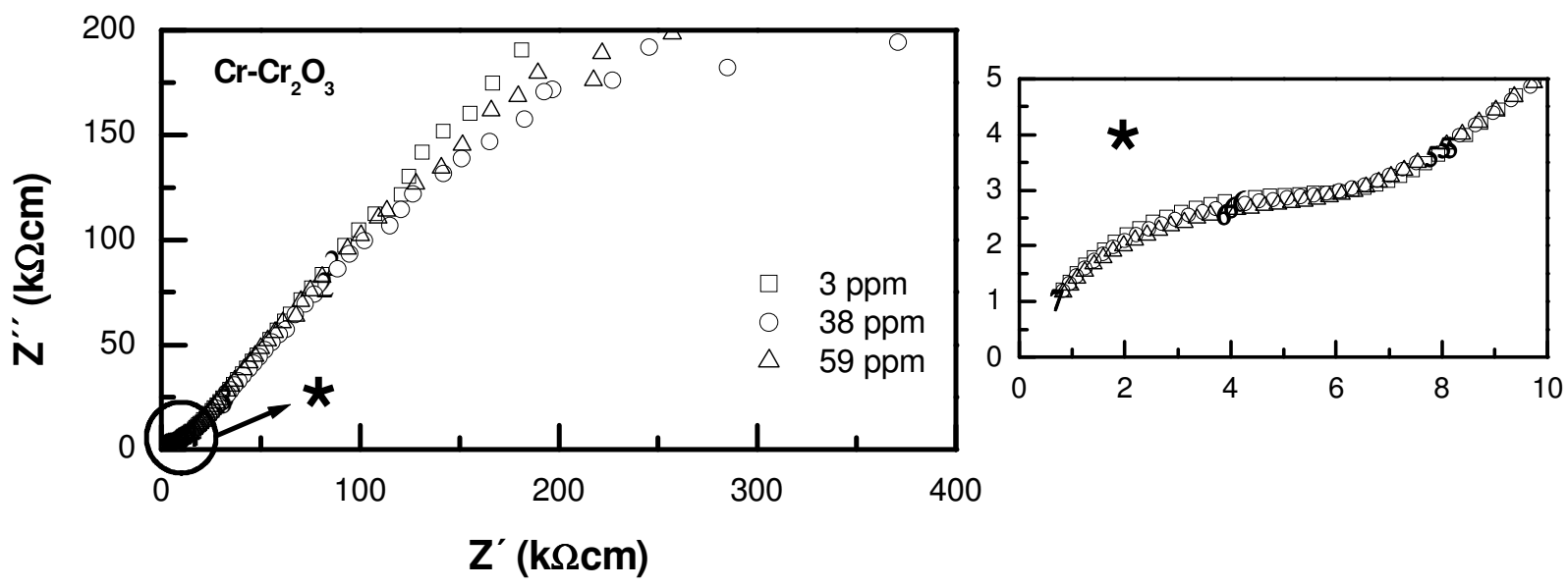

Figura 47: Diagramas de impedância dos compactos cerâmicos sinterizados, na forma de tubo, $\left(\mathrm{ZrO}_{2}: 8,6 \mathrm{~mol} \% \mathrm{MgO}\right)_{0,2}\left(\mathrm{ZrO}_{2}: 3 \mathrm{~mol} \% \mathrm{Y}_{2} \mathrm{O}_{3}\right)_{0,8}$, medidos a aproximadamente $640{ }^{\circ} \mathrm{C}$ sob diferentes teores de oxigênio ( 3 a 59 ppm); eletrodo de referência $\mathrm{Cr}-\mathrm{Cr}_{2} \mathrm{O}_{3}$. 


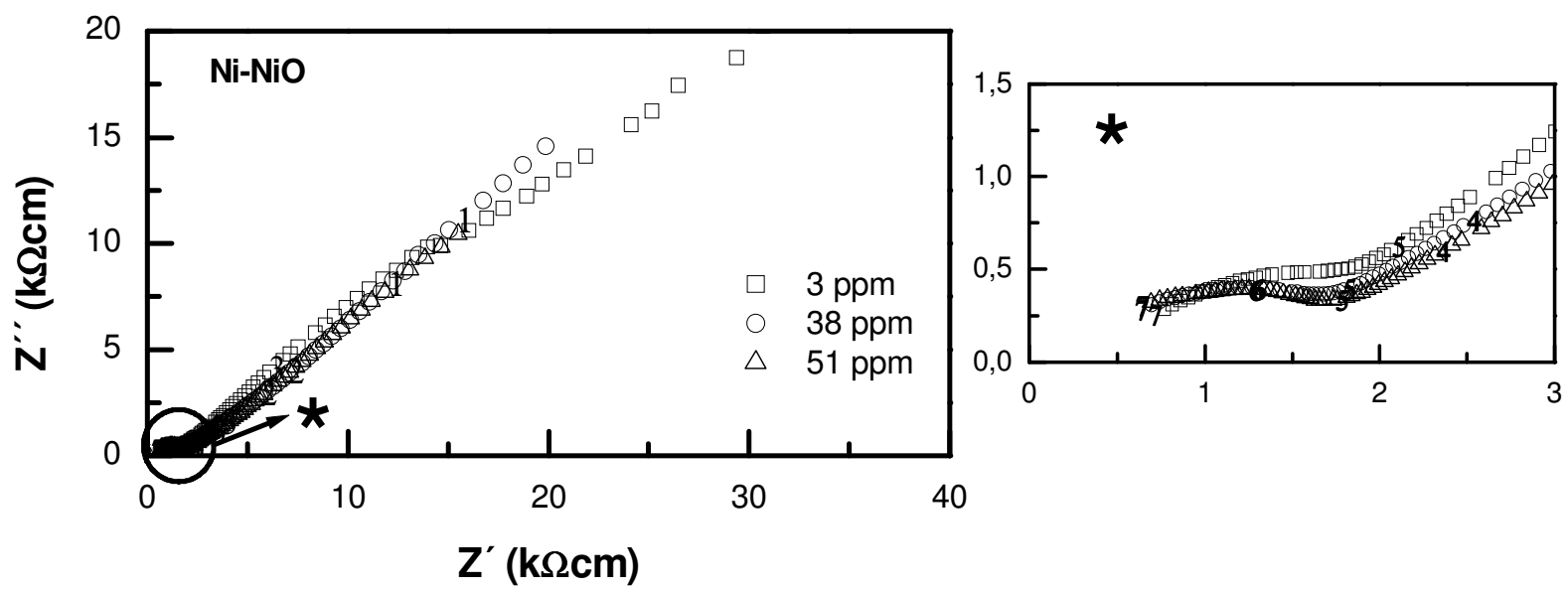

Figura 48: Diagramas de impedância dos compactos cerâmicos sinterizados, na forma de tubo, $\left(\mathrm{ZrO}_{2}: 8,6 \mathrm{~mol} \% \mathrm{MgO}\right)_{0,2}\left(\mathrm{ZrO}_{2}: 3 \mathrm{~mol} \% \mathrm{Y}_{2} \mathrm{O}_{3}\right)_{0,8}$, medidos a aproximadamente $640{ }^{\circ} \mathrm{C}$ sob diferentes teores de oxigênio (3 a 59 ppm); eletrodo de referência Ni-NiO.

A diferença entre diagramas de impedância em condições próximas de medida (temperatura e atmosfera) para eletrólitos sólidos com diferentes eletrodos mostra que eletrodos de Ni-NiO são mais eficientes para detectar baixos teores de oxigênio. (Detalhe na Figura 49).

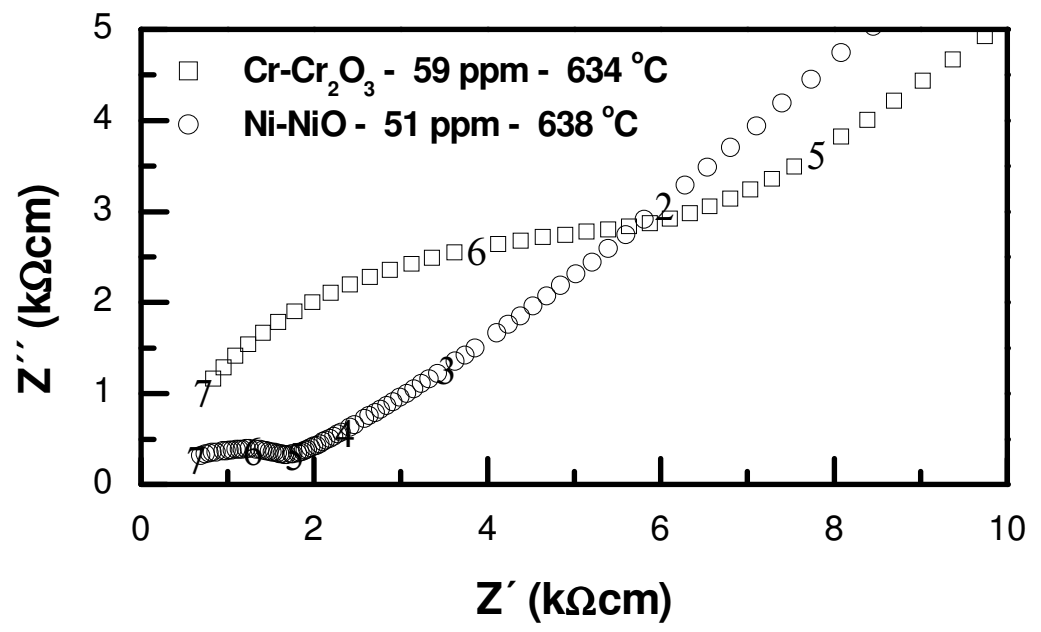

Figura 49: Comparação entre diagramas de impedância obtidos para $\left(\mathrm{ZrO}_{2}: 8,6 \mathrm{~mol} \% \mathrm{MgO}\right)_{0,2}$ $\left(\mathrm{ZrO}_{2}: 3 \mathrm{~mol} \% \mathrm{Y}_{2} \mathrm{O}_{3}\right)_{0,8}$; eletrodos de referência $\mathrm{Cr}-\mathrm{Cr}_{2} \mathrm{O}_{3}$ e Ni-NiO. 


\section{CONCLUSÕES}

1) Foram preparados compósitos cerâmicos densos e parcialmente estabilizados nas fases monoclínica, cúbica e tetragonal, por mistura de pós e sinterização a $1500{ }^{\circ} \mathrm{C}$, com as seguintes características:

- comportamento térmico similar ao da zircônia:magnésia usada como eletrólito sólido em sensores de oxigênio comerciais. O comportamento retração/expansão dos compósitos sinterizados evidenciou o efeito da transformação monoclínica $\rightarrow$ tetragonal com a variação de volume, possibilitando o uso destes materiais em sensores a altas temperaturas.

- a adição de zircônia:ítria na zircônia:magnésia modifica as contribuições intergranular e intragranular da resistividade elétrica, com diminuição da resistividade total.

2) Foi feita uma montagem experimental que permite a aferição automática on-line de sensores de oxigênio na faixa de temperatura entre ambiente e $1000{ }^{\circ} \mathrm{C}$. Os testes realizados mostraram o bom funcionamento dos sensores construídos com eletrólitos sólidos compósitos cerâmicos à base de zircônia, respondem às diferentes quantidades de oxigênio, de acordo com a lei de Nernst.

3) A medida da resistividade elétrica em função da pressão parcial de oxigênio mostrou que é possível construir sensores com compósitos à base de $\left(\mathrm{ZrO}_{2}: 8,6 \text { mol\% } \mathrm{MgO}\right)_{\mathrm{x}}\left(\mathrm{ZrO}_{2}: 3\right.$ mol\% $\left.\mathrm{Y}_{2} \mathrm{O}_{3}\right)_{1-\mathrm{x}}$, sendo $\mathrm{x}=0,2$ o mais adequado para detecção de baixos teores de oxigênio; além de mostrar uma melhora de até $85 \%$ da resistividade elétrica em baixas pressões parciais de oxigênio (1-97 ppm), quando comparada ao eletrólito sólido com a mesma composição do encontrado em sensores comerciais. 


\section{REFERÊNCIAS}

[1] E. C. Subbarao, Zirconia - an Overview, in Advances in Ceramics, Vol. 3, Science and Technology of Zirconia I, eds. A. H. Heuer, L. W. Hobbs, The Am. Ceram. Soc. (1981) 1.

[2] R. M. Dell, A. Hooper, Oxygen Ion Conductors, in Solid Electrolytes, eds. P. Hagenmuller, W. Van Gool, Academic Press, N. York, (1978) 291.

[3] N. Yamamoto, H. Yanagida, Science and Technology of Zirconia III, in Advances in Ceramics, Vol. 24, The Am. Ceram. Soc, (1988).

[4] S. C. Singhal, MRS Bull. 25 (2000) 16.

[5] R. Stevens, An Introduction to Zirconia, Magnesium El. Publ. 113 (1986).

[6] F. C. Fonseca, Relação Microestrutura-Propriedades Elétricas de Compósitos Cerâmicos à Base de Zircônia, Tese de Doutoramento, IPEN-USP (2001)

[7] C. M. Wayman, Martensitic Transformations, in Advances in Ceramics, Vol. 3, Science and Technology of Zirconia I, eds. A. H. Heuer, L. W. Hobbs, The Am. Ceram. Soc. (1981) 64.

[8] T. H. Etsell, S. N. Flengas, Chem. Rev. 70 (1970) 339.

[9] E. M. Levin, C. R. Robbins, H. F. Mc Murdie, Phase Diagrams for Ceramists, Vol. 1, The Am. Ceram. Soc., Westerville, OH, EUA (1967).

[10] J. R. McDonald, Impedance Spectroscopy: Emphasizing Solid Materials and Systems, Wiley Interscience, New York (1987).

[11] J. E. Bauerle, J. Phys. Chem. Solids 30 (1969) 2657.

[12] J. G. Fletcher, A. R. West, J. T. S. Irvine, J. Electrochem. Soc. 142 (1995) 2650.

[13] E. N. S. Muccillo, Espectroscopia de Impedância e Atrito Interno de Eletrólitos Sólidos de $\mathrm{ZrO}_{2}: \mathrm{MgO}$, Tese de Doutoramento, IPEN-USP (1983).

[14] D. Z. de Florio, Estudos de Sinterização e de Envelhecimento Térmico de Cerâmicas de Zircônia-Ítria por Espectroscopia de Impedância, Dissertação de Mestrado, IPEN-USP (1998).

[15] H. S. Isaacs, Zirconia Fuel Cells and Electrolyzes, in Advances in Ceramics, Vol. 3, Science and Technology of Zirconia I, eds. A. H. Heuer, L. W. Hobbs, The Am. Ceram. Soc. (1981) 406. [16] K. P. Jagannathan, S. K. Tiku, H. S. ray, A. Ghosh, E. C. Subbarao, Technological Applications of Solid Electrolytes, in Solid Electrolytes and their Applications, ed. E. C. Subbarao, Plenum Press, New York and London (1980) 201. 
[17] M. Gauthier, A. Belanger, Y. Meas, M. Kleitz, Solid Potentiometric Gauges for Gaseous Species, in Solid Electrolytes, eds. P. Hagenmuller, W. Van Gool, Academic Press, N. York, (1978) 497.

[18] H. Rickert, Electrochemistry of Solids An Introduction, Inorganic Chemistry Concepts, Springer-Verlag BerlinHeidelberg, N. York, (1982).

[19] P. Jasinski, Mater. Sci. Poland 24 [1] (2006) 269.

[20] J. H. Lee, J. Mater. Sci. 38 [21] (2003) 4247.

[21] T. Takeuchi, Sensors and Actuators 14 (1988) 109.

[22] J. W. Fergus, JOM-e 52 [10] (2000) 1.

[23] D. J. Fray, Solid State Ionics 86-88 (1996) 1045.

[24] Q. Liu, Solid State Ionics 86-88 (1996) 1037.

[25] K. Yamada, Y. Shinya, K. Tanaka, Solid State Ionics 3/4 (1981) 595.

[26] D. J. Fray, Mater. Sci. Tech 16 [3] (2000) 237.

[27] E. T. Turkdogan, R. J. Fruehan, Can. Metall. Quart. 11 [2] (1972) 371.

[28] K. F. Portella, Projeto, Montagem e Caracterização de um Sensor de Flúor com Eletrólito Sólido Cerâmico de $\mathrm{PbF}_{2}$, Tese de Doutoramento, IPEN-USP (1997).

[29] J. B. Goodenough, Solid State Ionics 94 (1997) 17.

[30] R. J. Brook, Preparation and Electrical Behavior of Zirconia Ceramics, in Advances in Ceramics, Vol. 3, Science and Technology of Zirconia I, The Am. Ceram. Soc. (1981).

[31] R. Ramamoorthy, P. K. Dutta, S. A. Akbar, J. Mater. Sci. 38 (2003) 4271.

[32] J. W. Fergus, J. Mater. Sci. 38 (2003) 4259.

[33] G. M. Kale, R. Kurchania, Ceram. Trans. 42 (1999) 195.

[34] W. Weijiang, T. Shaohua, H. Shiqiang, L. Qingguo, Solid State Ionics 70/71 (1994) 606.

[35] D. Janke, Solid State Ionics 3/4 (1981) 599.

[36] W. L. Worrell, Q. Liu, Solid State Ionics 40/41 (1990) 761.

[37] A. Weyl, S. Wei Tu, D. Janke, Steel Research 65 (1994) 167.

[38] O. M. Sreedharan, C. Mallika, J. B. Gnanamoorthy, Bulletin of Electrochemistry 2 [3] (1986) 297.

[39] Q. Liu, S. An, W. Qiu, Solid State Ionics 121 (1999) 61.

[40] M. Iwase, M. Yamamoto, M. Tanida, T. Mori, Trans. ISIJ 22 (1982) 349.

[41] J. Gong, Y. Li, Z. Tang, Z. Zhang, Mater. Lett. 46 (2000) 115. 
[42] V. S. Stubican, J. R. Hellmann, Advances in Ceramics, Vol. 3, Science and Technology of Zirconia, The Am. Ceram. Soc. (1981).

[43] J. R. Hellmann, V. S. Stubican, J. Am. Ceram. Soc. 66 [4] (1983) 265.

[44] M. T. Colomer, P. Durán, A. Caballero, J. R. Jurado, Mater. Sci. Eng. A229 (1997) 114.

[45] H. Kedin, X. Yuhua, W. Weijiang, L. Quingguo, L. Wen, H. Clauss, Solid State Ionics 70/71 (1994) 563.

[46] E. Fancio, Análise das Transformações de Fase da Hidroxiapatita em Temperaturas Altas por Difração de Raios X com Aplicação do Método de Rietveld, Tese de Doutoramento, IPENUSP (2005).

[47] D. Balzar, N. Audebrand, M. R. Daymond, A. Fitch, A. Hewat, J. I. Langford, A. Le Bail, D. Louer, O. Masson, C. N. McCowan, N. C. Popa, P. W. Stephens, B. H. Toby, J. Appl. Cryst. 37 (2004) 911.

[48] M. C. Steil, F. C. Fonseca, Y. V. França, J. F. Q. Rey, E. N. S. Muccillo, R. Muccillo, Cerâmica 48 [307] (2002) 146.

[49] E. Butler, N. Bonanos, Mater. Sci \& Eng. 71 (1985) 49.

[50] U. Dworak, H. Olapinski, W. Burger, J. Am. Ceram. Soc. 69 [7] (1986) 578.

[51] S. K. Tadokoro, E. N.S. Muccillo, Cerâmica 46 [300] (2000) 230.

[52] N. Bonanos, R. K. Slotwinski, B. C. H. Steele, E. P. Butler, J. Mater. Sci. 19 (1984) 785.

[53] P. A. Evans, R. Stevens, J. G. P. Binner, Br. Ceram. Trans. J. 83 (1984) 39.

[54] R. Srinivasan, R. J. De Angelis, G. Ice, B. H. Davis, J. Mater. Res. 6 [6] (1991) 1287.

[55] V. S. Stubican, G. S. Corman, J. R. Hellmann, G. Senft, Phase relationship in some $\mathrm{ZrO}_{2}$ systems; 96-106 in Advances in Ceramics, Vol. 12, Science and Technology of Zirconia II. Ed. N. Claussen, M. Ruhle, A. H. Heuer, The Am. Ceram. Soc., Inc., Columbus, OH, (1984).

[56] A. I. Ioffe, M. V. Inozemtzev, A. S. Lipilin, M. V. Perfilev, S. V. Karpachov, Phys. Stat. Sol. A30 (1975) 87.

[57] S. H. Chu, M. A. Seitz, J. Sol. St. Chem. 23 (1978) 287.

[58] M. J. Verkerk, B. J. Middelhuis, A. J. Burggraaf, Solid State Ionics 6 (1982) 159.

[59] E. N. S. Muccillo, M. Kleitz, J. Eur. Ceram. Soc. 15 (1995) 51.

[60] R. Radhakrishnan, A. V. Virkar, S. C. Singhal, G. C. Dunham, O. A. Marina, Sensors and Actuators B 105 (2005) 312.

[61] A. G. Mortimer, G. P. Reed, Sensors and Actuators B 24-25 (1995) 328. 
[62] J. Sun, C. Jin, L. Li, Y. Hong, J. University of Science and Technology Beijing 8 [2] (2001) 137. 